UNIVERSIDAD NACIONAL DE LA PLATA

FACULTAD DE CIENCIAS VETERINARIAS

Trabajo de tesis realizado como requisito para optar al título de DOCTOR EN CIENCIAS VETERINARIAS

Caracterización genética cuantitativa y molecular de la producción lechera y mastitis en ovinos Pampinta

AUTOR: Stazionati, Micaela Fiorela

DIRECTORA: Dra. Gigli, Isabel

CODIRECTOR: Dr. Giovambattista, Guillermo

LUGARES DE TRABAJO:

INTA, EEA Anguil "Ing. Agr. Guillermo Covas"

MIEMBROS DEL JURADO:

Dr. Poli, Mario Andrés

Dra. Marrube, Graciela

Dra. Villegas Castagnasso, Egle

AÑO 2017 


\section{ÍNDICE DE CONTENIDOS}

Índice de cuadros de abreviaturas utilizadas

2 Estimación de parámetros genéticos para producción de leche, grasa, proteínas y mastitis subclínica en ovinos Pampinta................................................................... 14

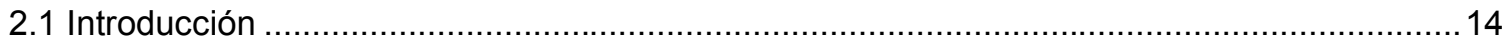

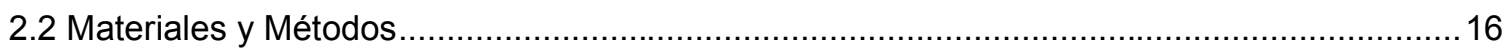

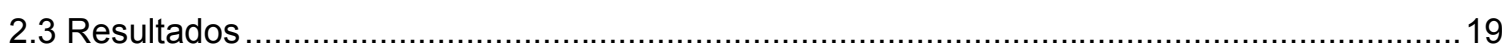

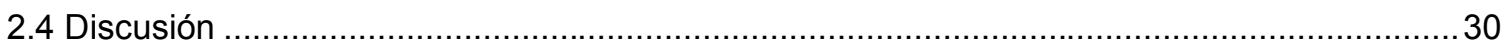

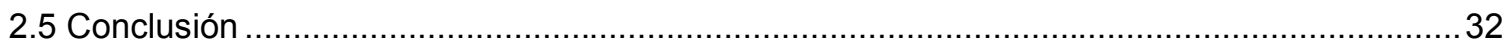

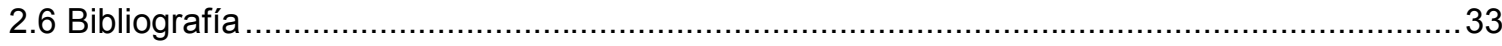

3 Caracterización de ovinos Pampinta por variabilidad genética en genes de las

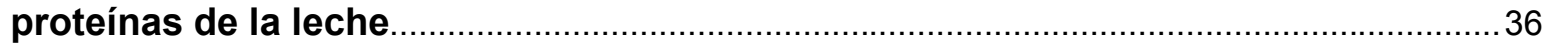

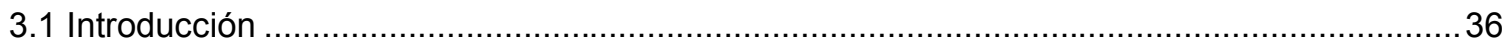

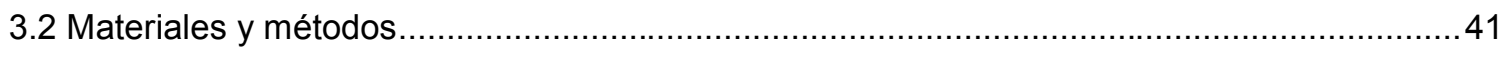

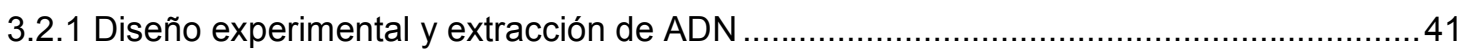

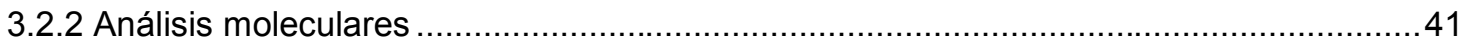

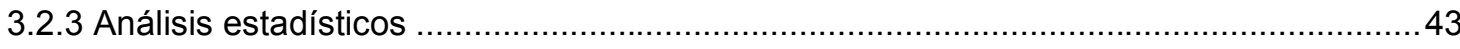

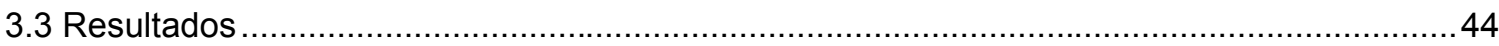

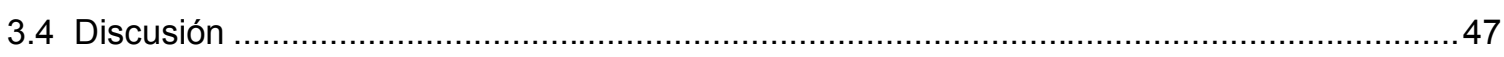

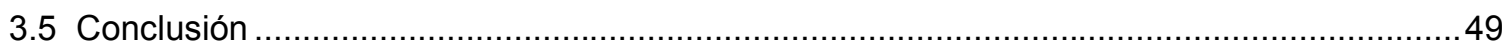

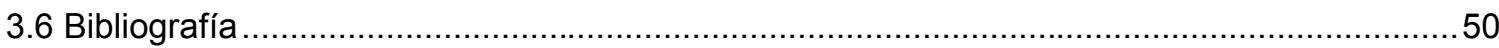

4 Estimación de la asociación entre polimorfismos genéticos de las proteínas de la leche con características de producción de lechera y mastitis subclínica .................54

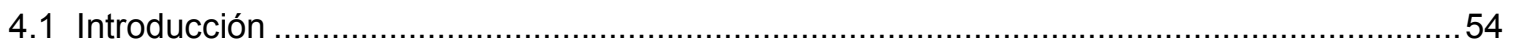

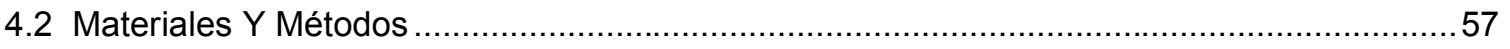

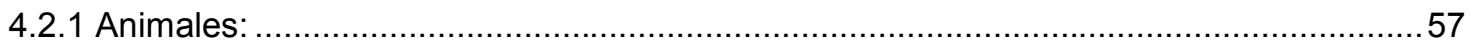

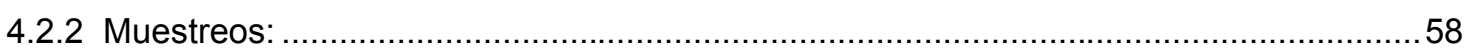


ADN y Análisis moleculares:.

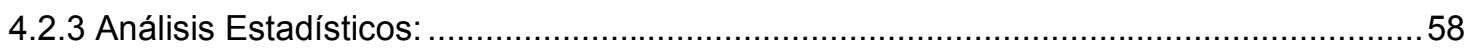

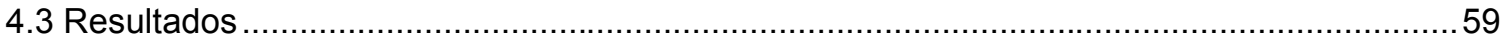

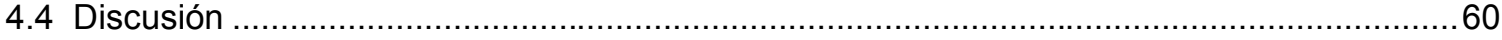

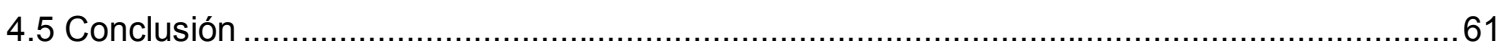

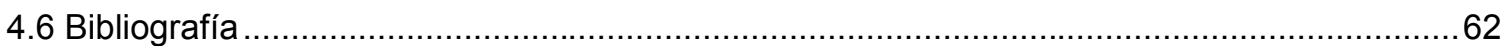

5 Kappa caseína, tiempo de coagulación y rendimiento quesero..................................66

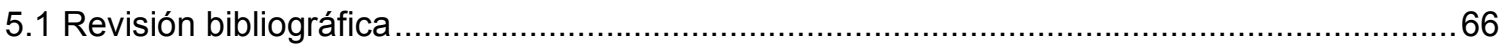

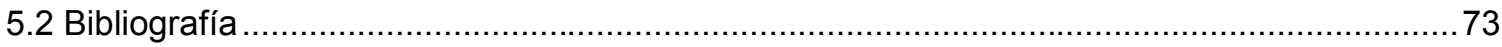

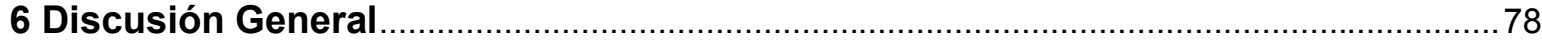

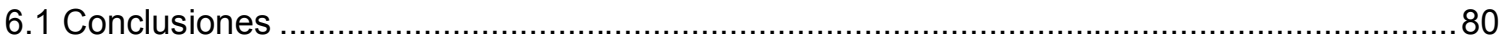




\section{Agradecimientos}

- Quiero agradecer a todos los que de alguna u otra forma participaron y contribuyeron a este largo camino recorrido.

- A mis directores de tesis, Daniel, Isabel y Guillermo por su apoyo y orientación durante este tiempo.

- Al primer contacto que tuve en INTA, Margarita Busetti, gracias porque hiciste que me interesara en este campo de la investigación y un poco más en las ovejas.

- A mis compañer@s de oficina, y de otras oficinas, por los mates, las charlas, las confidencias.

- Al personal de campo, por su disponibilidad y por hacer más sencillo este camino.

- A las chicas de EEA Rafaela, por su apoyo incondicional en todo momento.

- A mi familia, en especial mis padres y mi hermana por ayudar que mis sueños se hagan realidad, porque cada uno aporta algo a mi vida.

- Y, por supuesto a Emanuel, por brindarme el optimismo necesario, constancia y dedicación para vencer los más difíciles obstáculos para poder hacer realidad este sueño, te quiero. 


\section{Lista de abreviaturas utilizadas}

1raL: Primera lactancia

2daL: Segunda lactancia

3raL: Tercera lactancia

AEP: Año- época de parto

CL: Control lechero

CSN: caseínas

CSN1S1: gen de $\alpha_{\mathrm{s} 1}$ caseína

CSN2: gen de ßeta caseína

CSN3: gen de Kappa caseína

CV\%a: Coeficiente de variación genética aditiva

DEa: Desvío estándar aditivo

DPPCL: Días desde el parto al primer control lechero

ELAC: Extensión de lactancia

EPP: Edad al primer parto

EqHW: Equilibrio Hardy- Weinberg

fA: Frecuencias alélicas

fGo: Frecuencias genotípicas observadas

g/d: Gramos por día

$\mathrm{G}_{\mathrm{ST}}$ : Diferenciación génica 
GT: Grasa total

$\mathrm{h}^{2:}$ Heredabilidad

HI: Heterocigosidad promedio observada

HS: Heterocigosidad promedio esperada

HT: Heterocigosidad esperada

l/d: Litros por día

LAA: gen de a lacto- albumina

LGB: gen de Beta lacto- globulina

MSC: Mastitis subclínica

OPAR: orden de parto

PCR: Reacción en cadena de la polimerasa

PCR-RFLP: Polimorfismos en la longitud de los fragmentos de restricción

PCR-SSCP: Polimorfismos de conformación de cadena simple

PL: Producción de leche

PT: Proteína total

RCS: Recuento de células somáticas

SBD1: gen de Beta defensina 1

SBD2: gen de Beta defensina 2

SCN: Staphylococcus coagulasa negativo

SNP: Polimorfismo de un solo nucleótido

TMC: Test Mastitis California 
TPC: Tipo de parto y crianza

VEp: Ambiente permanente

VGA: Varianza genética aditiva

VP: Varianza fenotípica 


\section{Índice de cuadros}

Cuadro 1.1. Medias de RCS (incluyendo células epiteliales) correspondientes a los diferentes grados de TMC.

Cuadro 2.1. Descripción estadística de las observaciones fenotípicas de producción de leche acumulada en 210 días y expresadas como promedio diario, basada en lactancias de ovinos Pampinta, de distintas edades y número de partos, entre los años 2009 y 2016.

Cuadro 2.2. Valores $p$ para los efectos clasificatorios: AEP, EPP, OPAR, TPC, DPPCL y ELAC empleados en los modelos mixtos univariados para $P$ L, GT, PT, G\%, P\% y $\boldsymbol{M S C}$, en 210 días expresados como promedio diario, de ovejas Pampinta con tres o más CLs en lactancias registradas entre los años 2009 y 2016.

Cuadro 2.3. Estimaciones de mínimo cuadrado del efecto OPAR para las variables $P L(I / d), G T$ (g/d), PT (g/d), G\%, P\% y MSC (incidencia). Las estimaciones son referidas al primer nivel de las otras variables clasificatorias en el modelo ASP, EPP, TPC, DPPCL y ELAC en ovejas Pampinta.

Cuadro 2.4. Estimaciones de mínimo cuadrado del efecto TPC para las variables $P L(I / d), G T$ (g/d), PT (g/d), G\%, P\% y MSC (incidencia). Las estimaciones son referidas al primer nivel de las otras variables clasificatorias en el modelo ASP, EPP, OPAR, DPPCL y ELAC en ovejas Pampinta.

Cuadro 2.5. Estimaciones de mínimo cuadrado del efecto $D P P C L$ para las variables $L P(I / d), G T$ (g/d), PT (g/d), G\%, P\% y MSC (incidencia). Las estimaciones son referidas al primer nivel de las otras variables clasificatorias en el modelo ASP, EPP, TPC, OPAR y ELAC en ovejas Pampinta.

Cuadro 2.6. Estimaciones de mínimo cuadrado del efecto ELAC para las variables $L P(I / d), G T$ (g/d), PT (g/d), G\%, P\% y MSC (incidencia). Las estimaciones son referidas al primer nivel de las otras variables clasificatorias en el modelo ASP, EPP, TPC, OPAR y DPPCL en ovejas Pampinta.

Cuadro 2.7. Estimaciones de los componentes de varianza genética aditiva (VGA), ambiental permanente (VEp) y fenotípica (VP), desvío estándar aditivo (DEa), coeficiente de variación genética aditiva (CV\%a), heredabilidades $\left(\boldsymbol{h}^{2}\right)$, repetibilidades $(\boldsymbol{r})$ y error estándar (e.e.) para las estimaciones de $\mathrm{h}^{2}$ y $\mathrm{r}$ para las características $\boldsymbol{P L}, \mathbf{G T}, \mathbf{P T}, \mathbf{G} \%, \mathbf{P} \%$ y $\boldsymbol{M S C}$ en ovinos Pampinta. 
Cuadro 2.8. Estimaciones de correlaciones genéticas aditivas (por encima de la diagonal) y fenotípicas (por debajo de la diagonal) entre las características $P$ L, GT, PT, G\%, P\% y $\boldsymbol{M S C}$ en ovinos Pampinta.

Cuadro 3.1. Resumen de las variaciones para las caseínas (CSN1S1, CSN2, y CSN3) y el gen lacto-globulina (LGB) reportadas en la literatura.

Cuadro 3.2. Frecuencias genotípicas observadas (fGo), frecuencias alélicas (fA), valor $p$ para el equilibrio de Hardy-Weinberg ( $p$ Eq.HW) estimadas en la población EEA Anguil y Población Cabañas, para los loci CSN1S1, CSN2, CSN3, LGB y SBD2.

Cuadro 3.3. Estimaciones de los estadísticos de Wright $\left(F_{I S}, F_{S T}\right.$ y $\left.F_{I T}\right)$ y Nei $\left(G_{S T}\right.$ y $\left.H_{T}\right)$ para cada locus y a nivel global en las muestras de las sub-poblaciones Anguil y Cabañas para la raza Pampinta.

Cuadro 3.4. Frecuencias esperadas de los haplotipos para las caseínas CSN1S1, CSN2, CSN3 en la población Pampinta estimados mediante el programa PHASE. $\mathrm{N}=115$.

Cuadro 4.1. Resumen de las asociaciones entre genotipos para proteínas de leche y su efecto en caracteres productivos según datos reportados.

Cuadro 4.2. Efecto de la asociación de los polimorfismos (caseínas y LGB) con caracteres de producción, composición de leche y RCS. 


\section{Índice de figuras}

Figura 1.1. Porcentajes de producción de leche ovina a nivel mundial

Figura 2.1. Ejemplos de gráficos diagnósticos de autocorrelación

Figura 2.2. Ejemplos de gráficos diagnósticos de densidades de las distribuciones posteriores Figura 2.3. Ejemplos de gráficos diagnósticos de running means

Figura 2.4. Ejemplos de gráficos diagnósticos traceplots

Figura 2.5. Estimaciones de mínimo cuadrado del efecto $A E P$ para cada variable respuesta, A) $L P$ en I/d; B) MSC incidencia; C) $G T$ en $\mathrm{g} / \mathrm{d}$; D) $P T$ en $\mathrm{g} / \mathrm{d}$; E) $G \%$ y F) $P \%$. Las estimaciones son referidas al primer nivel de cada variable clasificatoria en el modelo EPP, OPAR, TPC, DPPCL y ELAC en ovejas Pampinta. 


\title{
Caracterización genética, cuantitativa y molecular de la producción lechera y mastitis en ovinos Pampinta
}

\begin{abstract}
Resumen
Se han estudiado aspectos de la oveja Pampinta, una raza sintética desarrollada en la EEA de Anguil, constituida por 3/4 Frisona del Este (East Friesian) y $1 / 4$ Corriedale. Considerada de triple propósito (carne, leche y lana), pero seleccionada fenotípicamente hacia la raza Frisona del Este, siendo una de las principales razas que se la utiliza en ordeñe en Argentina. Con datos recogidos en los controles lecheros entre los años 2009 y 2017, se estimaron parámetros genéticos para producción de leche $(\mathbf{P L})$, grasa total $(\mathbf{G T})$, proteínas totales (PT), grasa en porcentaje (G\%), proteína en porcentaje (P\%) y mastitis subclínica (MSC). Las estimaciones de heredabilidad resultaron intermedias a bajas, para los caracteres de producción entre 0,21 y 0,33 , y para mastitis subclínica fue de 0,1. Para esta característica no se han reportado previamente estimaciones de heredabilidad. Las estimaciones de repetibilidades para los caracteres productivos fueron altas, entre 0,42 y 0,51 , indicando que una observación fenotípica sería un buen predictor de la futura producción, ya que alrededor del 50\% del carácter depende del componente genético total más el ambiente permanente. En tanto que para mastitis subclínica fue de 0,20. Las correlaciones entre PL, GT y PT resultaron altas con valores ente 0,92 y 0,98 . Las correlaciones entre $\mathbf{G} \%$ y PL y PT resultaron negativas, siendo aún más negativas las genéticas que las fenotípicas. Las estimaciones de estos parámetros indican que es posible seleccionar por PL y composición, y reducir la incidencia de MSC. A su vez, se realizó una caracterización de la raza Pampinta por variabilidad genética para los genes de las proteínas de la leche. Se obtuvieron las frecuencias génicas y genotípicas para mutaciones previamente descriptas en la literatura de alfa caseína (CSN1S1), beta caseína (CSN2), kappa caseína (CSN3), lacto-globulina (LGB) y defensina 2 (SBD2) para la cabaña de EEA Anguil y para 5 cabañas privadas.

Los genes CSN1S1, CSN2, CSN3 y LGB mostraron polimorfismo, en cambio, SBD2 no se puede considerar polimórfico, ya que el alelo SBD2-A se encontró en muy baja frecuencia. La prueba
\end{abstract}


exacta de Fisher indicó que, en general, los genes en estas sub-poblaciones se encontraron en equilibrio Hardy-Weinberg; siendo la excepción los loci CSN1S1 $(p<0,0001)$ y CSN2 $(p<0,0001)$ en la Cabaña Anguil y el locus LGB $(p<0,0151)$ en las Cabañas Comerciales, que presentaron desvíos significativos con respecto a las proporciones teóricas hacia el exceso de heterocigotas. Las estimaciones de los estadísticos $\mathrm{F}_{\mathrm{ST}}$ y $\mathrm{G}_{\mathrm{ST}}$ globales, que resultaron iguales $(0,0109)$, indicaron un bajo nivel de variación entre estas sub-poblaciones de Pampinta para las proteínas de la leche, explicando solo un $1 \%$ de la variación total de la varianza interpoblacional. En coincidencia con este resultado, la distancia estándar (D) de Nei fue de -0,0038, con un error estándar igual a 0,0092 , en tanto que la distancia DA resultó 0,0053 . Ambas muy cercanas a cero. La falta de diferenciación, también se reflejó a nivel de cada locus estudiado. En relación a la heterocigosidad $\left(H_{T}\right)$, las estimaciones evidenciaron altos niveles de diversidad genética, tanto a nivel global como de cada locus. Con la excepción del locus CSN3 debido a que las frecuencias alélicas estimadas estuvieron cercanas a cero y a uno. Los alelos más frecuentes fueron CSN1S1-T; CSN2-A; CSN3C y LGB-A. Se estimaron también los haplotipos de los genes de caseína, resultando TAC ser el haplotipo más frecuente, representando el $34 \%$ del total, en tanto que sólo cuatro haplotipos (TAC, CAC, TGC, TAT) representaron aproximadamente el $77 \%$ del total. Posteriormente se realizó la estimación de asociaciones, utilizando un modelo de regresión, entre los polimorfismos genéticos identificados y los caracteres productivos. Resultaron significativas $(p<0,05)$ las asociaciones para CSN1S1 con GT y para CSN2 con PT. En tanto que CSN1S1 con PL y con PT y para CSN2 con PL y con GT mostraron una tendencia $(p<0,1)$. No se observó ningún efecto significativo entre los caracteres productivos con CSN3 y LGB. En CSN1S1, el efecto sobre GT significa 1,09 kg por lactancia de 210 días del genotipo TT en relación al CC, en tanto una tendencia es positiva para PL y PT del genotipo TT sobre el CC. Con respecto a CSN2, para PT el genotipo AA significó 0,99 kg sobre el genotipo GG, y tendencia similar se observó para PL y GT. En función de la variabilidad del polimorfismo de CSN3, la probabilidad de encontrar ovejas de los tres genotipos fue baja. Además, el efecto acumulativo de realizar la prueba en dos años consecutivos, se malogró por la pérdida de muestras debido a una mala cadena de frío y error en el protocolo inicial de conservación de las mismas. Por lo cual, se trabajó con muestras repetidas de muy pocos 
animales. Los valores obtenidos, sin embargo, estuvieron cercanos a los mínimos de los rangos reportados en otras razas, posiblemente por las diferencias de manejo que existen. Los resultados, se presentan dentro de una revisión bibliográfica en el capítulo 5. 


\title{
Genetic, quantitative and molecular characterization of dairy production and mastitis in Pampinta sheep
}

\begin{abstract}
Aspects have been studied about the Pampinta sheep, a synthetic breed developed in EEA Anguil, (East Friesian $3 / 4$ and Corriedale $1 / 4$ ). It is a triple purpose (meat, milk and wool) breed, but it was phenotypically selected towards East Friesian. It is one of the most important dairy breed in Argentinian. The genetic parameters for yield milk (YM), total fat (TF), total protein (TP), percentage protein $(\% \mathrm{P})$, percentage fat $(\% \mathrm{~F})$ and subclinical mastitis, were estimated using data collected from dairy controls between 2009 and 2017. Estimated heritability value was medium to low, for production traits were between 0.21 and 0.33 and 0.1 for subclinical mastitis. For the last trait, heritability estimates have not been previously reported. The repeatability for the productive trait was high, between 0.42 and 0.51 , indicating that a phenotypic observation would be a good predictor of future production; approximately $50 \%$ of the traits depend on the total genetic component plus the permanent environment. While for the subclinical mastitis was 0.20 . The correlation between YM, TF and TP was high with values 0.92 and 0.98 . The correlation between $\% \mathrm{~F}$ and $\mathrm{YM}$ and TP was negative, being the genetic ones more negative than the phenotypic ones. Estimates of these parameters indicate that it is possible to select by YM and composition, and reduce the incidence of MSC. Also, a characterization on the Pampinta breed was carried out by genetic variability of milk protein genes. Genetic and genotype frequencies were obtained for point mutations of alpha casein (CSN1S1), beta casein (CSN2), kappa casein (CSN3), lactoglobulin (LGB) and defensin 2 (SDB2), for the EEA Anguil farm and for 5 other private farm. The genes CSN1S1, CSN2, CSN3 and LGB showed polymorphism, whereas SDB2-A was found in very low frequency. Fisher's exact test indicated that in general, genes in these sub-population were found in Hardy-Weinberg equilibrium, with the exception of CSN1S1loci ( $p<0.0001$ ) and CSN2 $(p<0.0001)$ in Anguil farm and LGB locus $(p<0.0151)$ in commercial farms, which showed significant deviations from theoretical proportions towards the excess of heterozygotes. Estimates of the global
\end{abstract}


$F_{s t}$ and $G_{s t}$, which were the same (0.0109), indicated a low level of variation among these Pampinta sub- populations for milk proteins, explaining only $1 \%$ of the total inter-populations variance. In agreement with this result, the standard distance (D) of Nei was -0.0038 , with a standard error equal to 0.0092 , while the distance DA resulted 0.0053 . Both very close to zero. The lack of differentiation was also reflected at the level of each locus studied. In relation to heterozygosity $\left(H_{T}\right)$, the estimates showed high levels of genetic diversity, both globally and at each locus. Except for the CSN3 locus where the estimates allelic frequencies were close to zero and one. The most frequent alleles were CSN1S1- T; CSN2-A; CSN3-C and LGB-A. The haplotypes of casein genes were also estimated, being TAC the most frequent haplotype, representing $34 \%$ of the total, while only four haplotypes (TAC, CAC, TGC, TAT), represented approximately $77 \%$ of the total. Later an estimation of associations using a regression model was made between identified genetic polymorphism and productive traits. In associations for CSN1S1 with TF and for CSN2 with TP resulted significant $(p<0.05)$. While for CSN1S1 with YM and TP and CSN2 with YM and TF they showed a trend $(p<0.1)$. No significant effect was observed between productive traits with CSN3 and LGB. In CSN1S1, the effect on TF means $1.09 \mathrm{~kg}$ per lactation of 210 days of the TT genotype in relation to the $\mathrm{CC}$, while a trend is positive for YM and TP of the TT genotype over the CC. With regard to CSN2, for TP the genotype AA means $0.99 \mathrm{~kg}$ over the GG genotype and a similar trend was observed for YM and TF. Due to CSN3 observed variability, the probability of finding the three genotypes was low. In addition, some samples were lost due to faults in the cold chain and in the initial protocol. Therefore, we used repeated samples of very few animals. The values obtained, however, were close to the minimum of the ranges reported in other breeds, possibly due to differences in management. The results are presents within the bibliographical review in Chapter 5 . 


\section{Introducción general}

La producción de leche ovina es considerada típica de regiones donde otras especies, como la bovina, no son explotadas (García-Díaz et al., 2012). Es así que el continente asiático aporta prácticamente la mitad de la producción mundial (46\%) (Figura 1.1). Sin embargo, en las últimas décadas, la lechería ovina está planteada como una alternativa en países desarrollados o en vías de desarrollo, donde esta actividad productiva no es tradicional, y está orientada a la obtención de productos de alta calidad.

Se estima que, aproximadamente, el 95\% de la leche obtenida se destina a la producción de quesos, por su alto contenido proteico (principalmente caseínas) y el resto a yogurt y helados, aunque en algunos países asiáticos se la consume fluida (Pulina, 2006).

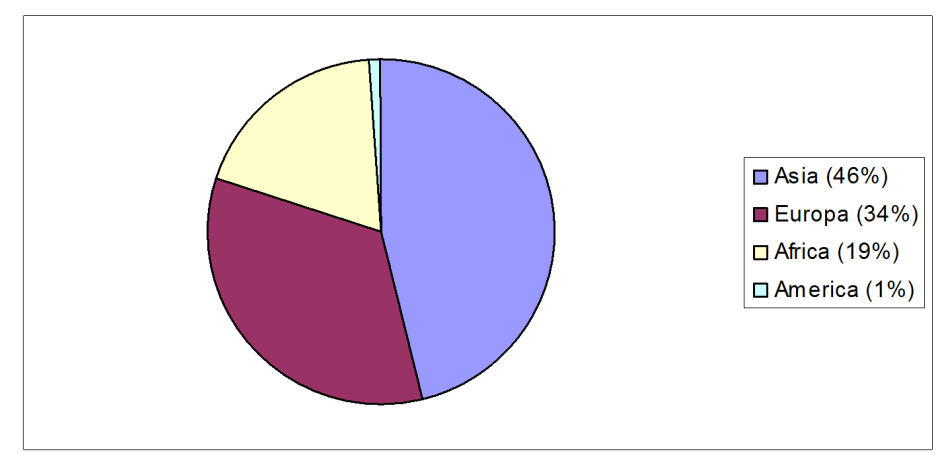

Figura 1.1 Porcentajes de producción de leche ovina a nivel mundial

Elaboración propia, datos tomados de FAO 2009.

En Sudamérica, la producción lechera es extremadamente moderada, obteniéndose unas 45,000 toneladas anuales, correspondiendo la mayor parte a Brasil, a pesar de no ser un país tradicionalmente productor de leche, y caracterizado por sus sistemas productivos ineficientes, incapaces de mantener una producción constante (Lôbo et al., 2005). 
De cara al futuro, considerando que en Sudamérica la producción continúa aumentando y que la leche de oveja constituye un producto muy importante para las economías regionales y de subsistencia, es razonable pensar que se debería prestar mayor atención a estos sistemas productivos. Además, habría que establecer medidas tendientes a mejorar su composición, para aumentar la eficiencia de la industria.

En Argentina, el desarrollo de la producción ovina lechera está en manos de pequeños y medianos productores, quienes han buscado aumentar sus ingresos a partir de productos elaborados como los quesos. Para dimensionar esto, en 2008, se registraron 48 establecimientos tamberos, de los cuales el 59\% eran tambos fábricas (Busetti et al., 2008).

Contemplando que estos sistemas productivos nacionales cuentan con una interesante variabilidad de razas, entre ellas Frisón (46\%), Pampinta y sus cruzas (42,8\%), Frisón x Texel $(11,2 \%)$ (Busetti et al., 2008), podemos aseverar que dentro de los principales aspectos a desarrollar en el sector, se encuentran el genético, ya que no existen evaluaciones en este sentido ni mediciones objetivas. Sin embargo, existen impedimentos financieros, tecnológicos y otros vinculados a la idiosincrasia de los propios productores dedicados a la actividad. A su vez, tampoco existe una cadena de comercialización acorde a la alta demanda de quesos que favorezca el crecimiento del mercado.

Pampinta es una raza ovina sintética, originada del cruzamiento de East Friesian ( $3 / 4)$ y Corriedale (1/4) en la Estación Experimental Agropecuaria (EEA) Anguil "Ing. Agr. Guillermo Covas" (INTA) en la década del 70, y adaptada al semiárido y sub-húmedo de la región pampeana (Busetti \& Suárez, 1999). Está región se caracteriza por presentar las temperatura más bajas en julio, con una temperatura media de $7,3^{\circ} \mathrm{C}$, y las más elevadas en el mes de enero, cuya temperatura media es de $22,9^{\circ} \mathrm{C}$, siendo las temperaturas máximas absolutas registran valores de $41,5^{\circ} \mathrm{C}$ y las mínimas absolutas hasta $13,2^{\circ} \mathrm{C}$ (periodo 1973-2011). La zona bajo estudio se encuentra entre las isohietas de $700 \mathrm{~mm}$ y $850 \mathrm{~mm}$ de precipitación anual. La leche de estas ovejas tiene un contenido promedio de sólidos totales del $19,1 \%$, constituido a su vez por proteína $(6,7 \%)$, grasa $(7,4 \%)$, lactosa $(4,7 \%)$ y cenizas $(0,3 \%)$, según valores obtenidos localmente (Busetti, 2008 comunicación 
personal). Su composición se haya dentro de valores promedios citados por Juárez \& Ramos (1986), sólidos totales (15,8-23,4\%), grasa (4,5-12,6\%), proteínas $(4,3-6,8 \%)$, caseínas $(4,3-4,5 \%)$, lactosa $(4,2-5,3 \%)$ y cenizas $(0,8-1,0 \%)$.

Los factores que causan variaciones en la composición de la leche pueden ser propios del animal o bien externos al mismo. Entre los primeros tenemos genéticos, edad y tipo de parto, que son factores no controlables mediante el manejo. Respecto a los factores externos, que sí pueden modificarse, se encuentran el momento de la lactación, el destete, el peso de los animales influenciados por la alimentación, la sanidad, la esquila, entre otros. La influencia genética sobre los componentes de la leche ha sido demostrada a través de varios estudios de enfoque cuantitativo. En éstos, se calcularon los componentes genéticos a través del análisis de los registros de producción de leche, incluyendo el registro de la genealogía. Las heredabilidades fueron muy variables, dependiendo de la raza y la muestra utilizada (Maioli et al., 2007). En ovinos lecheros, los caracteres de producción y calidad de leche son de baja a mediana heredabilidad $(0,10-0,25)$. En Pampinta, la estimación de heredabilidad para la producción acumulada en los primeros 150 días postparto resultó 0,17 (Maizon et al., 2011) mientras que en la raza Latxa fue de 0,20 (Legarra \& Ugarte, 2001). Ahora bien, para Pampinta, es necesario obtener estimaciones de correlaciones genéticas entre producción de leche $(P L)$, grasa total $(G T)$, proteínas totales (PT), porcentaje de grasa $(\% \mathrm{G})$ y proteína en porcentajes $(\% \mathrm{P})$, para así poner énfasis en la selección.

La utilización de marcadores moleculares en programas de mejoramiento es particularmente beneficiosa cuando los caracteres que se pretenden mejorar están limitados por el sexo o expresados tardíamente en la vida del animal. Por lo tanto, el sistema de producción de leche ofrece una excelente oportunidad técnica y económica para implementar un programa de selección asistido por marcadores moleculares. Con esa finalidad poder identificar los polimorfismos genómicos de los genes candidatos que codifican las principales proteínas de la leche en las ovejas Pampinta, y así poder obtener el máximo progreso genético, combinando dos tipos de información, molecular y fenotípica, como así también acortar el período generacional. 
En la leche ovina, se encuentran diferentes fracciones proteicas, las caseínas $\alpha_{\mathrm{s} 1}$ (CSN1S1), $\beta$ caseína (CSN2) y K caseína (CSN3), son las principales, representando en conjunto el $76-83 \%$ del total. También se encuentran las proteínas del lacto-suero beta-lacto-globulina (LGB), alfa lacto-albumina (LAA) siendo las mayoritarias, lacto-ferrinas y defensinas (SBD1 y SBD2) en menor cantidad.

En general, en todas las especies estudiadas se ha descripto mayor heterogeneidad para las caseínas que para las proteínas del suero. El polimorfismo genético de las caseínas ovinas, en particular, se ha estudiado para las fracciones CSN1S1, CSN2, CSN3, resultando importante tanto para los efectos cuantitativos como para las características tecnológicas de la leche. Estas variantes genéticas se encuentran en diferentes frecuencias dentro de la población. Según Ceriotti et al. (2004), las caseínas CSN1S1 y CSN2 tienen una alta frecuencia de mutación $(0,12-0,26)$, lo que representa una oportunidad para considerar estos polimorfismos en la investigación de la diversidad de razas.

Un estudio en ovinos de la raza Valle del Belice mostró que animales con genotipos BB y $A B$ para el gen de la beta lacto-globulina se asocian a una mayor incidencia de cultivos bacteriológicos positivos en leche con respecto a aquellos con genotipo AA (Gigli et al., 2007). De manera que la identificación de los genotipos que presenten mayor nivel de defensa inespecífica y, por lo tanto, mayor resistencia a mastitis, permitiría su utilización en programas de selección. Por otro lado, Bolla et al. (1989) ha asociado el polimorfismo de la beta lacto-globulina con rendimiento lechero, reportando que la variante B estaba asociada con alta producción de leche. En tanto que Di Stazio et al. (1992) encontró que los heterocigotos de la raza Siciliana dieron mayor producción de leche. Por su parte Garzón \& Martínez (1992), encontraron que ovejas con genotipos AB tenían mayor proteína y contenido de caseína. Respecto a las mastitis, la clínica produce menores perdidas en la producción (Bergonier et al., 2003), siendo los procesos sub-clínicos los causantes principales de mermas productivas, afectando la calidad y la cantidad de leche. Además, aparejado a estas pérdidas económicas directas, hay también pérdidas indirectas, como las causadas por los costos de los tratamientos antibióticos, el incremento de la mano de obra, menor ganancia diaria de peso de los corderos amamantados (Fthenakis et al., 1990), menor volumen de leche 
comercializada, y las repercusiones en los cambios de composición en la industria quesera. La incidencia de mastitis clínica en ovejas es del 5\% anual, siendo Staphylococcus aureus el agente causal más frecuente (entre 17 y 57\%), siguiendo los Staphylococcus coagulasa negativos (SCN) (entre 10 y 53\%; Marguet et al., 2000; Suárez et al., 2002). En Argentina, un relevamiento indicó que el $56 \%$ de los tambos encuestados manifestó haber padecido al menos un caso de mastitis clínica en la historia de la majada (Busetti \& Suárez, 2010). Para la mastitis subclínica (MSC), se estima una incidencia alrededor del 10 al 50\% (Bergonier et al., 2003), dicha reacción inflamatoria puede ser identificada por un elevado recuento de células somáticas (RCS) en leche o a través del cultivo bacteriano. Suárez et al. (2002) en ovejas en ordeñe, reportaron una incidencia entre 18 y 36\% para mastitis subclínica, evaluada mediante el Test mastitis California (TMC). Dentro de este contexto, el RCS en leche se presenta como un buen indicador de la incidencia de mastitis subclínica (MSC) y posibilita su uso dentro de programas de mejora genética. Aunque la bibliografía es muy escasa comparada con la existente para bovinos, diversos estudios han demostrado la posibilidad de utilizar la selección genética para aumentar la resistencia a mastitis usando como criterio de selección el RCS (Barrilet et al., 2001; Rupp et al., 1999).

Existe una relación entre las bacterias aisladas de glándulas mamarias y la media geométrica de RCS obtenidos, encontrándose en INTA Anguil una correlación del 60\% entre RCS y el estado infeccioso (Cuadro 1.1). La importancia del RCS radica en su inversa relación con la producción de leche (Gray \& Schalm 1962; Raubertas \& Shook, 1982). Torres-Hernandez y Hohenboken (1979), informaron que ovejas libres de mastitis producen $11 \%$ más leche que aquellas con un medio afectado y $58 \%$ más que aquellas con ambos medios afectados. Por otro lado, Saratsis (1998) demostró que ovejas inoculadas con Staphylococcus epidermidis disminuyen hasta un 55\% su producción. El efecto del RCS sobre la aptitud quesera, quedo demostrado por Pisiri et al. (1994) donde leches con elevados números de células somáticas tienen un valor elevado de $\mathrm{pH}$, un mayor tiempo de coagulación, pero sin embargo no influyó negativamente con el rendimiento quesero. 
Cuadro 1.1 Medias de RCS (incluyendo células epiteliales), correspondientes a los diferentes grados de TMC, adaptado de Suárez et al. (2002)

\begin{tabular}{|c|c|c|c|c|c|}
\hline Grados de TMC & $\mathbf{0}$ & Trazas & $\mathbf{1}$ & $\mathbf{2}$ & $\mathbf{3}$ \\
\hline RCS & & & & & \\
\hline m. aritmética & 223576 & 245248 & 397778 & 1159109 & 2460833 \\
\hline m. geométrica & 194984 & 208181 & 317774 & 915250 & 1990535 \\
\hline
\end{tabular}

${ }^{1}$ La utilización del TMC ha sido probada en EEA Anguil, mostrando una correlación del $80 \%$ entre el TMC y la bacteriología, con una sensibilidad y especificidad del $69 \%$ y $76 \%$, respectivamente.

La aptitud quesera de la leche depende de un conjunto de factores que se refleja, en gran medida, por su comportamiento en las fases de coagulación y de desuerado. La calidad quesera de la leche se puede definir como su aptitud para dar un buen queso, con un rendimiento satisfactorio, en condiciones de trabajo normales. Las caseínas parecen ser los principales componentes que explican la velocidad de endurecimiento y firmeza del gel. La velocidad de endurecimiento de la leche de oveja está influenciada negativamente por el tamaño de la micela, las pequeñas tienen mayor relación volumen/superficie, formando geles más firmes; y positivamente por un mayor contenido de calcio coloidal. También la firmeza del gel esta correlacionada con el contenido de proteína y caseína (Delacroix-Buchet et al., 1994). Brulé et al. (2000) establecieron diferencias en el tamaño promedio de las micelas, presentando las de leche ovina un tamaño intermedio $(202 \mathrm{~nm})$ entre las de leche bovina $(175 \mathrm{~nm})$ y caprina $(255 \mathrm{~nm})$. Este atributo es importante, ya que aquellas micelas pequeñas contienen mayor proporción de CSN3. Cuanto menor es el diámetro medio de las micelas, mayor es el tiempo de coagulación, este efecto se debe a las diferentes composiciones de las micelas en función a sus dimensiones, fundamentalmente a su contenido en fosfato cálcico coloidal, el cual está en mayor proporción en las micelas de tamaño superior. La sensibilidad de la leche a la acción del cuajo, está fuertemente relacionada con el fosfato cálcico de la micela, siendo el tiempo de coagulación más corto y un gel más elástico cuando éste aumenta.

Las proteínas de la leche tienen gran influencia en la textura de la pasta del queso, pues constituye la única fase sólida continúa, en la que se encuentran los glóbulos grasos y el lacto- 
suero. También pueden influir en su sabor y aroma, por la proteólisis que pueden sufrir en los quesos madurados.

La relación entre el tiempo de coagulación y la concentración de caseínas explica el fenómeno de coagulación, la hidrólisis de la CSN3 y la agregación de las micelas modificadas. La formación de la cuajada depende de la hidrólisis inicial de la CSN3, cuando el 85-90\% de ésta se hidroliza, mientras que la coagulación empieza por la formación de enlaces que conducen a la agregación de CSN1S1, CSN2 y CSN3 hidrolizada parcialmente (paracaseína) y la formación de una malla que atrapa la grasa, algunas proteínas y minerales.

El tiempo de coagulación es mucho más sensible a las variaciones de CSN3 que a las de CSN1S1 y CSN2. En bovinos, se han descripto 9 variantes del gen de la CSN3, siendo las variantes $A$ y $B$ las más importantes, aunque la $B$ es la de mayor interés debido a que se asocia a un menor tiempo de coagulación, mejor formación del cuajo y tamaño de micelas, todas características deseables para la elaboración de quesos (Requena et al., 2007). En animales con genotipo homocigoto BB hay un incremento de $0,8 \%$ más de proteínas, sólidos totales, menor tiempo de coagulación y mejor consistencia del cuajo, lo que se traduce en un 5 a $10 \%$ más en la producción de quesos, respecto a la leche de aquellos individuos con genotipo homocigoto AA (Azevedo et al., 2008). El efecto de los polimorfismos de las proteínas de la leche en su composición y en el proceso de coagulación, es posible explicarlo por diferentes menciones de investigación: 1.- contenido de caseína total, distintas proporciones; 2.- dimensión de las micelas; 3.- grado de glicosilación de CSN3; 4.- composición físico química de la leche. La detección del polimorfismo en las proteínas de la leche ofrece nuevas explicaciones para la variación de las propiedades de la leche de animales individuales (Gálvez, 1993). Como la proporción de CSN3 en la leche es genotipo dependiente, se pretendió estudiar la asociación entre los genotipos y el tiempo de coagulación y rendimiento quesero, como se observó una baja variabilidad, no se pudo realizar el estudio de asociación propuesto. Los resultados del rendimiento quesero se presentan en el Capítulo 5 dentro de la revisión bibliográfica realizada en el tema. 


\section{Hipótesis}

\section{Hipótesis general}

En ovejas de la raza Pampinta existen polimorfismos de los genes que codifican para las caseínas (CSN1S1, CSN2, CSN3) y proteínas del suero (LGB y SBD2), que se correlacionan con los caracteres cuantitativos como producción de leche (PL), grasa total $(G T)$, proteína total (PT), porcentaje de grasa (G\%), porcentaje de proteína (P\%) y mastitis subclínica (MSC); como así también asociados a parámetros de la calidad del queso, como rendimiento quesero y tiempo de coagulación.

\section{Hipótesis especificas}

- El modelo genético infinitesimal explica la variación de los caracteres cuantitativos: las producciones de leche $(P L)$, grasa total $(G T)$, proteína tota $(P T)$, grasa porcentaje $(G \%)$, proteína porcentaje (P\%) y la incidencia de mastitis subclínica (MSC).

- Existen genes cuantitativos con efecto pleiotrópico o ligados que correlacionan genéticamente las variables PL, GT, PT, G\%, P\% y MSC.

- La raza ovina Pampinta presenta polimorfismos genómicos en los genes que codifican para las caseínas (CSN1S1; CSN2; CSN3), beta lactoglobulina (BLG), beta defensina 2 (SBD2).

- Los polimorfismos genómicos de los genes en estudio están en desequilibrio de ligamiento con respecto a los genes cuantitativos.

- $\quad$ El polimorfismo de la kappa caseína (CSN3) está asociado a diversos parámetros de la calidad del queso. 


\section{Objetivos del trabajo}

\section{Objetivos generales:}

- Obtener estimaciones de la variabilidad genética de características productivas y de mastitis, y la relación de estos con polimorfismos genéticos, en ovinos Pampinta para permitir el desarrollo de programas de mejora genética orientados a la producción de leche para elaboración de quesos.

\section{Objetivos específicos:}

- Estimar las varianzas genéticas y fenotípicas, y las heredabilidades para las producciones de leche (PL), proteína total (PT), grasa total (GT), el conteo de células somáticas (RCS), y Mastitis Subclínica (MSC).

- $\quad$ Estimar las correlaciones genéticas y fenotípicas entre PL, PT, GT, RCS, y MSC.

- Identificar polimorfismos genómicos para caseínas: CSN1S1, CSN2 y CSN3, SBD2, LGB.

- Estimar asociaciones entre los polimorfismos genómicos identificados con PL, PT, GT, RCS, y MSC.

- Estimar las asociaciones entre el genotipo del gen CSN3 y el tiempo de coagulación y rendimiento quesero durante la elaboración de quesos. Este último objetivo no se pudo cumplir por la baja variabilidad observada.

\section{Animales e información fenotípica}

La EEA INTA Anguil posee un plantel de pedigrí de la raza Pampinta, que año tras año va aumentando su tamaño, con él se trabajó en el presente estudio. Actualmente posee unas 342 madres y 39 carneros. Cada año se ordeñaron aproximadamente 150 ovejas. Esta información se sumó a la información de producción y genealogía obtenida desde 2001. Se pusieron a prueba 
unos 10-15 machos por año. Los animales comienzan el ordeñe a los 40-45 días post parto, y lo finalizan (se secan) cuando su producción es menor a $300 \mathrm{ml}$ por día (aproximadamente 200-220 días post parto); se realizaron alrededor de 5 a 6 controles por animal en ordeñe. Los datos fenotípicos, que se generaron del control lechero mensual son los siguientes: PL en $\mathrm{kg}, \mathrm{PT} \mathrm{g} / \mathrm{ml}$ y GT g/ml, MSC (Mastitis Subclínica) (presencia/ausencia). PL se midió con lactómetros (TRU-Test), \%P y \%G se midió con un equipo infrarrojo EKOMILK. En tanto que la MSC se evaluó con el método Test Mastitis California (Schalm \& Noorlander, 1957). Del mismo modo, se realizaron controles genealógicos, para lo cual se registraron los servicios, que fueron dirigidos, y los partos; donde se anotó para cada parto: la oveja, la fecha de parto, el número y sexo de los corderos paridos, y sus pesos.

\section{Bibliografía}

Azevedo, A. L. S., Nascimento, C. S., Steinberg, R. S., Carvalho, M. R. S., Peixoto, M. G. C. D., Teodoro, R. L., \& Machado, M. A. (2008). Genetic polymorphism of the kappa-casein gene in Brazilian cattle. Genet. Mol. Res. 7: 623-630.

Barillet, F., Rupp, R., Mignon Grasteau, S., Astruc, J.M., \& Jacquin, M. (2001). Genetic analysis for mastitis resistance and milk somatic cell score in French Lacaune dairy sheep. Genet. Select. Evol. 33: 397-415.

Bergonier, D., De Crémoux, R., Rupp, R., Lagriffoul, G., \& Berthelot, X. (2003). Mastitis of dairy small ruminants. Vet. Res. 34: 689-716.

Bolla, P., Caroli, A., Mezzelani, A., Rizzi, R., Pagnacco, G., Fraghì, A., \& Casu, S. (1989). Milk protein markers and production in sheep. Anim. Genet., 20: 78-79.

Brule, G., Lenoir, J., \& Remeuf, F. (2000). In: Eck A, Gillis JC (eds) The casein micelle and milk coagulation. Lavoisier Publishing, Paris.

Busetti, M.R \& Suarez V.H. (2010). Situación actual de los tambos ovinos en Argentina. [En línea]. Disponible en: http://www.produccion-animal.com.ar/ (09/02/2017). 
Busetti, M.R. (2008). Composición de la leche de ovejas Pampinta a lo largo de un periodo de lactancia. Comunicación personal. [En línea]. Disponible en: http://www.produccionanimal.com.ar/ (07/02/2017).

Busetti, M.R. \& Suárez, V.H. (2010). Encuesta Sanitaria-Productiva. [En línea]. Disponible en: http://www.produccion-animal.com.ar/ (09/02/2017).

Ceriotti, G., Chessa, S., Bolla, P., Budelli, E., Bianchi, L., Duranti, E., \& Caroli, A. (2004). Single nucleotide polymorphisms in the ovine casein genes detected by polymerase chain reaction-single strand conformation polymorphism. J. Dairy Sci. 87:2606-2613.

Delacroix-Buchet, A., Barillet, F., \& Lagriffoul, G. (1994). Caractérisation de l'aptitude fromagère des laits de brebis Lacaune à l'aide d'un Formagraph. Le lait, 74: 173-186.

Di Stazio, L., Giocconi, P., Portolano, B., \& Rasero, R. (1992). B- lactoglobulin types and milk production in sheep. Anim. Genet. 23: 107.

Fthenakis, G.G., \& Jones, J.E.T. (1990). The effect of experimentally induced subclinical mastitis on milk yield of ewes and on the growth of lamb. Br Vet J. 146: 43-49.

García-Díaz, L. K., Mantecón, A. R., Sepúlveda, W. S., \& Maza, M. T. (2012). Producción de leche ovina como alternativa de negocio agropecuario: modelo de producción en Castilla y León (España). Revista Mexicana de Agro-negocios, XVI: 6-18.

Garzón, A., \& Martinez, J. (1992). Beta- lactoglobulins in Manchega sheep breed; Relationship with milk technological indexes in handcraf manufacture of Manchego cheese. Int. Conf. Anim. Genet.

Gigli, I., Riggio, V., Monteleone, G., Cacioppo, D., Rosa, A. J. M., \& Maizon, D. O. (2007). Relationship between beta lactoglobulin and subclinical mastitis in Valle del Belice sheep breed. Ital. J. Anim. Sci. 6:140-142.

Gray, D.M., \& Schalm, O.W. (1962). The mastitis variable in milk as estimated by the California mastitis test. Am. J. Vet Res. 23: 541-3.

Juàrez, M., \& Ramos, M. (1986): Physico-chemical characteristics of goat milk as distinct from those of cow milk. In: International Dairy Federation, Editor, Proceedings of the IDF 
Seminar Production and Utilization of Ewe's and Goat's Milk, Bulletin No. 202 Athens, Greece, 54-67.

Legarra, A., \& Ugarte, E. (2001). Genetic parameters of milk traits in Latxa dairy sheep. Anim. Sci. 73: 407-412.

Lôbo, R. N. B., Facó, O., \& Vasques Vilella, L. C. (2005). Desafíos para el mercado en un programa de mejoramiento genético.

López-Gálvez, G. (1993) .Estudio del polimorfismo de las proteínas de leche de oveja de las razas Manchega y Segureña. Aptitud a la coagulación y rendimiento quesero. Tesis Doctoral. Universidad complutense. Facultad de Veterinaria. Madrid.

Maizon, D.O., Etchegaray, J.L., Busetti, M.R., \& Gigli, I. (2011). Control lechero y mejora genética en ovinos Pampinta. RAPA 1: 107-153.

Marguet, E. R., Vilanova, C. P. \& Salgado, V. (2000). Estudio de mastitis subclínicas en un rodeo ovino lechero. Vet. Arg., XVII 163: 190-197.

Maioli, B., D’Andrea, M., \& Pilla, F. (2007). Candidate genes affecting sheep and goat milk quality. Small Rumin. Res. 68: 179-192.

Pirisi, A., Colin, O., Laurent, F., Scher, J., \& Parmentier, M. (1994). Comparison of milk composition, cheesemaking properties and textural characteristics of the cheese from two groups of goats with a high or low rate of as1-casein synthesis. Int. Dairy J. 4: 329-345.

Pulina, G., Nudda, A., Battacone, G., \& Cannas, A. (2006). Effects of nutrition on the contents of fat, protein, somatic cells, aromatic compounds, and undesirable substances in sheep milk. Anim. Feed Sci. Technol. 131: 255-291.

Raubertas, R.F., \& Shook, G.E. (1982). Relationship Between Lactation Measures of Somatic Cell Concentration and Milk Yield. J. Dairy Sci. 65: 419-425.

Requena, F. D., Agüera, E. I., \& Requena, F. (2007). Genética de la caseína de la leche en el bovino Frisón. REDVET. Rev. electron. vet. 8: 1-9.

Rupp, R., \& Boichard, D. (1999). Genetic Parameters for Clinical Mastitis, Somatic Cell Score, Production, Udder Type Traits, and Milking Ease in First Lactation Holsteins. J. Dairy Sci. 82: 2198-2204. 
Saratsis, P., Leontides, L., Tzora, A., Alexopoulos, C., \& Fthenakis, G. C. (1998). Incidence risk and aetiology of mammary abnormalities in dry ewes in 10 flocks in Southern Greece. Prev. Vet. Med. 37: 173-183.

Schalm, O.W., \& Noorlander, D.O. (1957). Experiment and observations leading to development of the California mastitis test. J. Am. Vet. Med. Asoc., 5:199-207.

Suarez, V.H. Lechería Ovina y Raza Pampinta. Comunicación personal. [En línea]. Disponible en: http://www.produccion-animal.com.ar/ (09/02/2017).

Suarez, V.H. (1999). Mastitis en ovejas lecheras. . [En línea]. Disponible en: http://www.produccion-animal.com.ar/ (09/02/2017).

Suarez, V.H., Busetti, M.R, Miranda, A. O., Calvinho, L. F., Bedotti, D. O., \& Canavesio, V.R. (2002). Effect of Infectious Status and Parity on Somatic Cell Count and California Mastitis Test in Pampinta Dairy Ewes. J. Vet. Med. 49: 230-234.

Torres-Hernandez, G., \& Hohenboken, W. (1979). Genetic and environmental effects on milk production, milk composition and mastitis incidence in crossbred ewes. J. Anim. Sci. 49: 410-417. 


\section{Estimación de parámetros genéticos para producción de leche, grasa, proteínas y mastitis subclínica en ovinos Pampinta}

\subsection{Introducción}

Las estimaciones de componentes de varianza, así como las de heredabilidades y correlaciones genéticas y fenotípicas, cumplen un rol fundamental en el desarrollo de programas de mejora genética (Falconer \& Mackay, 1996). En relación a característica de producción, tales como leche, grasa y proteína, y de enfermedades, por ejemplo mastitis subclínicas, se han definido diversas variables respuesta, que han variado en el tiempo de producción (120, 180, 210 días en lactancia) y en la escala de medición (litros, kilogramos, por día o por período). Por ejemplo, Legarra \& Ugarte (2001) estimaron en la raza Latxa valores de heredabilidad de 0,$20 ; 0,16 ; 0,18$; 0,14 y 0,38 para producción de leche $(\mathrm{l})$, grasa $(\mathrm{kg})$, proteína $(\mathrm{kg})$, y porcentajes de grasa $(\mathrm{g} / \mathrm{l})$ y de proteínas (g/l), respectivamente, para la producción acumulada en 120 días. En la raza Frisona del Este (East Friesian, desde ahora FE), Hamann et al. (2004) estimaron heredabilidades de 0,15 para leche $(\mathrm{kg})$, grasa $(\mathrm{g})$ y proteína $(\mathrm{g})$ y 0,09 para porcentaje de proteínas (\%) y 0,20 para porcentaje de grasa (\%) con un modelo del día de producción. Gutiérrez et al. (2007), mediante análisis del día de producción, estimaron en ovejas Assaf para producción de leche (kg) estandarizada a 180 días una heredabilidad de 0,13. Esto nos indica que la variación en las estimaciones es debida no sólo a su definición, escala y tiempo, sino que también a la raza y al ambiente en que se la críe y seleccione.

Pampinta es una raza sintética $3 / 4$ FE y $1 / 4$ Corriedale que se seleccionó fenotípicamente desde su origen, a fines de los años 70 , en la dirección del estándar racial de la raza FE. Por ser esta última una de las principales razas Europeas para producción de leche, Pampinta tiene una importante aptitud lechera en comparación a otras razas que se crían en el país (Busetti et al., 2008). Desde el año 1995 en la EEA Anguil "Ing. Agr. Guillermo Covas" del INTA, se mantiene un tambo experimental de la raza Pampita. Desde el inicio de la actividad, se han realizado controles 
lecheros individuales a cada animal que se ordeñó. Inicialmente sólo se registraba la producción de leche, en litros, y la presencia o ausencia de mastitis subclínicas mediante el test mastitis california (Suárez et al., 1999). Desde el 2010, se registra también la composición de la leche: grasas, proteínas, sólidos totales y la densidad. Los registros de control lechero evidencian que Pampinta produce aproximadamente un litro día de leche en lactancias de entre 180 a 210 días, valor substancialmente menor a los 2,4 litros por día producido por la raza alemana FE (Hamann et al., 2004). Esto puede ser consecuencia de que la alimentación y las condiciones de manejo nunca llega a ser la ideal en Argentina y que además, la comercialización no ha incentivado la selección a favor de esta variable. Sin embargo, en relación a otras razas empleadas a nivel nacional su nivel de producción es bueno, tal es así que es de las razas predominantes en los tambos existentes en Argentina (Busetti \& Suárez, 2010).

La mastitis es una inflamación del tejido mamario, no siempre debida a una infección. Como respuesta al proceso inflamatorio, se produce una migración de leucocitos principalmente neutrófilos al lumen alveolar mamario y posteriormente a la leche (Harmon, 1994). La mastitis subclínica (sin alteraciones visibles de la leche o glándulas mamarias) puede ser identificada indirectamente por el recuento de células somáticas en leche (RCS) o a través del test mastitis california (TMC). En Argentina, Suárez et al. (2002) reportaron una incidencia del 18 al 36\% para mastitis subclínicas evaluadas mediante el TMC, en ovejas en ordeñe. En este contexto, el RCS y el TMC se presentan como buenos indicadores de la incidencia de mastitis subclínicas, lo que posibilita su uso dentro de programas de mejoras genéticas. En este sentido, aunque la bibliografía es muy escasa comparada con la existente para bovinos, diversos estudios han demostrado la posibilidad de utilizar el RCS para seleccionar genéticamente para resistencia al desarrollo de mastitis (Barrilet et al., 2001, Rupp et al., 2002). En la situación nacional, el uso de RCS tendría un costo muy alto, por lo cual resulta interesante trabajar con TMC.

Para implementar un esquema de selección en la raza Pampinta, que considere tanto la producción de leche en litro como su composición y sanidad, es necesario contar con estimaciones de los parámetros genéticos de los caracteres mencionados. Por lo cual, para producción de leche $(\mathrm{l} / \mathrm{d})$, contenido de grasa total y proteínas totales $(\mathrm{g} / \mathrm{d})$, y para porcentaje de grasa $(\%)$ y de 
proteínas (\%), y mastitis subclínica (presencia/ausencia en base a TMC), el presente trabajo tuvo los siguientes objetivos: ajustar modelos que reflejen los efectos de los principales factores ambientales sobre las variables mencionadas y obtener estimaciones de componentes de varianza y covarianza, heredabilidades y correlaciones genéticas.

\subsection{Materiales y Métodos}

Para el presente estudio, se empleó información de producción de leche de la Cabaña Pampinta obtenida entre los años 2009 y 2016 en el tambo experimental de la EEA Anguil "Ing. Agr. Guillermo Covas" del INTA (Anguil, La Pampa, Argentina). En este tambo se realiza sólo un ordeñe diario por la mañana, y las ovejas ingresan al ordeñe al momento del destete de sus crías. Los destetes se realizan cuando el peso de la cría supera 2,5 veces el peso al nacer, lo que ocurre en promedio a los 45 días postparto. Los controles lecheros $(\mathrm{CL})$ se realizaron cada 28 a 35 días, con un tiempo promedio desde el parto al primer CL de 63,9 d con un desvío estándar (DE) de 18,5 d. En cada CL se obtuvo la producción en kilogramos mediante lactómetros (TRUTEST) y la presencia/ausencia de mastitis subclínica por el método TMC (Schalm \& Noorlander, 1957). Posteriormente, en el laboratorio de leche de la Experimental, se determinó la composición (grasa total, proteínas totales, densidad y residuo sólidos totales) mediante un equipo de infrarrojo (EKOMILK, Córdoba, Argentina) y se confirmó la presencia/ausencia de mastitis subclínica mediante un contador automático de células (Alfa DeLaval, Buenos Aires, Argentina). Fueron consideraron con mastitis subclínica, los animales con un TMC positivo y un recuento de células somáticas superior a 600.000 por mililitros en una muestra de leche. Los kilogramos de leche de cada oveja se pasaron a litros de leche empleando la densidad individual. Se consideró fin de lactancia cuando la cantidad de leche ordeñada fue igual o menor a 0,3 l/d en el día del CL, lo que ocurrió en promedio a los 209,1 d con un DE de 50,8 d. Para el análisis estadístico sólo se retuvieron las ovejas con tres o más CLs entre el inicio del ordeñe y los 210 d posparto. La producción de leche acumulada entre el día de parto y los 210 d, en coincidencia con el tiempo 
promedio de duración de las lactancias en la EEA Anguil, se estimó empleando el procedimiento sugerido por Legarra \& Ugarte (2001). Así se obtuvieron para el período 2009-2016, 833 lactancias, correspondientes a 425 ovejas. El archivo de pedigrí se generó incorporando los ancestros de cada una de las ovejas con registros de producción. Sólo se agregaron ancestros que conectaran dos o más animales con registro productivos, con lo cual se obtuvo un pedigrí de 1.092 animales que incluía: 425 ovejas con datos productivos, 218 padres y 637 madres.

Los seis caracteres evaluados fueron "producción de leche" (PL, I/d); "grasa total" (GT, g/d); "proteínas totales" (PT, g/d); "porcentaje de grasa" (G\%, \%); "porcentaje de proteínas" (P\%, \%) y "mastitis subclínica" (MSC, presencia/ausencia) en 210 d de lactancia. Por la naturaleza dicotómica de MSC, se consideraron afectadas aquellas ovejas que tuvieron al menos un TMC positivo, confirmado por recuento de células somáticas en laboratorio, en algún momento de la lactancia.

Los efectos clasificatorios considerados en el modelo de cada variable respuesta fueron:

1.- Edad al primer parto (EPP), con tres niveles: 1) menor o igual a 14 meses; 2) entre 15 y 22 meses; y 3) mayor a 23 meses;

2.- La combinación año de parto y época de parto (AEP): los años 2009 a 2015, y la época: 1) si el parto ocurrió entre julio y octubre y 2) si ocurrió en otros meses. Hubo nueve niveles pues sólo los años 2013 y 2015 tuvieron partos fuera de estación reproductiva (llamados partos contra estación).

3.- Orden de parto (OPAR), con cuatro niveles: primer; segundo; tercer y cuarto o más partos. Este efecto clasificatorio estuvo altamente asociado $(p<0,01)$ con la edad al parto, por lo cual sólo se empleó OPAR.

4.- Tipo de parto y crianza (TPC) con cinco niveles, resultando de la combinación del número de nacidos [agrupados como uno (1) y dos o más $(2 \circ+)$ ] y el número de crías destetadas [agrupadas como cero (0), una (1) y dos o más $\left(20^{+}\right)$]. Por ejemplo, "21" indica un parto doble pero se destetó una sola cría.

5.- Días desde el parto al primer control lechero (DPPCL), con tres niveles: 1) menor a 52 días; 2) entre 52 a 75 días; y 3) mayor a 75 días. 
6.- Extensión de lactancia (ELAC). Tuvo tres niveles: 1) la lactancia fue menor a 200d; 2) la lactancia estuvo entre $200 \mathrm{~d}$ y $220 \mathrm{~d}$; 3) la lactancia fue mayor a $220 \mathrm{~d}$.

Previo a la estimación de los componentes de varianza, se efectuó un análisis preliminar para seleccionar los efectos clasificatorios a incluir en los modelos de cada variable respuesta. El mismo se realizó mediante modelos mixtos univariados con observaciones repetidas con el programa R (R Core Team, 2014; https://www.r-project.org/) con el paquete "Ime 4" (versión 1.113), incluyendo como efecto aleatorio las observaciones repetidas por oveja. Para cada variable respuesta, el modelo de estimación sólo incluyó los efectos clasificatorios con valores $\boldsymbol{p}$ menores o iguales a 0,10 .

Los efectos aleatorios considerados para la estimación de componentes de varianza fueron los siguientes:

1.- el componente permanente de las observaciones repetidas entre lactancias de ovejas. Se asumió una distribución normal e independiente entre ovejas, reflejando los efectos genéticos no aditivos y el ambiente permanente;

2.- el componente genético aditivo, que se asumió con distribución normal multivariada y proporcional a la matriz de relaciones aditivas $(\boldsymbol{A})$ que se construyó considerando el pedigrí obtenido al incorporar los ancestro de las ovejas con registros productivos;

3.- el término del error, que se asumió de distribución normal e independiente entre las ovejas.

Para las estimaciones de los componentes de varianza y covarianza se empleó un procedimiento bayesiano mediante el muestreo de Gibbs (Sorensen \& Gianola, 2002) teniendo en consideración el bajo número de ovejas con observaciones y la presencia de un carácter dicotómico como la mastitis subclínica (MSC). A tal fin, se usó el programa Threshold Model (TM) de Legarra et al. (2008). Para MSC se empleó un modelo umbral con observaciones repetidas, asumiendo un valor igual a cero para el umbral entre presencia y ausencia de $\boldsymbol{M S C}$ y una varianza del término del error igual a uno (Sorensen \& Gianola, 2002). Las estimaciones se realizaron, primero mediante modelos mixtos univariados, en los que se consideró para cada variable respuesta los efectos clasificatorios obtenidos y el componente ambiental permanente. Luego, mediante modelos bivariados, en los que se partió de las estimaciones realizadas para cada 
variable con los modelos univariados, se estimó las covarianzas entre las distintas variables respuesta. Si bien se intentó modelar con tres o más caracteres, como algunas estimaciones presentaron problemas numéricos de convergencia para los muestreos de Gibbs, se decidió emplear sólo los modelos bivariados. Para cada situación se generó una cadena única de $1 \times 10^{6}$ muestras de las distribuciones marginales posteriores de cada componente de varianza (varianza genética aditiva, de ambiente permanente, y del error y sus respectivas covarianzas). Se tomó como período de calentamiento (burn-in) las primeras $1 \times 10^{5}$ muestras. Para disminuir el efecto de la auto-correlación sobre las estimaciones, se tomaron valores cada 25 muestras de la cadena única. Para comprobar la correcta convergencia del muestreo se utilizó el paquete BOA (Bayesian Output Analysis Program for MCMC) en R (Smith, 2005). Se obtuvieron los siguientes gráficos: a) valor muestreado del componente de varianza en función del número de iteración (traceplot), b) las densidades de la distribución posterior de los componentes de varianza, c) las medias de los valores muestreados de los componentes de varianza hasta una iteración en función de ésta última (running mean) y d) los gráficos de autocorrelaciones de los valores muestreados de componentes de varianza para distintas iteraciones. Además, para el diagnóstico de convergencia se realizaron las pruebas de Geweke, siempre utilizando el paquete BOA (Geweke, 1992) y de Heidelberger y Welch (Heidelberger \& Welch, 1983). La primera, prueba la hipótesis de que ambas cadenas de Markov provienen de una misma distribución. Para ello, compara las medias de dos partes de la cadena: el $10 \%$ inicial y el $50 \%$ final. La segunda prueba, calcula un estadístico para probar si la cadena muestreada corresponde a la de una distribución estacionaria.

\subsection{Resultados}

En el Cuadro 2.1 se presentan los promedios, desvíos estándares (DE), mínimos y máximos de las características de producción lechera de las 833 lactancias. Cabe aclarar que en el año 2009, sólo se tuvo registro de litros de leche y mastitis. La incidencia de MSC fue 0,174 en todo el período considerado. 
Las pruebas de Geweke y de Heidelberger y Welch indicaron que los muestreos convergieron a las distribuciones posteriores. El período de calentamiento de $10^{5}$ fue adecuado en general, aunque en muy pocas situaciones se lo debió incrementar para obtener un muestreo estable. Los gráficos permitieron corroborar los resultados de las pruebas de Geweke y de Heidelberger y Welch. En las figuras 2.1, 2.2, 2.3 y 2.4 se muestran algunos ejemplos de estos gráficos. En general, las autocorrelaciones disminuyeron al incrementarse las iteraciones. Esto ocurrió más rápido para los componentes de varianza que para los de covarianza (ver figura 2.1). Las densidades fueron simétricas aunque las que tomaron valores muy cercanos a cero tuvieron una leve cola a derecha (ver figura 2.2). La estacionalidad de los muestreos se puede observar en los gráficos traceplot y running mean (figura 2.3 y 2.4). Esto permite asumir que el muestreo de Gibbs representó una muestra de las distribuciones posteriores de los componentes de varianza y parámetros genéticos que se pretende estimar.

Cuadro 2.1. Descripción estadística de las observaciones fenotípicas de producción de leche acumulada en 210 días y expresadas como promedio diario, basada en lactancias de ovinos Pampinta, de distintas edades y número de partos, entre los años 2009 y 2016.

\begin{tabular}{rrrrrr}
\hline Características & N & Promedio & DE & Mínimo & Máximo \\
\hline Leche (I/d) & 833 & 1,0 & 0,38 & 0,2 & 2,2 \\
Grasa (g/d) & 768 & 66,3 & 26,5 & 12,7 & 162,1 \\
Proteína (g/d) & 768 & 61,7 & 24,1 & 9,4 & 139,9 \\
Grasa (\%) & 768 & 6,6 & 0,9 & 3,8 & 10,1 \\
Proteína (\%) & 768 & 6,1 & 0,4 & 4,7 & 7,9 \\
\hline
\end{tabular}

N: número de observaciones; DE: Desvío Estándar

En el Cuadro 2.2 se observan los valores de $\boldsymbol{p}$ de los efectos clasificatorios estimados bajo modelos mixtos de observaciones repetidas univariados con el programa $\mathrm{R}$ para cada variable respuesta. La significación de estos efectos se realizó para elegir un modelo adecuado para cada variable respuesta al estimar los componentes de la varianza. Se destaca por un lado la 
importancia del efecto año-estación de parto (AEP) y lo irrelevante que resultó la edad al primer parto (EPP).

Las estimaciones del efecto $\boldsymbol{A E P}$ fueron significativas en todas las variables respuesta estudiadas $P$ L, GT, PT, G\%, P\% y MSC (Figura 2.2). Se tomó como referencia el primer nivel de cada uno de los otros efectos clasificatorios en el modelo: EPP, OPAR, TPC, DPPCL y ELAC. Se destaca la variabilidad en el período que estuvo relacionado con la variación ambiental. Es importante destacar que hubo temperaturas anuales promedios y precipitaciones muy distintas entre los años estudiados, que se tradujo en algunos años muy húmedos y otros muy secos con la variación esperada en la oferta forrajera. A su vez, si bien la incidencia de MSC promedio fue relativamente baja, se notan dos períodos donde fue mayor en coincidencia con año y estación de partos muy húmedos, 2010_1 y 2015_1, que afectaron sin duda la salud mamaria.

Cuadro 2.2. Valores $p$ para los efectos clasificatorios: AEP, EPP, OPAR, TPC, DPPCL y ELAC empleados en los modelos mixtos univariados para $P$ L, GT, PT, G\%, P\% y $\mathbf{M S C}$, en 210 días expresados como promedio diario, de ovejas Pampinta con tres o más CLs en lactancias registradas entre los años 2009 y 2016.

\begin{tabular}{lrrrrrr}
\hline Efectos & PL & GT & PT & G\% & P\% & MSC \\
\hline AEP & $<0,0001$ & $<0,0001$ & $<0,0001$ & $<0,0001$ & $<0,0001$ & $<0,0001$ \\
EPP & 0,2729 & 0,27 & 0,3594 & 0,6208 & 0,8985 & 0,3628 \\
OPAR & 0,0592 & $<0,0001$ & 0,2694 & $<0,0001$ & 0,0002 & 0,0004 \\
TPC & 0,3072 & 0,0617 & 0,2383 & 0,0642 & 0,0236 & 0,0231 \\
DPPCL & 0,0092 & 0,0277 & 0,0084 & 0,0169 & 0,0805 & 0,7214 \\
ELAC & $<0,0001$ & $<0,0001$ & $<0,0001$ & 0,0103 & 0,7699 & 0,5367
\end{tabular}

AEP: año-época de parto; EPP: edad primer parto; OPAR: orden de parto; TPC: tipo de parto y crianza; DPPCL: días desde el parto al primer control lechero; ELAC: extensión de lactancia. PL: producción de leche; GT: grasa total; PT: proteína total; G\%: grasa porcentaje; P\%: proteína porcentaje; MSC: mastitis subclínica.

Las estimaciones para el efecto OPAR fueron significativas para GT, G\%, P\% y $\mathbf{M S C}$ (cuadro 2.3). Para GT se observó un aumento en g/d hasta el tercer parto, y luego una diminución. En tanto, OPAR tuvo un efecto opuesto para $\mathbf{G} \%$ y $\mathbf{P} \%$. Mientras que $\mathbf{G} \%$ incrementó su valor con el aumento del número de partos, $\boldsymbol{P} \%$ disminuyó. La incidencia de $\boldsymbol{M S C}$ aumentó sustancialmente con el número de partos. 
Las estimaciones para el efecto TPC se observan en el cuadro 4, el mismo fue significativo para $\boldsymbol{P} \%$ y $\boldsymbol{M S C}$. Las mayores incidencias de $\boldsymbol{M S C}$ se presentaron cuando la oveja parió una cría y la perdió, o cuando parió más de dos o más crías, pero sólo crió una.

Las estimaciones para el efecto DPPCL resultaron significativas para las características $\boldsymbol{P L}, \boldsymbol{G T}, \boldsymbol{P T}$ y $\mathbf{G} \%$ (cuadro 2.5). En estas variables se observa una tendencia a disminuir el valor cuanto más tiempo transcurre entre el parto y el comienzo del ordeñe. Con excepción de G\% que tiende a aumentar levemente.

Cuadro 2.3. Estimaciones de mínimo cuadrado del efecto OPAR para las variables $P L(I / d), G T$ (g/d), PT (g/d), G\%, P\% y MSC (incidencia). Las estimaciones son referidas al primer nivel de las otras variables clasificatorias en el modelo ASP, EPP, TPC, DPPCL y ELAC en ovejas Pampinta.

\begin{tabular}{ccccccc}
\hline OPAR & PL & GT & PT & G\% & P\% & MSC \\
\hline 1 & 0,691 & 43,4 & 57,7 & 4,72 & 6,06 & 0,069 \\
2 & 0,712 & 49,0 & 57,6 & 5,15 & 5,93 & 0,137 \\
3 & 0,772 & 55,6 & 60,6 & 5,45 & 5,92 & 0,195 \\
$40+$ & 0,720 & 53,1 & 57,3 & 5,65 & 5,91 & 0,306 \\
\hline
\end{tabular}

OPAR: orden de parto

Cuadro 2.4. Estimaciones de mínimo cuadrado del efecto TPC para las variables $P L(I / d), G T$ (g/d), PT (g/d), G\%, P\% y MSC (incidencia). Las estimaciones son referidas al primer nivel de las otras variables clasificatorias en el modelo ASP, EPP, OPAR, DPPCL y ELAC en ovejas Pampinta.

\begin{tabular}{rrrrrrr}
\hline TPC & PL & GT & PT & G\% & P\% & MSC \\
\hline 10 & 0,691 & 43,4 & 57,7 & 4,72 & 6,06 & 0,069 \\
11 & 0,713 & 46,9 & 60,5 & 4,81 & 6,14 & 0,020 \\
20 & 0,608 & 36,9 & 54,0 & 4,51 & 6,17 & 0,015 \\
21 & 0,707 & 47,0 & 60,1 & 4,87 & 6,15 & 0,061 \\
22 & 0,714 & 46,0 & 60,6 & 4,78 & 6,19 & 0,032
\end{tabular}

TPC: tipo de parto y crianza 

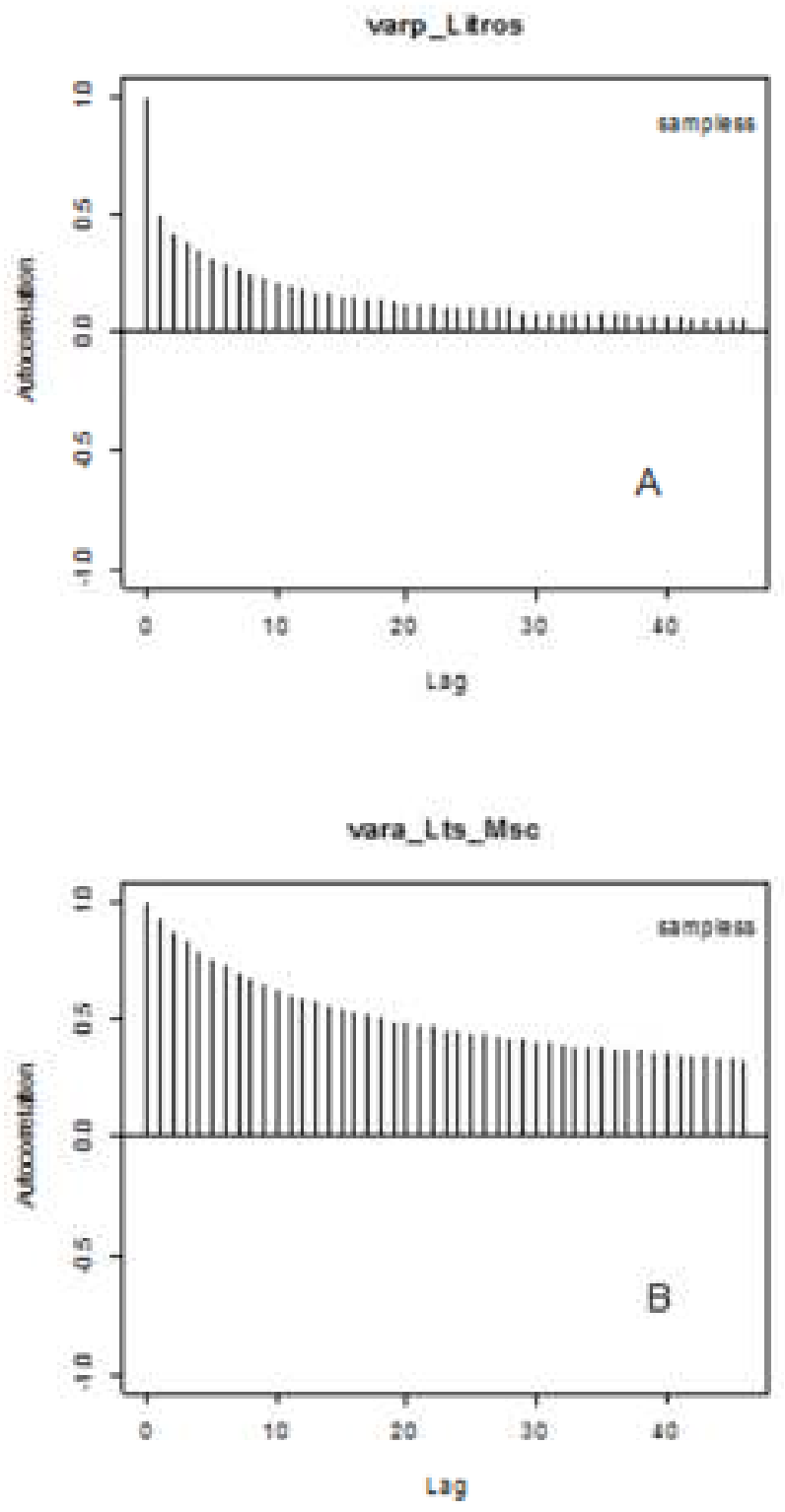

Figura 2.1. Los gráficos diagnósticos de autocorrelación, que se muestran a modo de ejemplo, son para A) la varianza fenotípica de LT y B) la covarianza genética aditiva entre LT y MSC. 

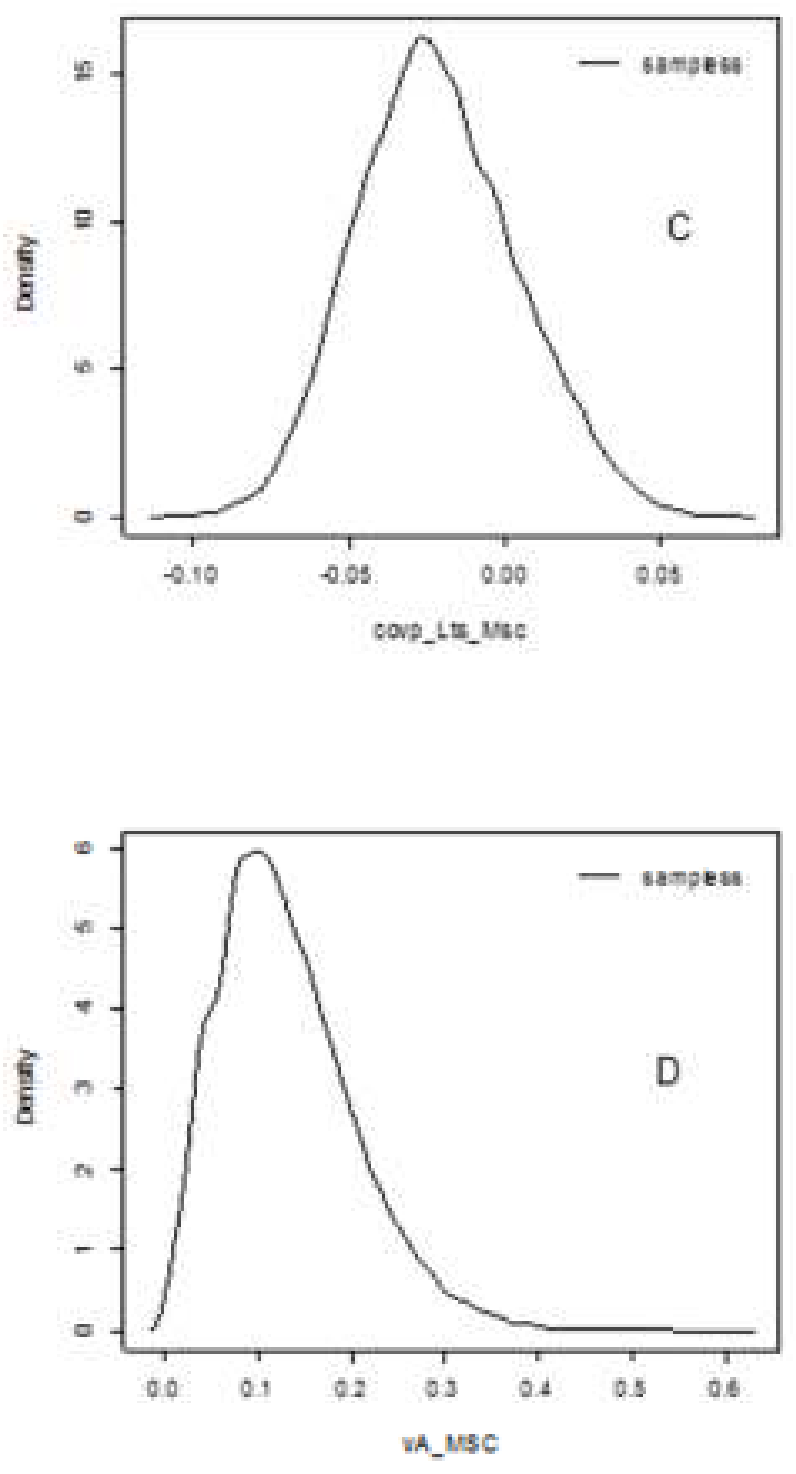

Figura 2.2. A modo de ejemplo, se presentan los gráficos de las densidades de las distribuciones posteriores para C) la correlación fenotípica entre LT y MSC y D) la varianza genética aditiva de MSC. 

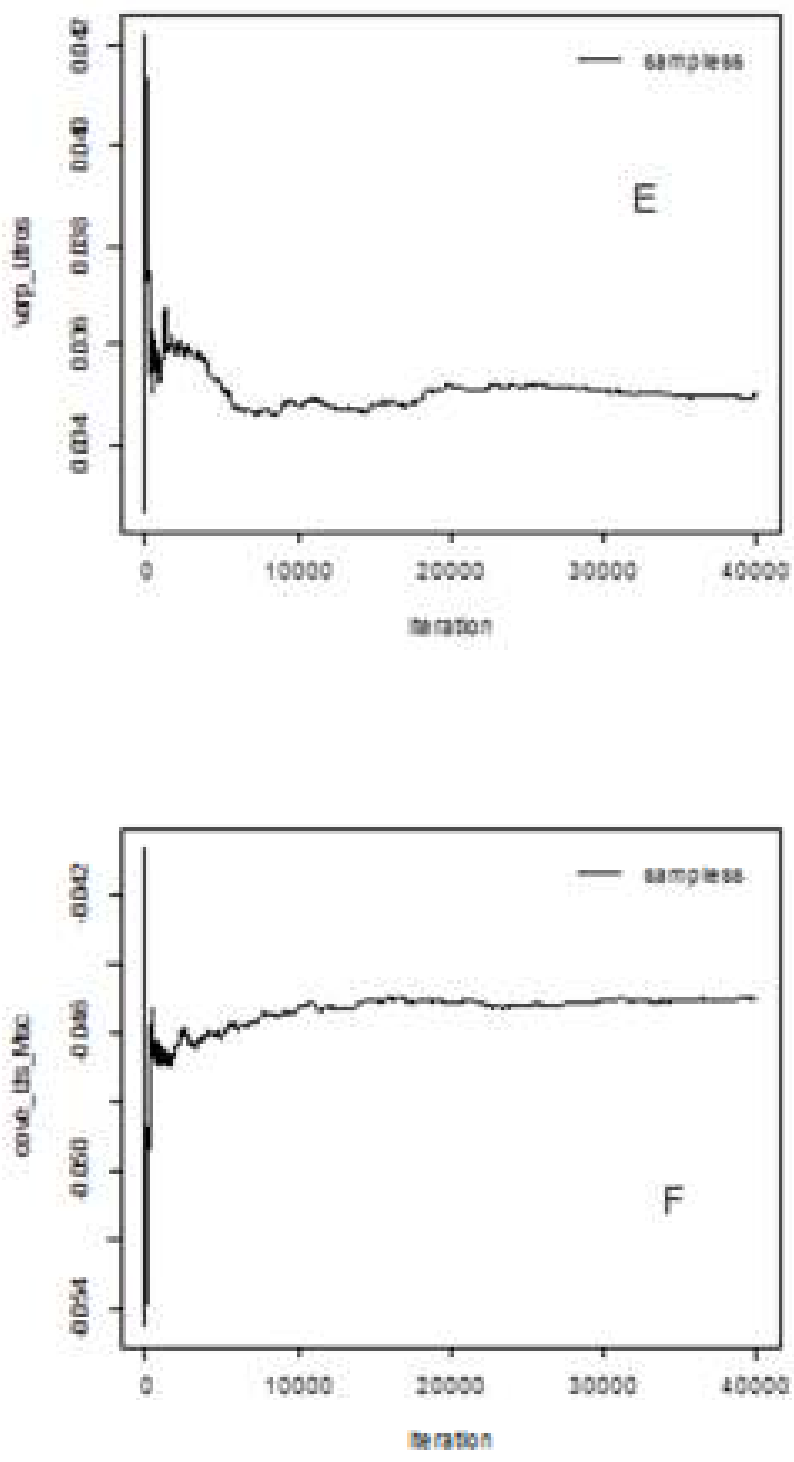

Figura 2.3. En los gráficos diagnósticos de running means, se observan las medias E) para varianza fenotípica para LT y en F) para la correlación ambiental entre LT y MSC. 

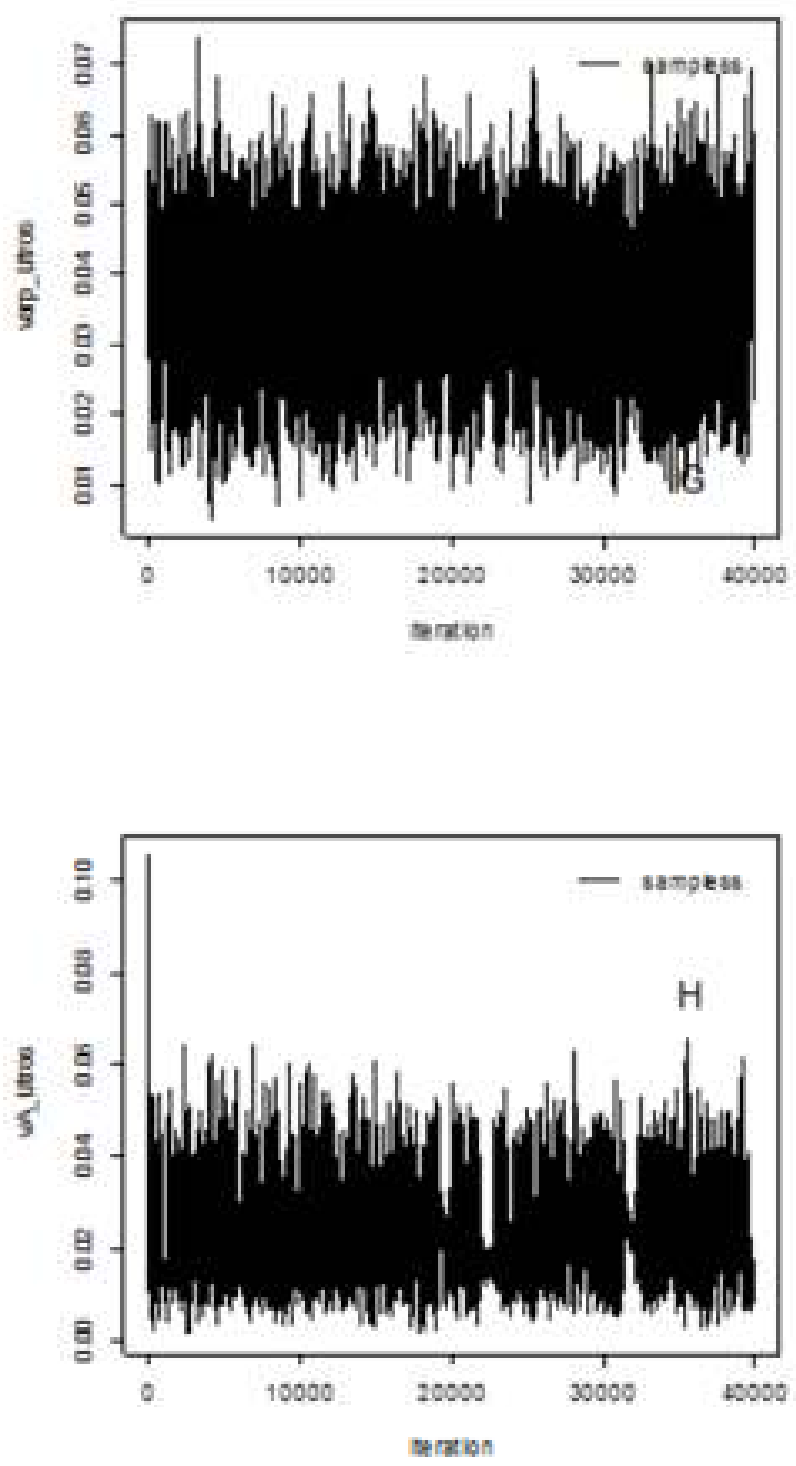

Figura 2.4. En los gráficos diagnósticos traceplots, presentados a modo de ejemplo, se puede observar en G) el gráfico de la varianza fenotípica para LT y en H) el de la varianza aditiva para LT. 

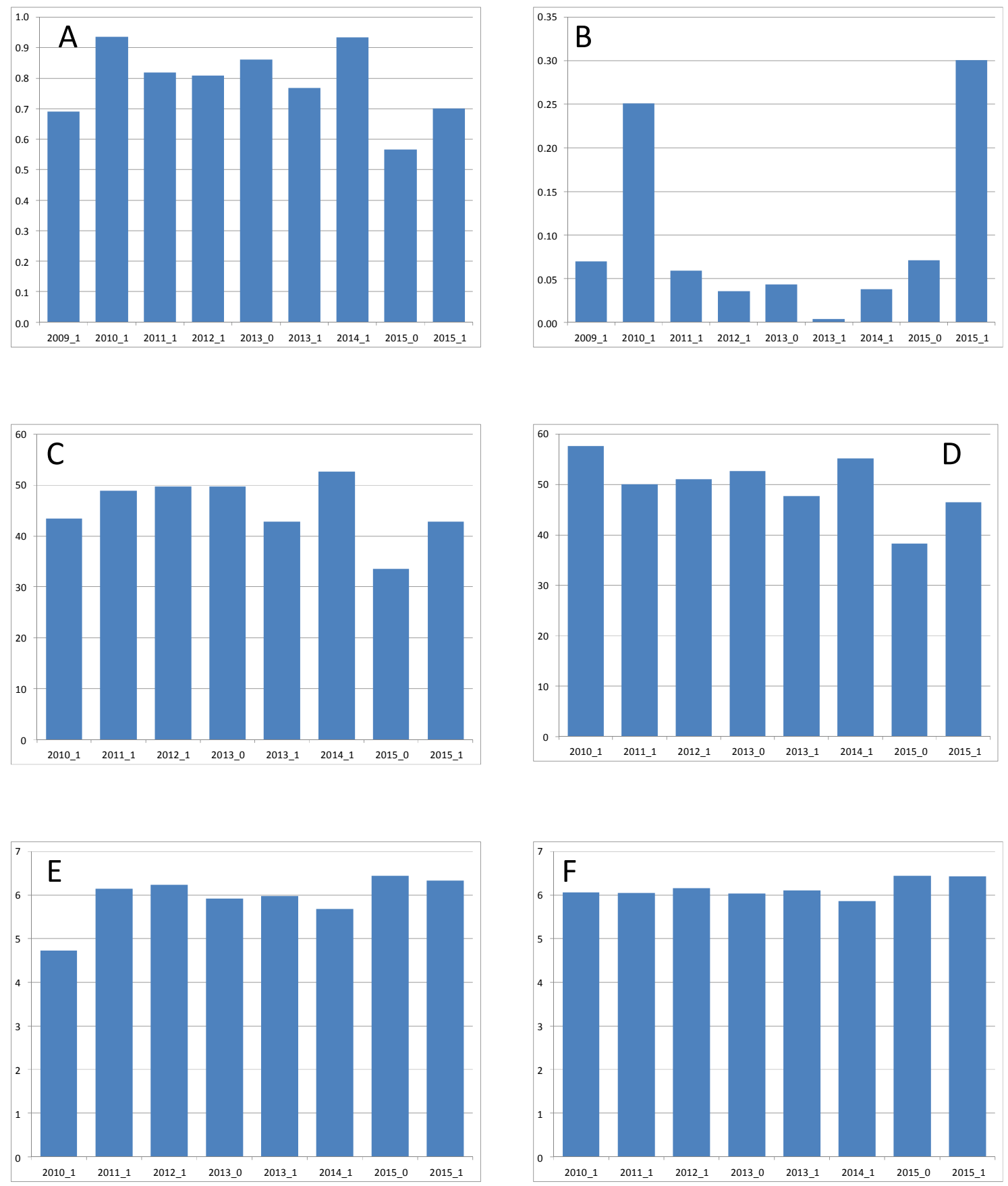

Figura 2.5. Estimaciones de mínimo cuadrado del efecto $\boldsymbol{A E P}$ para cada variable respuesta, A) $\boldsymbol{P L}$ en I/d; B) $\boldsymbol{M S C}$ incidencia; C) $\boldsymbol{G T}$ en $\mathrm{g} / \mathrm{d}$; D) $\boldsymbol{P T}$ en $\mathrm{g} / \mathrm{d}$; E) $\mathbf{G} \%$ y F) $\boldsymbol{P} \%$. Las estimaciones son referidas al primer nivel de cada variable clasificatoria en el modelo EPP, OPAR, TPC, DPPCL y ELAC en ovejas Pampinta. 
Cuadro 2.5. Estimaciones de mínimo cuadrado del efecto DPPCL para las variables $P L(I / d), G T$ (g/d), PT (g/d), G\%, P\% y MSC (incidencia). Las estimaciones son referidas al primer nivel de las otras variables clasificatorias en el modelo ASP, EPP, TPC, OPAR y ELAC en ovejas Pampinta.

\begin{tabular}{crrrrrr}
\hline DPPCL & PL & GT & PT & G\% & P\% & MSC \\
\hline 1 & 0,691 & 43,4 & 57,7 & 4,72 & 6,06 & 0,069 \\
2 & 0,602 & 37,6 & 51,8 & 4,73 & 6,07 & 0,070 \\
3 & 0,592 & 37,3 & 50,8 & 4,92 & 6,13 & 0,052 \\
\hline
\end{tabular}

DPPCL: días desde el parto al primer control lechero

Para el efecto ELAC, las estimaciones se observan en el cuadro 2.6. Este efecto fue altamente significativo para $\boldsymbol{P L}, \boldsymbol{G T}$ y $\boldsymbol{P T}$, variables que mostraron un pronunciado incremento en la medida que las lactancias fueron más extensas.

En cuadro 2.7, se observan las estimaciones para la varianza genética aditiva (VGA), ambiental permanente (VEp) y fenotípica (VP), desvío estándar aditivo (DEa), coeficiente de variación genética aditiva (CV\%a), la heredabilidades $\left(\boldsymbol{h}^{2}\right)$, la repetibilidades $(\boldsymbol{r})$ y el error estándar (e.e.) para las estimaciones de heredabilidad, obtenidas para cada una de las variables respuestas bajo estudio. Las estimaciones de repetibilidades para los caracteres productivos fueron altas, variando entre 0,42 y 0,51 , en tanto que para $\boldsymbol{M S C}$ fue de 0,20. En tanto que las estimaciones de heredabilidad resultaron intermedias a bajas, para los caracteres de producción, variando entre 0,21 y 0,33 , mientras que para $\boldsymbol{M S C}$ fue de 0,1. A su vez, MSC mostró mucha variación genética aditiva un 55\%, en tanto que GT presentó la menor variación genética aditiva con sólo un 25\%. 
Cuadro 2.6. Estimaciones de mínimo cuadrado del efecto ELAC para las variables $P L(I / d), G T$ (g/d), PT (g/d), G\%, P\% y MSC (incidencia). Las estimaciones son referidas al primer nivel de las otras variables clasificatorias en el modelo ASP, EPP, TPC, OPAR y DPPCL en ovejas Pampinta.

\begin{tabular}{crrrrrr}
\hline ELAC & PL & GT & PT & G\% & P\% & MSC \\
\hline 1 & 0,691 & 43,4 & 57,7 & 4,72 & 6,06 & 0,069 \\
2 & 0,983 & 64,2 & 75,3 & 4,90 & 6,08 & 0,071 \\
3 & 1,091 & 71,3 & 82,1 & 4,77 & 6,05 & 0,101
\end{tabular}

ELAC: extensión de lactancia

Las estaciones de correlaciones genéticas y fenotípicas entre las variables bajo estudio se observan en cuadro 2.8. Las correlaciones entre $\mathbf{P L}, \mathbf{G T}$ y $\boldsymbol{P T}$ resultaron altas con valores ente 0,92 y 0,98. Las correlaciones entre $\mathbf{G} \%$ con $\boldsymbol{P L}$ y $\boldsymbol{P T}$ resultaron negativas, siendo las genéticas de mayor valor (entre 0,26 y 0,28). Si bien las correlaciones fenotípicas entre $\mathbf{M S C}$ y los caracteres productivos resultaron negativas, lo cual es favorable desde el punto de vista productivo, las correlaciones genéticas resultaron todas positivas, indicando que una mejora en $P L$ o $G T$, aumentaría la incidencia de MSC.

Cuadro 2.7. Estimaciones de los componentes de varianza genética aditiva (VGA), ambiental permanente $(\boldsymbol{V E p})$ y fenotípica (VP), desvío estándar aditivo (DEa), coeficiente de variación genética aditiva $(\mathbf{C V} \% \mathbf{a})$, heredabilidades $\left(\boldsymbol{h}^{2}\right)$, repetibilidades $(\boldsymbol{r})$ y error estándar (e.e.) para las estimaciones de $\mathrm{h}^{2}$ y $\mathrm{r}$ para las características $P$ L, GT, PT, G\%, P\% y $M$ SC en ovinos Pampinta.

\begin{tabular}{lllllllll}
\hline & $\boldsymbol{V A}$ & VEp & $\boldsymbol{V P}$ & $\mathbf{D E a}$ & $\mathbf{C V} \% \mathbf{a}$ & $\boldsymbol{h 2}$ & $\boldsymbol{R}$ & e.e. \\
\hline $\boldsymbol{P L}$ & 0,0235 & 0,0343 & 0,1131 & 0,0085 & 36,2 & 0,208 & 0,512 & 0,08 \\
$\mathbf{G T}$ & 110,46 & 138,17 & 538,74 & 40,918 & 37,0 & 0,205 & 0,462 & 0,07 \\
$\boldsymbol{P T}$ & 109,23 & 132,81 & 476,77 & 38,504 & 35,2 & 0,229 & 0,508 & 0,08 \\
$\mathbf{G \%}$ & 0,1887 & 0,0489 & 0,5701 & 0,0465 & 24,7 & 0,331 & 0,417 & 0,08 \\
$\boldsymbol{P \%}$ & 0,0332 & 0,0220 & 0,1299 & 0,0105 & 31,8 & 0,255 & 0,424 & 0,08 \\
$\mathbf{M S C}$ & 0,1334 & 0,1218 & 1,2552 & 0,0732 & 54,9 & 0,106 & 0,203 & 0,05 \\
\hline
\end{tabular}


Cuadro 2.8. Estimaciones de correlaciones genéticas aditivas (por encima de la diagonal) y fenotípicas (por debajo de la diagonal) entre las características $P$ L, GT, PT, G\%, P\% y $\boldsymbol{M S C}$ en ovinos Pampinta.

\begin{tabular}{lcccccc}
\hline & $\boldsymbol{P L}$ & $\boldsymbol{G T}$ & $\boldsymbol{P T}$ & $\mathbf{G} \%$ & $\boldsymbol{P} \%$ & $\boldsymbol{M S C}$ \\
\hline $\boldsymbol{P L}$ & & 0,917 & 0,942 & $-0,259$ & 0,147 & 0,183 \\
$\boldsymbol{G T}$ & 0,941 & & 0,957 & 0,083 & 0,256 & 0,166 \\
$\boldsymbol{P T}$ & 0,978 & 0,952 & & $-0,278$ & 0,298 & 0,085 \\
$\mathbf{G \%}$ & $-0,078$ & 0,221 & $-0,062$ & & 0,405 & 0,109 \\
$\boldsymbol{P \%}$ & 0,222 & 0,261 & 0,370 & 0,155 & & 0,055 \\
$\mathbf{M S C}$ & $-0,150$ & $-0,188$ & $-0,180$ & $-0,105$ & $-0,182$ & \\
\hline
\end{tabular}

\subsection{Discusión}

En el presente trabajo, se evaluaron distintos efectos clasificatorios y se realizaron estimaciones de componentes de varianza y parámetros genéticos para las siguientes variables: producción de leche $(\boldsymbol{P L}, \mathrm{I} / \mathrm{d})$, contenidos de grasa total $(\boldsymbol{G T}, \mathrm{g} / \mathrm{d})$ y proteínas totales $(\boldsymbol{P T}, \mathrm{g} / \mathrm{d})$, porcentaje de grasa (G\%) y de proteínas (P\%), y mastitis subclínica (MSC, presencia/ausencia). Para ello, se emplearon modelos mixtos en una población de ovinos Pampinta criados en la EEA Anguil.

Los caracteres se vieron afectados principalmente por el efecto año estación de parto $(A E P)$, lo cual tendría relación con la variación ambiental del semi-árido de la región centro de la provincia de La Pampa. En correspondencia con lo reportado para la raza Rambouillet por Ochoa Cordero et al. (2007), y para la raza Frisona del Este por Kremer et al. (2015), la producción lechera aumentó con el número de lactancia y el número de crías nacidas. En este sentido, Real Ortellado (1999) encontró que ovejas que criaban mellizos producían casi un $50 \%$ más de leche que aquellas que criaban un solo cordero.

En general, las estimaciones de heredabilidad y correlaciones genéticas para los caracteres de producción, se encontraron dentro de los rangos reportados por una reciente revisión 
bibliográfica de Carta et al. (2009). Para PL, se obtuvo una estimación de heredabilidad de 0,22 que está en concordancia con las reportadas previamente. Por ejemplo, Ligda et al. (2000) reportaron una estimación de 0,23 para la raza Chíos con producción acumulada a 180 d y Legarra \& Ugarte (2001) una $\mathrm{h}^{2}$ de 0,20 para la raza Latxa con producción acumulada a $120 \mathrm{~d}$. La estimación fue levemente superior a la estimación de 0,15 reportada por Hamann et al. (2004) en la raza FE, de la cual Pampinta se origina, con un modelo del día de producción, y a la de 0,16 reportada por Ramón et al. (2006) con producción acumuladas a 120 d en la raza Manchega. Estas diferencias, pueden deberse por un lado a las distintas condiciones ambientales y de manejo en que se encontraban los animales evaluados, y por otro a que fueron estudiados distintos grupos genéticos.

Las estimaciones de heredabilidad para $\boldsymbol{G T}$ y $\boldsymbol{P T}$ fueron levemente superiores a las obtenidas por Legarra \& Ugarte (2001) para la raza Latxa y por Hamann et al. (2004) en la raza FE. La heredabilidad estimada para $\mathbf{G} \%$ resultó sustancialmente mayor en Pampinta que las estimadas en las razas Latxa (Legarra \& Ugarte, 2001), East Friesian (Hamann et al., 2004) y Manchega (Ramón et al., 2006). En tanto que la estimada para $\boldsymbol{P} \%$ fue intermedia a las obtenidas para Latxa y FE, por Legarra \& Ugarte (2001) y Hamann et al. (2004), respectivamente, y se asemejó el estimado para la raza Manchega en lactancia de $150 \mathrm{~d}$, mediante un modelo del día de control lechero (Serrano et al., 2001) y para la raza Manchega en lactancia acumulada a 120 d (Ramón et al., 2006).

Para mastitis subclínicas la estimación de heredabilidad fue 0,11 en ovejas Pampinta. Es importante resaltar que para esta característica no se han reportado previamente estimaciones de heredabilidad. Esta resultó levemente inferior a las estimaciones para recuentos de células somáticas, característica que se usa para seleccionar indirectamente por resistencia a mastitis. Por ejemplo, Barrilet et al. (2001) reportaron una $\mathrm{h}^{2}$ de 0,15 en la raza Lacaune, en tanto que Riggio et al. (2007) estimaron un valor de 0,14 para la raza Valle del Belice.

Las repetibilidades para las características productivas resultaron entre 0,42 y 0,51 indicando que una observación fenotípica sería buena predicción de la futura productividad, ya que alrededor del $50 \%$ del carácter depende del componente genético más del ambiente permanente. 
Las estimaciones fueron mayores que las reportadas por Ramón et al. (2006) para la raza Manchegas, y para $\boldsymbol{P} \%$ reportada por Serrano et al. (2001). Esto podría ser explicado por el hecho de haber trabajado en un solo predio, lo cual favorece la estabilidad del ambiente en el caso de Pampinta. En tanto que para $\mathbf{M S C}$, la repetibilidad resultó ser baja, 0,20, mostrando la gran influencia ambiental en la determinación de esta variable y posibilidad de evitarla manejando correctamente el ambiente.

Todas las correlaciones genéticas estuvieron en los rangos presentados por Carta et al. (2009) en una revisión de nueve trabajos, salvo las correlaciones entre $\boldsymbol{P} \%$ con $\boldsymbol{G T}$ y $\boldsymbol{P T}$, que resultaron en el presente trabajo positivas y en la revisión de Carta et al. (2009) el rango es negativo. A su vez, las correlaciones fenotípicas fueron del mismo signo y orden que las genéticas para los caracteres productivos ( $P L, G T, P T, G \%$ y $P \%)$. Las correlaciones genéticas entre $\mathbf{M S C}$ y los caracteres productivos fueron todas positivas, en tanto que las fenotípicas resultaron negativas. Esto pone de relieve la importancia del manejo ambiental (nutrición, sanitario, y en general) que favorece una mayor producción y también lograr una baja incidencia de MSC. Por último es importante recalcar que en base a los resultados obtenidos, la selección por producción sin considerar la incidencia de MSC, incrementaría la incidencia de esta última por las correlaciones genéticas positivas.

\subsection{Conclusión}

Las estimaciones de parámetros genéticos indican que es posible seleccionar por producción de leche y composición, y reducir la incidencia de MSC. La variabilidad genética aditiva es suficiente como para emplear estas características como objetivos y/o criterios de selección en la mejora del ovino lechero Pampinta. Esto sin duda, será una contribución importante en los sistemas ovinos lecheros nacionales. Por último, cabe destacar una vez más la importancia de realizar estudios en poblaciones locales debido a que las estimaciones de los parámetros genéticos de características de interés productivo varían según la raza como se comprueba por las diferencias observadas con los resultados reportados en la bibliografía. 


\subsection{Bibliografía}

Barillet, F., Rupp, R., Mignon-Grasteau, S., Astruc, J.M., \& Jacquin, M. (2001). Genetic analysis for mastitis resistance and milk somatic cell score in French Lacaune dairy sheep. Genet. Sel. Evol. 33: 397-415.

Busetti, M.R. (2008). Composición de la leche de ovejas Pampinta a lo largo de un periodo de lactancia. Comunicación personal. [En línea]: Disponible en: http://www.produccionanimal.com.ar/ (07/02/2017).

Busetti, M.R., \& Suárez, V.H. (2010). Encuesta Sanitaria-Productiva. [En línea]: Disponible en: http://www.produccion-animal.com.ar/ (05/01/2017).

Carta, A., Casu, S., \& Salaris, S. (2009). Invited review: Current state of genetic improvement in dairy sheep. J. Dairy Sci. 92: 5814-5833.

Falconer, D.S., \& Mackay, T.F.C. (1996). Introduction to Quantitative Genetics. 4ta Edición. Editorial Longman, London.

Geweke, J. (1992). Evaluating the accuracy of sampling based approaches to the calculation of posterior moments. In Bayesian Statistics 4, Bernardo, J. M., Berger, J. O., Dawid, A. P. and Smith, A. F. M. (eds.), 169-193. Oxford: Oxford University Press.

Gutiérrez, J.P., Legaz, E., \& Goyache, F. (2007). Genetic parameters affecting 180-days standardised milk yield, test-day milk yield and lactation length in Spanish Assaf (Assaf.E) dairy sheep. Small Rumin. Res. 70: 233-238.

Hamann, H., \& Horstick, A. (2004). Estimation of genetic parameters for test day milk production, somatic cell score and litter size at birth in East Friesian ewes. Livest. Prod. Sci. 87: 153160.

Harmon, R. J. (1994). Physiology of mastitis and factors affecting somatic cell counts. J. Dairy Sci. 77: 2103-2112.

Heidelberger, P., \& Welch, P. (1983). Simulation Run Length Control in the Presence of an Initial Transient. Oper. Res. 31, 1109-1144. 
Kremer, R., Giordano, J.P., Rosés, L., \& Rista, L. (2015). Producción de ovejas Milchschaf en un sistema lechero en pastoreo. Veterinaria (Montevideo) 51:12-23.

Legarra, A., \& Misztal, I. (2008). Technical note: Computing strategies in genome-wide selection. J. Dairy Sci. 91: 360-366.

Legarra, A., \& Ugarte, E. (2001). Genetic parameters of milk traits in Latxa dairy sheep. Anim. Sci. 73: $407-412$.

Ligda, Ch., Gabriilidis, G., Papadopoulos, Th., \& Georgoudis, A. (2000). Estimation of genetic parameters for production traits of Chios sheep using a multitrait animal model. Livest. Prod. Sci. 66: 217- 221.

Ochoa-Cordero, M. A., Torres-Hernandez, G., Mandeville, P. B., \& Diaz-Gomez, M. O. (2007). Effects of physiological and management factors on the milk composition of Rambouillet ewes. Agrociencia, 41: 263-270.

Ramón, M., Fernández-Perea, M. T., Pérez-Guzmán, M. D., Sánchez, P. J., \& Serrano, M. (2006). Parámetros genéticos de los caracteres lecheros en la raza ovina manchega. XII Reunión de mejora genética animal. Gijón Asturias, España.

R Core Team (2014). R: A language and environment for statistical computing. R Foundation for Statistical Computing, Vienna, Austria. URL http://www.R-project.org/.

Real Ortellado, M.R. (1999). Caracterización productiva de la raza Pampinta en la región semiárida Pampeana. Tesis doctoral. Universidad de Córdoba. España.

Riggio, V., Finocchiaro, R., Van Kaam, J. B. C. H. M., Portolano, B., \& Bovenhuis, H. (2007). Genetic parameters for milk somatic cell score and relationships with production traits in primiparous dairy sheep. J. Dairy Sci. 90: 1998-2003.

Rupp, R., Boichard, D., Barbat, A., Astruc, J. M., Lagriffoul, G., \& Barillet, F. (2002). Selection for mastitis resistance in French dairy sheep. Proceedings 7th World Congress on Genetics Applied to Livestock Production, Montpellier, France. CD-ROM communication 09-28.

Schalm, O.W., \& Noorlander, D.O. (1957). Experiment and observations leading to development of the California mastitis test. J. Am. Vet. Med. Assoc. 5:199-207. 
Serrano, M., Ugarte, E., Jurado, J.J., Perez-Guzman, M.D., \& Legarra, A. (2001). Test day models and genetic parameters in Latxa and Manchega dairy ewes. Livest. Prod. Sci. 67: 253-264.

Sorensen, D., \& Gianola, D. (2002). Likelihood, Bayesian, and MCMC methods in quantitative genetics. Springer-Verlag, New York.

Suárez, V.H., \& Busetti, M.R. (1999). Lechería ovina pampeana. Veterinaria Argentina XVIII, 176: 411-422.

Suárez V.H., Busetti, M.R., Miranda, A.O., Calvinho, L.F., Bedotti, D.O., \& Canavesio, V.R. (2002). Effect of Infectious Status and Parity on Somatic Cell Count and California Mastitis Test in Pampinta Dairy Ewes.J. Vet. B. Infect. Dis. Vet. Public Health 49:1-5. 


\section{Caracterización de ovinos Pampinta por variabilidad genética en genes de las proteínas de la leche}

\subsection{Introducción}

Pampinta es una raza sintética desarrollada en la EEA de Anguil, constituida en su origen por $3 / 4$ Frisona del Este (East Friesian, de Alemania) y $1 / 4$ Corriedale. Presentando óptimas propiedades para la producción en la región pampeana, se ha extendido en toda Argentina. Las cabañas más importantes se encuentran ubicadas en La Pampa (donde está su núcleo fundador EEA Anguil) y en Buenos Aires. Aunque también las hay en Córdoba, Entre Ríos y Santa Fe, entre otras provincias.

La lechería ovina es una actividad reciente en Argentina. La producción de leche básicamente se destina a la elaboración de quesos. La raza Pampinta al haber sido seleccionada fenotípicamente hacia la raza Frisona del Este, una de las principales razas productora de leche en Europa, tiene un importante acervo genético lechero. Pampinta y sus cruzas son ampliamente utilizadas, constituyen alrededor del $43 \%$ de las ovejas en ordeñe (Busetti et al., 2010). Sin embargo, aún no se han realizado estudios de variabilidad genética para los genes que codifican las proteínas de la leche en esta raza.

Dentro de las proteínas de la leche se encuentran dos grupos principales, las caseínas y las proteínas del suero. En Pampinta, según Busetti (2008, Comunicación Personal) las caseínas (CSN) representan un promedio de $74 \%$ de las proteínas totales. Es importante considerar que hay diferentes caseínas codificadas por cuatro genes distintos: la $\alpha_{\mathrm{S} 1}$ (CSN1S1), la $\beta$ (CSN2), la $\alpha_{\mathrm{S} 2}$ (CSN1S2) y la K (CSN3). Estos genes se encuentran en el cromosoma 6 (Barrilet et al., 2005) y están estrechamente unidos (unas 250,000 bases), por lo cual, la unidad heredada se transmite en forma de haplotipo. Las proteínas del suero representan en promedio el $17,6 \%$ del total de las proteínas lácteas, la principal es la beta lacto-globulina. El gen que codifica esta proteína se denomina LGB y se localiza en el cromosoma 3. Por otro lado, entre las proteínas que intervienen 
en los mecanismos de defensa inespecíficos de la glándula mamaria, se encuentra la betadefensina que se purifica en leche. En ovejas, han sido descriptos dos tipos: beta-defensina 1 y beta-defensina 2, codificadas por los genes SBD1 y SBD2, respectivamente, localizados en el cromosoma 26.

La identificación de la variabilidad genética en estas proteínas resulta de interés para caracterizar el potencial productivo de una población, pues se han reportado asociaciones entre los genes que las codifican y la producción de leche, como así también con el rendimiento quesero y con incidencia de mastitis. Entonces, por relacionarse con la producción láctea tanto desde un punto de vista cualitativo como así también cuantitativo, la variabilidad genética de las principales proteínas de la leche, CSN y LGB, ha sido en años recientes, objeto de gran interés, tanto en bovinos como en caprinos (Bonvillani et al., 2000; Caroli et al., 2007; Chessa et al., 2005; Ikonen et al., 2001; Ramunno et al., 2001). En ovinos, por el contrario la variabilidad genética de las proteínas de la leche ha sido menos estudiada. En general, en las especies ovinas consideradas, se encontró mayor variabilidad en las caseínas que en las proteínas del suero (Amigo et al., 2000).

La determinación de alelos presentes en una población genera información útil para mejorar características productivas. Pues permite, mediante estrategias de selección, aumentar la frecuencia de los alelos asociados favorablemente con las características de importancia productiva. En ovinos, los estudios reportados en la bibliografía, se han concentrado principalmente en la variabilidad genética de tres caseínas (CSN1S1, CSN2, CSN3) y LGB, y su influencia en las características de producción (Tetens et al., 2014). A la fecha, se han descripto muchas variantes de cada una de ellas (ver Cuadro 3.1). Para los estudios de asociación se prefiere utilizar mutaciones puntuales, es decir causadas por el polimorfismo de un sólo nucleótido (SNP). En CSN1S1 (Genbank NM 0011009795), Tetens et al. (2014) reportó varias mutaciones en el exón 8, y determinó que el alelo CSN1S1-C es el predominante (C>T posición 602,), en tanto que los alelos CSN1S1-A (G>A posición 82 y C>T posición 602), CSN1S1-D (G>A posición 248) y CSN1S1-H (deleción de tres nucleótidos en exón 8 y un nucleótido en intrón 8) son raros. En relación a la $\beta$ caseína (CSN2) (Genbank X16582), el alelo CSN2-A (A>G posición 596) fue el más frecuente (Tetens et al.,2014). Para la K caseína (CSN3) (GenBank NM 0011009378), Tetens et al. 
(2014); no encontraron variación en las razas ovinas estudiadas. Sin embargo, en razas italianas en el exón 4 Ceriotti et al. (2004) reportaron la presencia de dos alelos (C y T) por una mutación puntual (C>T) en posición 443 y Feligini et al. (2005) también describe el cambio de C>T en posición 237 en otras razas italianas (GenBank NM 001009378.1).

El polimorfismo estudiado para el LGB es más consistente en la bibliografía, ya que todos los trabajos publicados describen la variación $A$ y $B$ que corresponde al cambio $C>G$ en posición 1684 del exón 2 (GenBank X12817.1); y ha sido caracterizado en muchas razas (Elmaci et al., 2005; Barrilet et al., 2005; Mohammadi et al., 2006; Corral et al., 2010; Tetens et al., 2014; Chesa et al., 2010; Feligini et al., 2005). A nivel de la proteína lactoglobulina, los estudios de asociación entre las distintas proteínas LGB en los rasgos de producción de ovejas han dado resultados diferentes (Recio et al., 1997; Bolla et al., 1989; Garzón et al., 1992; Mohammadi et al., 2006). Algunos genotipos (BB) se han asociado con un mayor rendimiento de leche, mientras que otros ( $A A$ y $A B$ ) parecen ser superiores en contenido de proteína y caseína, como así también en rendimiento de cuajada (Bolla et al., 1989; Garzón et al., 1992). Según Giambra et al. (2010) las proteínas variantes LGB-A y LGB-B están presentes en todas las razas estudiadas, pero la variante LGB-C, un subtipo de la variante LGB-A con un único intercambio de aminoácidos de Arg con Glu en la posición 148 (Erhardt et al., 1989), resulta ser específico para la raza Merino (Barrilet et al., 2005). Por otro lado, dentro de los mecanismos de defensa inespecíficos de la glándula mamaria, el gen SBD2 se describió asociado a un recuento elevado de células somáticas en leche en bovinos (Ryniewicz et al., 2002). En la raza Valle del Belice, el gen SBD2 presenta un polimorfismo genómico (Gigli, comunicación personal), por lo que su estudio resultaría de interés como posible marcador de resistencia/susceptibilidad a mastitis.

Por lo explicado anteriormente, el objetivo general del presente trabajo fue describir la variabilidad genética para las proteínas de la leche en ovinos Pampinta. Los objetivos específicos fueron: 1.- obtener frecuencias génicas y genotípicas en ovinos Pampinta para CSN1S1, CSN2, CSN3, LGB y SBD2 en mutaciones reportadas previamente para otras razas; 2.- estimar la frecuencia de los haplotipos para los genes de las caseínas y 3.- evaluar si existe estructuración poblacional entre la Cabaña Pampinta y las Cabañas privadas, que serán consideradas sub- 
poblaciones de la población nacional de Pampinta. Debido a que en otras razas ovinas, se han encontrado asociaciones entre las variantes de los genes mencionados con producción de leche y de queso, los resultados de la presente investigación permitirían evaluar el potencial de producción lechero a partir de las frecuencias de alelos. 
Cuadro 3.1. Resumen de las variaciones para las caseínas (CSN1S1, CSN2, y CSN3) y el gen lacto-globulina (LGB) reportadas en la literatura.

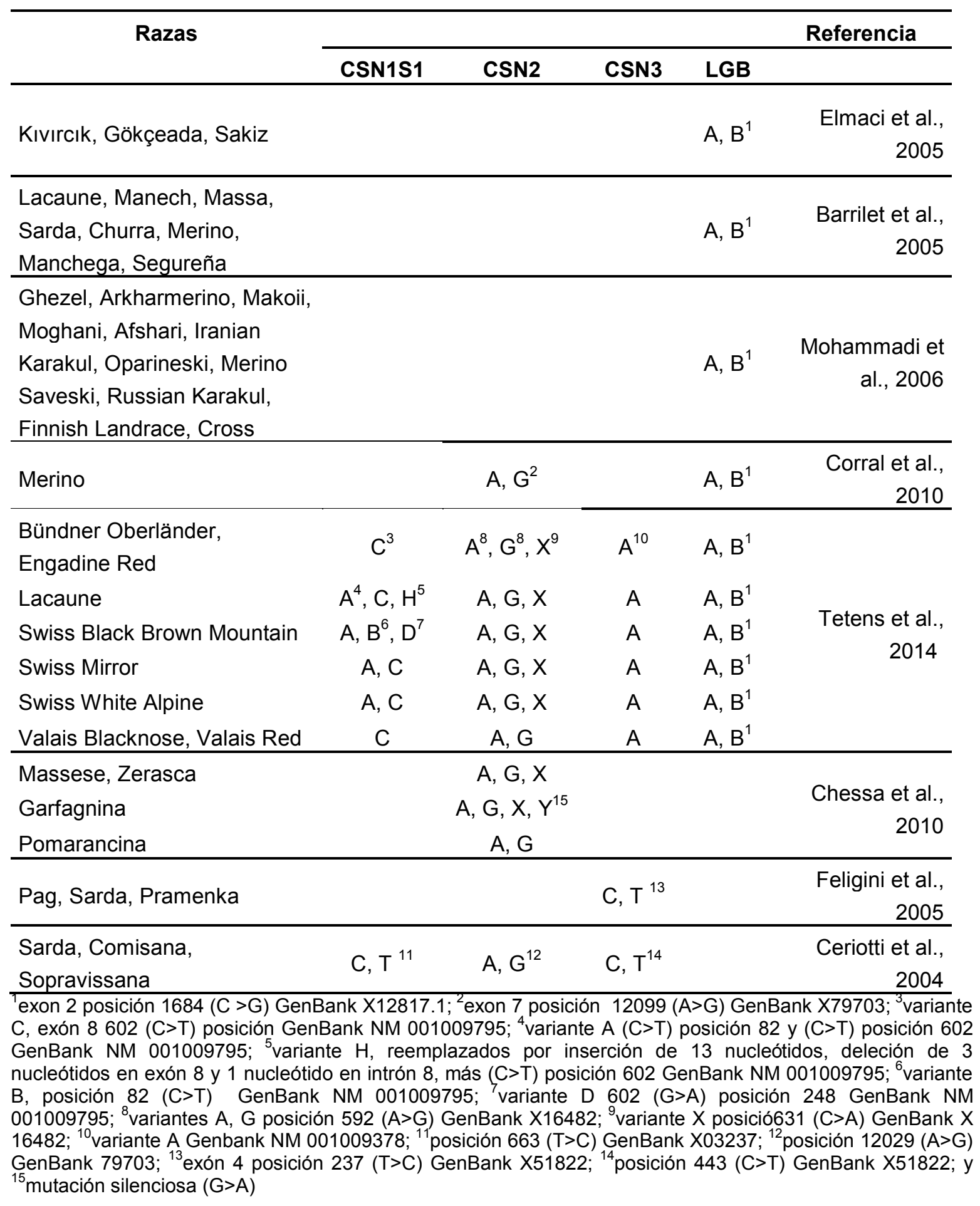




\subsection{Materiales y métodos}

\subsubsection{Diseño experimental y extracción de ADN}

Se obtuvieron muestras de sangre de 201 ovinos Pampinta; 177 de la Cabaña de la EEA Anguil (156 hembras y 21 machos), denominados, para este estudio, sub-población A y 24 machos de cinco Cabañas privadas ubicadas en provincia de La Pampa y Buenos Aires, denominados subpoblación B. A cada animal, se le extrajo 15-20 ml de sangre de la vena yugular, colectándose en un tubo con EDTA 0,2 M como anticoagulante y refrigerados hasta el traslado al laboratorio de la EEA Anguil. En el laboratorio, las muestras se conservaron a $-20^{\circ} \mathrm{C}$ hasta su procesamiento. La extracción y purificación de ADN se realizó por membrana de sílica (Axygen Biosciences, Union City, CA, USA).

\subsubsection{Análisis moleculares}

El gen CSN1S1 se tipificó mediante la metodología PCR-SSCP descripta por Ceriotti et al. (2004), analizando el polimorfismo T>C en la posición 15926 (acceso GenBank: JN560175.1) del exón 17 (correspondiente a la posición 663 de la secuencia el ARNm X03237). El polimorfismo del gen CSN2 (A>G posición 12029, acceso Genbank: X 79703.1) en exón 7 se determinó a través de la metodología de PCR-SSCP descripta por Ceriotti et al. (2004). CSN3 se identificó el SNP C>T posición 443, acceso GenBank: X51822; (Feligini et al., 2005), mediante la técnica PCR alelo específico y pirosecuenciación. En este último también se identificó el SNP T>C posición 237 (Ceriotti et al., 2004). Para analizar por piro secuenciación los dos SNPs del gen, fueron necesarios tres cebadores: un forward, un reverse y uno interno de secuenciación. El primer forward tuvo que tener una marca de biotina en el extremo 5`para su purificación. Los cebadores fueron los siguientes, posición 1: K-cas_SNP1-F Biotina-5'- TCCCAATTCAGTATGTGCTGAGTA -3'; Kcas_SNP1-R 5'- TTGAAGAGTTTGGGCAGGTGA - $\quad$ 3'; $^{\prime}$ K-cas_SNP1_Interno 5'- 
TAATTGAGTCCATAACTAGG -3'. Posición 2: K-cas_SNP2-F Biotina-5'ACGTCACCCACACCCACATTTA-3'; K-cas_SNP2-R 5'- TTCACTACTGCTTCGGTGGTAGG- 3"; K-cas_SNP2_Interno 5'-GGTGGAATGGCCATA-3'. Siendo las secuencias a analizar para el SNP1: A/GTACCTACTCAG y para el SNP2: AATG/AATAAATGTGGG. La PCR fue llevada a cabo con un volumen total de $50 \mu \mathrm{l}$, el cual contenía $3 \mu \mathrm{l}$ de ADN, $10 \mu \mathrm{l}$ de buffer, $4 \mu \mathrm{l}$ de dNTPS (2mM), $2 \mu \mathrm{l}$ de cebadores, $31 \mu \mathrm{l}$ de agua, 0,2 $\mu \mathrm{l}$ de DNA polimerasa. La amplificación se realizó con una desnaturalización inicial de $95^{\circ} \mathrm{C}$ por 10 minutos, seguido de 30 ciclos de 15 segundos a $95^{\circ} \mathrm{C}, 30$ segundos a $58^{\circ} \mathrm{C}, 1$ minuto a $72^{\circ} \mathrm{C}$ y extensión final de 10 minutos a $72^{\circ} \mathrm{C}$. Los productos de PCR fueron corridos en un gel de agarosa teñido con Gelred (Genbiotech) para su comprobación de amplificación. La genotipificación fue realizada mediante el empleo del pirosecuenciador automático PSQ® 96 MA (Pyrosequencing AB, Uppsala, Suecia) utilizando una placa de unión con $20 \mu \mathrm{l}$ del producto de PCR, $40 \mu \mathrm{l}$ de Buffer, $3 \mu \mathrm{l}$ de sefarosa y $17 \mu \mathrm{l}$ de agua, y una placa de reconocimiento con $45 \mu \mathrm{l}$ de buffer y $0,135 \mu \mathrm{l}$ de cebadores internos, colocándose en la termocicladora por $2 \mathrm{~min}$ a $80^{\circ} \mathrm{C}$. La lectura automática se realizó utilizando el software informático PSQ ${ }^{\circledR}$ 96 MA 2.1.1 (Pyrosequencing AB, Uppsala, Suecia). El gen LGB se estudió mediante la metodología RFLP-SSCP descripta por Feligini et al. (1998), identificando los alelos A y B por el cambio T>C de la posición 1684 del exón 2 (Genbank X12817.1),

Para tipificar el gen de la SBD2 se desarrolló un método basado en PCR-RFLP. Las secuencias para los genes SBD1 y SBD 2 (U75251 y U75252. GenBank) fueron alineadas mediante el programa descripto por Duret et al. (1994) para identificar las regiones variables entre ambos genes. Luego se procedió al diseño de los cebadores específicos para SBD2 utilizando el programa Primer-BLAST (NCBI). Se amplificó un fragmento de 215 bp del exón 2 del gen (cebadores directo 5' GCAGGTGCCCTAGACA y cebador inverso 5'ATG ACC AGT GGG CAA GAT TC3') que incluía el polimorfismo G>A posición 1756 del exón 2. Para identificar el polimorfismo se seleccionó la enzima de restricción Rsal mediante un estudio in silico utilizando el programa NEB cutter V2.0 (Vincze et al., 2003). Se tomaron algunas muestras para su secuenciación por electroforesis capilar, utilizando la técnica de Sanger \& Nicklen (1977) como control de la metodología utilizada.. 
Las reacciones en cadena de la polimerasa (PCR) se llevaron a cabo en un volumen de reacción de 25 microlitros finales, conteniendo 50 ng de ADN molde, 1x de buffer de reacción, 5 pmol de cada primer, 0,16 mM de dNTP, 1,5 mM de MgCl2 y una unidad de Taq polimerasa. Los fragmentos obtenidos se evaluaron en un gel de agarosa teñido con Gelred (Genbiotech, Bs As, Argentina), utilizando un transiluminador de LUZ UV. En los casos de CSN1S1 y CSN2, los productos de amplificación se discriminaron en geles de poliacrilamida (30\%) con tinción de nitrato de plata luego de la desnaturalización de los mismos (Benbouza et al., 2006).

\subsubsection{Análisis estadísticos}

Las frecuencias génicas y genotípicas para cada locus se determinaron por conteo directo, y el Equilibrio de Hardy-Weinberg para cada locus dentro de cada sub-población se evaluó utilizando el test exacto de Fisher (Weir \& Cockerham, 1996) con el programa GENEPOP versión 4.6 (Rousset, 2008). La estructuración (diversidad) genética entre sub-poblaciones, se evaluó mediante los estadísticos F de Wright (Wright, 1969). Estos parten el coeficiente de endogamia de una población subdividida, estimando el estadístico $F_{\mathrm{IT}}$, que corresponde a la endogamia total, el estadístico $F_{I S}$, que mide la subdivisión intra-poblacional y el $F_{S T}$, que mide la subdivisión poblacional, los que se basan en las siguientes formulas:

$$
\mathrm{F}_{\mathrm{IT}}=(\mathrm{HT}-\mathrm{HI}) / \mathrm{HT} \quad \mathrm{F}_{\mathrm{IS}}=(\mathrm{HS}-\mathrm{HI}) / \mathrm{HS} \quad \mathrm{F}_{\mathrm{ST}}=\left(\mathrm{F}_{\mathrm{IT}}-\mathrm{F}_{\mathrm{IS}}\right) /\left(1-\mathrm{F}_{\mathrm{IS}}\right)
$$

Donde HT se refiere a la heterocigosidad esperada en la población total, HI es la heterocigosidad promedio observada en un grupo de poblaciones y HS es la heterocigosidad promedio esperada de cada población. Estos cálculos se realizaron usando el programa GENEPOP versión 4.6 (Rousset, 2008), bajo la hipótesis nula "Ios genotipos tienen la misma distribución en todas las poblaciones". A su vez, se complementó el estudio de la diversidad genética y la diferenciación relativa entre las sub-poblaciones con las estimaciones de los estadísticos de heterocigosidad $\left(\mathrm{H}_{\mathrm{T}}\right)$ y diferenciación génica $\left(G_{S T}\right)$ propuestos por Nei (1973) y distancia génica (D y DA) por Nei (1983) 
mediante el programa DISPAN (Ota, 1993). Tanto los estadísticos Wright como los de Nei fueron estimados para cada locus y a nivel global. Para el cálculo de los p-valor fueron utilizadas las fórmulas según Weir et al. (1996). El análisis se completó con la estimación de los haplotipos para los genes de las caseínas en estudio, $\alpha_{\mathrm{S} 1}, \beta$ y $\mathrm{K}$, mediante el programa PHASE (Stephens et al., 2001).

\subsection{Resultados}

En el Cuadro 3.2 se presentan las frecuencias alélicas y genotípicas observadas, como así también, los valores de significancia ( $p$ value) de las pruebas del equilibrio de Hardy-Weinberg para cada locus estudiado, dentro de cada una de las sub-poblaciones, Cabaña EEA Anguil y Cabañas Comerciales de ovinos Pampinta.

Los genes CSN1S1, CSN2, CSN3, y LGB mostraron polimorfismo, sí se toma como criterio que el alelo más frecuente sólo representa hasta un 95\% (Ott, 1999). En cambio, SBD2 no se puede considerar polimórfico, ya que el alelo SBD2-A se encontró en muy baja frecuencia. Es por esta razón que se decidió excluir este gen del análisis en la sub-población Cabañas. Las frecuencias alélicas para los otros genes se han observado en igual distribución entre todas las sub-poblaciones estudiadas. No se observaron individuos con el genotipo GG para CSN2, aunque hubo una alta proporción de heterocigotas. Para disminuir errores de técnica, no sólo se realizaron duplicados o triplicadas de los genotipados. Además, algunos animales fueron secuenciados, lo que evidenció una total consistencia en los resultados obtenidos.

La prueba exacta de Fisher indicó que, en general, los genes en las sub-poblaciones se encontraron en equilibrio HW; siendo la excepción los loci CSN1S1 $(p<0,0001)$ y CSN2 $(p<0,0001)$ en la sub-población Cabaña Anguil y el locus LGB $(p<0,0151)$ en la sub-población Cabañas Comerciales, que presentaron desvíos significativos con respecto a las proporciones teóricas hacia el exceso de heterocigotas. A nivel global, considerando ambas sub-poblaciones de manera conjunta, se destacó un exceso de heterocigotas en CSN1S1 ( $p<0,0001)$, CSN2 ( $p<0,0001)$, y 
CSN3 $(p=0,0307)$ que generó un desvío de la frecuencias esperadas según el equilibrio HW, en tanto que LGB no mostraron desvíos significativos $(p=0,5249)$.

Cuadro 3.2. Frecuencias genotípicas observadas (fGo), frecuencias alélicas (fA), valor $p$ para el equilibrio de Hardy-Weinberg ( $p$ Eq.HW) estimadas en la población EEA Anguil y Población Cabañas, para los loci CSN1S1, CSN2, CSN3, LGB y SBD2.

\begin{tabular}{|c|c|c|c|c|c|c|c|c|}
\hline & & \multicolumn{3}{|c|}{ Sub-Población A } & \multicolumn{3}{|c|}{ Sub-Población B } & \multirow[b]{2}{*}{ Tota } \\
\hline & & fGo & $\mathrm{fA}$ & $p$ Eq.HW & fGo & $\mathrm{fA}$ & $p$ Eq.HW & \\
\hline \multirow{3}{*}{$\begin{array}{c}\text { CSN1S } \\
1\end{array}$} & $\mathrm{CC}$ & 0,01 & 0,34 & \multirow{3}{*}{$<0,0001$} & 0,17 & 0,50 & \multirow{3}{*}{0,2154} & 5 \\
\hline & CT & 0,66 & & & 0,66 & & & 76 \\
\hline & TT & 0,33 & 0,66 & & 0,17 & 0,50 & & 34 \\
\hline & Total & 91 & & & 24 & & & 115 \\
\hline \multirow{3}{*}{ CSN2 } & AA & 0,39 & 0,70 & \multirow{3}{*}{$<0,0001$} & 0,46 & 0,73 & \multirow{3}{*}{0,1375} & 46 \\
\hline & $A G$ & 0,61 & & & 0,54 & & & 67 \\
\hline & GG & 0,00 & 0,30 & & 0,00 & 0,27 & & 0 \\
\hline & Total & 89 & & & 24 & & & 113 \\
\hline \multirow{3}{*}{ CSN3 } & $\mathrm{CC}$ & 0,69 & 0,84 & \multirow{3}{*}{0,2564} & 0,82 & 0,91 & \multirow{3}{*}{0,9999} & 140 \\
\hline & CT & 0,30 & & & 0,18 & & & 57 \\
\hline & TT & 0,01 & 0,16 & & 0,00 & 0,09 & & 2 \\
\hline & Total & 177 & & & 22 & & & 199 \\
\hline \multirow{3}{*}{ LGB } & AA & 0,28 & 0,56 & \multirow{3}{*}{0,3899} & 0,37 & 0,50 & \multirow{3}{*}{0,0151} & 34 \\
\hline & $A B$ & 0,55 & & & 0,25 & & & 55 \\
\hline & $\mathrm{BB}$ & 0,17 & 0,44 & & 0,38 & 0,50 & & 24 \\
\hline & Total & 89 & & & 24 & & & 113 \\
\hline \multirow{3}{*}{ SBD2 } & $A A$ & 0,00 & 0,02 & \multirow{3}{*}{0,9999} & & & & 0 \\
\hline & $A G$ & 0,05 & & & & & & 2 \\
\hline & GG & 0,95 & 0,98 & & & & & 39 \\
\hline & Total & 41 & & & & & & 41 \\
\hline
\end{tabular}

En el cuadro 3.3, se presenta la diversidad genética para Pampinta, estimadas para los estadísticos de Wright $\left(F_{I S}, F_{S T}\right.$ y $\left.F_{I T}\right)$ y Nei $\left(G_{S T}\right.$ y $\left.H_{T}\right)$ a partir de la información obtenida de los genotipados de las proteínas de la leche bajo estudio. Las estimaciones de $F_{S T}$ y $G_{S T}$ globales, que 
resultaron iguales $(0,0109)$, indicaron un bajo nivel de variación entre las sub-poblaciones de Pampinta para las proteínas de la leche, explicando la varianza interpoblacional el $1 \%$ de la variación total. En coincidencia con este resultado, la distancia estándar (D) de Nei fue -0,0038 (con un error estándar igual a 0,0092) y la distancia DA resultó 0,0053. La falta de diferenciación, también se reflejó a nivel de cada locus estudiado, como se puede apreciar en las estimaciones obtenidas que figuran en el Cuadro 3.3. A nivel global, las estimaciones de los parámetros $F_{I S}$ y $F_{I T}$ indicaron que las sub-poblaciones y población se desviaron significativamente de las condiciones de equilibrio HW $(p<0,05)$, con exceso de heterocigotas. A nivel de los loci, se observó que los genes CSN1S1 y CSN2 presentaron un exceso en el número de animales heterocigotas $(p<0,05)$. En tanto los otros loci, las estimaciones fueron cercanos a cero, indicando que las proporciones genotípicas de sub-poblaciones y población se ajustaron a las proporciones esperadas según HW. En relación a la heterocigosidad $\left(\mathrm{H}_{\mathrm{T}}\right)$, las estimaciones evidenciaron altos niveles de diversidad genética, tanto a nivel global como para los loci. Con la excepción del locus CSN3 debido a que las frecuencias génicas estimadas estuvieron cercanas a cero y a uno.

Cuadro 3.3. Estimaciones de los estadísticos de Wright $\left(F_{I S}, F_{S T}\right.$ y $\left.F_{I T}\right)$ y Nei $\left(G_{S T}\right.$ y $\left.H_{T}\right)$ para cada locus y a nivel global en las muestras de las sub-poblaciones Anguil y Cabañas para la raza Pampinta.

\begin{tabular}{lcccccc}
\hline Loci & $\mathbf{N}$ & $\mathbf{F}_{\text {IS }}$ & $\mathbf{F}_{\text {ST }}$ & $\mathbf{F}_{\text {IT }}$ & $\mathbf{G}_{\text {ST }}$ & $\mathbf{H}_{\mathbf{T}}$ \\
\hline CSN1S1 & 115 & -0.4301 & 0.0453 & -0.3653 & 0.0263 & 0.4872 \\
CSN2 & 113 & -0.4152 & -0.0052 & -0.4226 & 0.0011 & 0.4076 \\
CSN3 & 199 & -0.1027 & 0.0074 & -0.0945 & 0.0112 & 0.2188 \\
LGB & 113 & 0.0257 & -0.0073 & 0.0186 & 0.0036 & 0.4982 \\
SBD2 & 39 & -0.0127 & - & - & - & - \\
Global & & $-\mathbf{0 . 2 3 5 2}$ & $\mathbf{0 . 0 1 0 9}$ & $-\mathbf{0 . 2 2 2 2}$ & $\mathbf{0 . 0 1 0 9}$ & $\mathbf{0 . 4 0 2 9}$
\end{tabular}

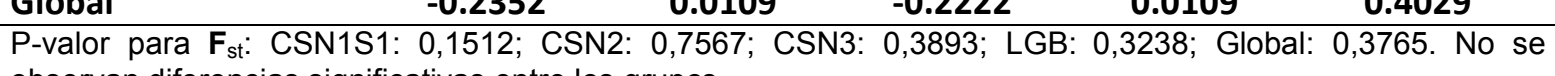
observan diferencias significativas entre los grupos

Las frecuencias esperadas para los haplotipos de los loci de las caseínas CSN1S1, CSN2, CSN3 se observan en el Cuadro 3.4. Las mismas fueron estimadas mediante el programa PHASE, asumiendo que los loci estaban a distancias de 19600 (CSN1S1-CSN2) y 186000 (CSN2-CSN3) pares de bases, y sin emplear relaciones de parentesco entre los individuos. El haplotipos 
CSN1S1-T, CSN2-A, CSN3-C (TAC) resultó el más frecuente, y los cuatro (TAC, CAC, TGC, TAT) haplotipos más frecuentes representaron el $75 \%$ de los haplotipos esperados.

Cuadro 3.4. Frecuencias esperadas de los haplotipos para las caseínas CSN1S1, CSN2, CSN3 en la población Pampinta estimados mediante el programa PHASE. $\mathrm{N}=115$.

\begin{tabular}{ccc}
\hline Haplotipos & Frecuencias & EE \\
\hline TAC & 0,337 & 0,021 \\
CAC & 0,186 & 0,020 \\
TGC & 0,132 & 0,018 \\
TAT & 0,115 & 0,017 \\
CGC & 0,086 & 0,019 \\
CAT & 0,068 & 0,015 \\
TGT & 0,042 & 0,013 \\
CGT & 0,034 & 0,013 \\
\hline
\end{tabular}

\subsection{Discusión}

En el presente estudio se caracterizó el polimorfismo de cinco loci de genes de proteínas de la leche en la raza Pampinta, a partir de muestras tomadas en seis cabañas: EEA Anguil y cinco Cabañeros distribuidos en provincias de La Pampa y Buenos Aires. Si bien se las podría considerar a un mismo nivel, la historia de la raza, en todas las cabañas que existen en la actualidad, indica que su origen fue en la EEA Anguil a fines de los años 70. A partir de este grupo fundador, al principio lentamente, pero en los 90 de manera muy intensa, las Cabañas incorporaron recursos genéticos desde EEA Anguil. Al inicio, madres y padres, y entre 2006 a 2012 solamente padres, y en los últimos años casi no ha habido flujo génico entre EEA Anguil y estas cabañas, así como tampoco a otras. Esto es así debido a que los cabañeros están organizados en la Asociación Argentina de Criadores de Pampinta $(\boldsymbol{A A C P})$, y son los responsables de mantener el pedigrí y la promoción de la raza. Por lo tanto, el INTA, al ser una institución pública, decidió no intervenir en la esfera privada que compete a la $\boldsymbol{A A C P}$ y sus cabañeros.

Casi todos los loci analizados (CSN1S1, CSN2, CSN3, y LGB) resultaron bialélico y polimórficos, si consideramos el criterio expresado por Ott (1999), un locus es polimórfico cuando 
el alelo más frecuente está presente hasta un 95\%. Por lo cual, el locus SBD2 cuyo alelo más representado (SBD2-A) tuvo una frecuencia de 0,976 y que a su vez presentó niveles muy bajos de diversidad genética, no puede ser considerado polimórfico. En el resto de los loci, los alelos CSN1S1-T, CSN2-A, CSN3-C, LGB-A resultaron ser los más abundantes. Aunque en los últimos años no hubo flujo genético entre la Cabaña EEA Anguil y las Cabañas comerciales, las frecuencias alélicas intrapoblacionales fueron muy similares, por lo que no se observó estructuración poblacional, considerada a través de los estadísticos $F_{S T}$ y $G_{S T}$, cuyas estimaciones resultaron muy cercanas a cero. La estimación de distancia genéticas de Nei confirmó los resultados anteriores.

Los resultados obtenidos en el presente estudio mostraron que para el locus CSN1S1, en la raza Pampinta el alelo CSN1S1-T fue el más frecuente. La mutación produce un cambio de aminoácido treonina en la posición 186 del aminoácido en la proteína madura, por isoleucina (Ceriotti et al., 2004). Este resultado coincide con el reportado por Ceriotti et al. (2004) en razas Comisana y Sopravissana. Esto llevó a Ceriotti et al. (2005) a proponer que la variante CSN1S1-C sería la variante ancestral. Alternativamente, la alta frecuencia del alelo CSN1S1-C en las razas bajo estudio podría ser consecuencia del efecto de la selección, ya que la misma estaría asociada positivamente con el contenido de proteína total y con caseínas como observaron a nivel proteico Pirisi et al. (1999); y Amigo et al. (2000). Podría deberse que la variante CSN1S1-T sea la más frecuente $(0,63)$ en Pampinta por un efecto fundador y por el no haber sido seleccionada por producción de leche, o por producción de queso. A su vez, entre los cuatro haplotipos más frecuentes, sólo uno tiene el alelo CSN1S1-C. Consecuentemente, si el alelo CSN1S1-C también estuviera relacionado en esta raza con producción de proteínas totales y caseínas en Pampinta, como han reportado Pirisi et al. (1999) y Amigo et al. (2000) para otras razas, existiría la posibilidad de mejorar la producción por selección asistida por marcadores. Más aún, al estar el alelo CSN1S1-C en baja frecuencia, se podría esperar una importante respuesta al incluir esta información en un programa de mejoramiento. Futuros estudios de asociación podrían confirmar o descartar esta hipótesis. 
Para el locus CSN2, alelo CSN2-A se observó una frecuencia de 0,70. Chessa et al. (2010) argumentaron que la variante CSN2-A podría ser considerada ancestral en base a trabajos de alineación de secuencias realizado en otras especies. Con respecto a CSN3, el alelo más frecuente en Pampinta fue CSN3-C $(0,85)$. Este alelo también fue reportado como el más frecuente por Ceriotti et al. (2004) y Feligini et al. (2005) en cuatro diferentes razas de ovejas Italianas.

En relación a LGB, en Pampinta la frecuencia de LGB-A fue de 0,54. Este valor concuerda con la mayoría de los trabajos publicados (ver cuadro 3.2) que han reportaron a LGB-A como el alelo más frecuente. Como por ejemplo, Corral et al. (2010) en la raza Merino, Maioli et al., (1998) en varias razas italianas y Elmaci et al., (2005) en razas de ovejas turcas nativas. Aunque, Mohammadi et al. (2006) indicaron que si bien el alelo LGB-A sería el más frecuente, el genotipo LGB-AB sería el más prevalente en la mayoría de las razas ovinas. Esto no se observó en la raza Pampinta.

\subsection{Conclusión}

Este es el primer estudio de polimorfismo genético en ovinos de raza Pampinta. Nuestros resultados muestran que la raza presenta polimorfismo para los genes de las proteínas de la leche bajo estudio. Los núcleos genéticos de la EEA Anguil y de las cabañas son aún cercanos para estos genes, presentando heterocigosidad; los desvíos del equilibrio HW son hacia un exceso de heterocigotas. Algunas frecuencias alélicas coincidieron con las reportadas en la bibliografía para otras razas, y algunos alelos se encontraron con frecuencias diferentes. Esto pone de relieve la importancia de realizar estudios en las poblaciones locales. 


\subsection{Bibliografía}

Amigo, L., Recio, I., \& Ramos, M. (2000). Genetic polymorphism of ovine milk proteins: its influence on technological properties of milk: a review. Int. Dairy J., 10:135-149.

Barrillet, F., Arranz, J.J., \& Carta, A. (2005). Mapping quantitative trait loci for milk production and genetic polymorphisms of milk proteins in dairy sheep. Genet. Select Evol. 37: 109-123.

Benbouza, H., Jacquemin, J.M., Baudoin, J.P., \& Mergeai, G. (2006). Optimization of a reliable, fast, cheap and sensitive silver staining method to detect SSR markers in polyacrylamide gels. Biot. Agro. Soc. Envir. 10: 77-81.

Bolla, P., Caroli, A., Mezzelani, A, Rizzi, R., Pagnacco, G., Fraghi, A. \& Casu, S. (1989). Milk protein markers and production in sheep. Anim. Genet. 20:78-78.

Bonvillani, A.G., Di Renzo, M.A., \& Tiranti, I.N. (2000). Genetic polymorphism of milk protein loci in Argentinian Holstein cattle. Gen. Mol. Biol. 23:819-823.

Busetti, M.R. \& Suárez, V.H. (2010). Encuesta Sanitaria-Productiva. [En línea]: Disponible en: http://www.produccion-animal.com.arl (05/01/2017).

Busetti, M.R. Composición de la leche de ovejas Pampinta a lo largo de un periodo de lactancia. Comunicación personal. [En línea]: Disponible en: http://www.produccion-animal.com.ar/ (07/02/2017).

Caroli, A., Chiatti, F., Chessa, S., Rignanese, D., Ibeagha-Awemu, E.M., \& Erhardt, G. (2007). Characterization of the casein gene complex in West African goats and description of a new alpha (s1)-casein polymorphism. J. Dairy Sci. 90:2989-2996.

Ceriotti, G., Chessa, S., Bolla, P., Budelli, E., Bianchi, L., Duranti, E., \& Caroli, A. (2004) Single nucleotide polymorphisms in the ovine casein genes detected by polymerase chain reactionsingle strand conformation polymorphism. J Dairy Sci. 87:2606-2613.

Ceriotti, G., Chiatti, F., Bolla, P., Martini, M., \& Caroli, A. (2005). Genetic variability of the ovine as1casein. Ital. J. Anim. Sci. 4:64-66. 
Chessa, S., Budelli, E., Chiatti, F., Cito, A.M., Bolla, P., \& Caroli, A. (2005). Short communication: predominance of beta-casein (CSN2) C allele in goat breeds reared in Italy. J. Dairy Sci. 88:1878-1881.

Chessa, S., Rignanese, D., Berbenni, M., Ceriotti, G., Martini, M., Pagnacco, G., \& Caroli, A. (2010). New genetic polymorphisms within ovine $\beta$ - and aS2-caseins. Small Rumin. Res. 88: 84-88.

Corral, J.M., Padilla, J.A., \& Izquierdo, M. (2010). Associations between milk protein genetic polymorphisms and milk production traits in Merino sheep breed. Livest. Sci. 129: 73-79

Duret, L., Mouchiroud, D., \& Gouy, M. (1994). HOVERGEN: a database of homologous. Nucleic Acids Res. 22:2360-2365.

Elmaci, C., Oner, Y., \& Balcioglu, M.S. (2005). Genetic Polymorphism of $\beta$-Lactoglobulin Gene in Native Turkish Sheep Breeds. Biochem. Genet. 44: 376-381.

Erhardt, G. (1989). Evidence for a third allele at the $\beta$-LG locus of sheep and its occurrence in different breeds. Anim. Genet. 20: 197-204.

Feligini, M., Parma, P., Aleandri, R., Greppi, G.F., \& Enne, G. (1998). PCR-RFLP test for direct determination of beta-lactoglobulin genotype in sheep. Anim. Genet. 29:473-474.

Feligini, M., Vlaco, S., Cubriccurik, V., Parma, P., Greppi, G. F., \& Enne, G. (2005). A single nucleotide polymorphism in the sheep k-casein coding region. J. Dairy Res. 72: 317-321.

Garzon, A.I., \& Martinez, J. (1992). $\beta$-LG in Manchega sheep breed. Relationship with milk technological indexes in handcraft manufacture of Manchego cheese. XXIII Int. Conf. Anim. Gen., Interlaken.

Giambra, I.J., Jäger, S., \& Erhardt, G. (2010). Isoelectric focusing reveals additional casein variants in German sheep breeds. Small Rumin. Res. 90: 11-17.

Ikonen, T., Bovenhuis, H., Ojala, M., Routtinen, O., \& Georges, M. (2001). Association between casein haplotypes and first lactation milk production traits in Finnish Ayrshire cows. J. Dairy Sci. 84: 507-514.

Maioli, B., Pilla, F., \& Tripaldi, C. (1998). Detection of milk protein genetic polymorphisms in order to improve dairy traits in sheep and goats: a review. Small Rumin. Res. 27: 185-195. 
Mohammadi, A., Nassiry, M.R., Elyasi, G., \& Shodja, J. (2006). Genetic polymorphism of $\beta$ lactoglobulin in certain Iranian and Russian sheep breeds. Iranian J. Biot. 4: 265-268.

Nei, M. (1973). Analysis of gene diversity in subdivided populations. Proceedings of the National Academy of Sci. 70: 3321-3323.

Nei, M., Tajima, F., \& Tateno, Y. (1983). Accuracy of estimated phylogenetic trees from molecular data. J. Mol. Evol. 19: 153-170.

Ota, T. (1993). DISPAN genetic distance and phylogenetic analysis. Pennsylvania State University, University Park, PA, b35.

Ott, J. (1999) Analysis of human genetic linkage. 3ra Edición, Johns Hopkins University Press, Baltimore, USA.

Pirisi, A., Piredda, G., Papoff, C.M., Di Salvo, R., Pintus, S., Garro, G., Ferranti, P., \& Chianese, L. (1999). Effects of sheep as1-casein CC, CD and DD genotypes on milk composition and cheesemaking properties. J. Dairy Res. 66: 409-419.

Ramunno, L., Longobardi, E., Pappalardo, M., Rando, A., Di Gregorio, P., Cosenza, G., Mariani, P., Pastore, N., \& Masina, P. (2001). An allele associated with a non-detectable amount of alpha s2 casein in goat milk. Anim. Genet. 32:19-26.

Rousset, F. (2008). Genepop'007: a complete re-implementation of the genepop software for Windows and Linux. Mol. Ecol. Res. 8: 103-106.

Ryniewicz, Z., Zwierzchowski, L., Bagnicka, E., Krzyewski, J., \& Strzalkowska, N. (2002). Preliminary investigations on the polymorphism of defensin genes in cattle. Relation with milk somatic cell count. Anim. Sci. Pap. Rep., 20:125-131.

Sanger, F., Nicklen, S., \& Coulson, A.R. (1977). DNA sequencing with chain - terminating inhibitors. Proc. Natl. Acad. Sci. USA. 74: 5463 - 5468.

Stephens, M., Smith, N. J., \& Donnelly, P. (2001). A new statistical method for haplotype reconstruction from population data. Am. J. Human Genet. 68: 978-989.

Tetens, J.L., Drögemüller, C., Thaller, G., \& Tetens, J. (2014). DNA-based identification of novel ovine milk protein gene variants. Small Rumin. Res. 121: 225-231. 
Vincze, T., Posfai, J., \& Roberts, R. J. (2003). NEBcutter: a program to cleave DNA with restriction enzymes. Nucleic Acids Res., 31: 3688-3691.

Weir, B.S., \& Cockerham, C.C. (1996). Genetic data analysis II: Methods for discrete population genetic data. Sinauer Assoc. Inc., Sunderland, MA, USA.

Weir, B.S. (1996). Genetic data analysis II. Sinauer Associates, Inc. Publishers. Canadá.

Wright, S. (1969). Evolution and Genetics of Populations, The theory of gene frequencies. Vol. II. Chicago: University of Chicago Press. 


\section{Estimación de la asociación entre polimorfismos genéticos de las proteínas de la leche con características de producción de lechera y mastitis subclínica}

\subsection{Introducción}

El interés por la leche de oveja en nuestro país comenzó a principios de los años '80. La mayoría de los tambos utiliza animales de las razas Frisona del Este (FE), Pampinta y sus cruzas. Tomando en consideración el rendimiento quesero de la leche de ovinos, uno de los objetivos de la actividad es desarrollar un emprendimiento, de pequeña a mediana escala, para competir con los productos bovinos. Muchos de los productores comercializan sus productos en forma local o regional (Busetti \& Suárez, 2010). La actividad, sin embargo, entró en un círculo vicioso, en el que 4 o 5 productores entran a la actividad cada año y una misma cantidad la deja. Esto es debería fundamentalmente, según Bettinoti (2005) a diferentes tipos de barreras: genéticas, financieras, tecnológicas y a una comercialización no ordenada. Aunque, también existen barreras de idiosincrasia. Sin embargo, Argentina tiene ventajas comparativas en relación a otros países, que deberían hacer viable y rentable la producción lechera de ovinos, en especial en pequeños y medianos productores.

Las variantes genéticas de las proteínas de la leche pueden tener efecto en la producción y la composición de la misma, lo que causa gran interés debido a las aplicaciones tecnológicas que implica (Amigo et al., 2000). Se han descripto un gran número de asociaciones entre los polimorfismos de las proteínas de la leche con caracteres productivos (ver cuadro 4.1). En LGB (GenBank X 12817.1) Corral et al. (2010) y Ramos et al. (2009) reportaron una mutación en el exón $2(C>G)$ en la posición 1684; mientras que Dario et al. $(2005 ; 2008)$ y Triantaphylopoulos et al. (2016) reportaron la mutación puntual en el exón 2 (T>C). En relación a CSN1S1 (GenBank JN 560175.1) Ramos et al. (2009) reportó una mutación ene I exón 17 posición 15926 (T>C). En CSN2 
(GenBank X 70703) Corral et al. (2010) reportó una mutación en el exón 7 posición 12099 (A>G). Sin embargo, los estudios de asociación entre los polimorfismos de las proteínas de la leche y las características de producción y composición han tenido resultados opuestos en distintas razas ovinas (Amigo et al., 2000; Barrilet et al., 2005). A su vez, algunos autores no han encontrado asociaciones entre los polimorfismos de las proteínas y las características de la producción (Staiger et al., 2010).

Diversos autores han estudiado los polimorfismos genéticos de las proteínas de la leche ovina y sus asociaciones con caracteres productivos. Tal es el caso del polimorfismo de la Lactoglobulina (LGB), Giambra et al. (2014) en ovinos FE reportaron que animales con genotipo $A B$ tuvieron mayor producción de leche, pero con bajos porcentajes de grasa y proteína, en comparación con animales BB. Por otra parte, Garzón \& Martínez (1992), encontraron en ovejas Manchegas heterocigotas un mayor contenido de proteína. Gigli et al. (2007) reportaron que el genotipo BB de LGB en ovejas del Valle del Belice, es el menos favorable en términos de resistencia a mastitis. Por otro lado, Triantaphylopoulos et al. (2016) encontró mayor número de células somáticas en leche en el genotipo $A A$ en comparación con el $A B$, pero no con el $B B$ en razas Chios y Karagouniko. En tanto que Mroczkowski et al. (2004) determinaron que animales Polish Merinos con este genotipo BB producía un alto porcentaje de grasa y proteína. Por otra parte, Mele et al. (2007) y Recio et al. (1997) no identificaron asociaciones entre polimorfismo genéticos de la LGB y caracteres lecheros, en las razas Merino y Lacha, respectivamente.

Giambra et al. (2014) y Mroczkowski et al. (2004), para el genotipo CC de la caseína alpha s1 (CSN1S1), reportaron mayor producción de leche, grasa y porcentaje de grasa, en tanto que los genotipos AA y DD se los asoció con baja producción de grasa y proteína. Para la beta caseína (CSN2) no se hallaron efectos significativos como los reportados por Corral et al. (2010) en Merinos españoles, donde el genotipo GG se asoció a un mayor rendimiento lechero y el genotipo AA, a mayor porcentaje de grasa. Dagnachew et al. (2014) demostró que los haplotipos (H1, H2, H3, H4 y H5) de kappa caseína (CSN3) están asociados con altos porcentajes de proteína en la raza de cabras lecheras Noruegas. 
Diferentes aproximaciones metodológicas han sido empleadas, en el curso de las últimas tres décadas, para estimar el efecto de un determinado marcador posiblemente asociado a genes cuantitativos de caracteres de interés comercial. Por ejemplo, el uso de los genotipos para un determinado marcador molecular en un contexto de ANOVA o regresión. Sin embargo, esto desconoce la existencia de relaciones de parentesco entre los individuos de una población. En otras palabras, la existencia de covarianza entre los individuos, lo cual genera al ignorarlas asociaciones espurias. Por este motivo, Aulchenko et al. (2007) proponen realizar la estimación en dos etapas: 1) mediante un modelo mixto que considera las relaciones de parentesco pero no marcador molecular, se realiza una predicción para cada observación y se obtiene el residuo; 2) sobre el residuo, ahora ajustado por los efectos fijos y de parentesco, se realiza una estimación mediante regresión en cada uno de los marcadores. Esto es lo que Aulchenko et al. (2007) llaman GRAMMAR.

El objetivo de esta investigación fue estimar la asociación entre los polimorfismos LGB y caseínas (CSN1S1, CSN2 y CSN3), identificados en el capítulo anterior, con la producción de leche $(P L)$, grasa total $(G T)$, proteína total $(P T)$, porcentaje de grasa $(G \%)$, porcentaje de proteínas (P\%) e incidencia de mastitis subclínicas (MSC) mediante la metodología propuesta por Aulchenko et al. (2007). 
Cuadro 4.1. Resumen de las asociaciones entre genotipos para proteínas de leche y su efecto en caracteres productivos según datos reportados.

\begin{tabular}{|c|c|c|c|c|c|}
\hline Genes & genot. & efectos & razas & método & Autores \\
\hline \multirow{7}{*}{ LGB } & $\mathrm{BB}^{1}$ & $\begin{array}{l}\text { mayor } \mathrm{PL} y \\
\text { menor } \mathrm{P} \%\end{array}$ & \multirow{2}{*}{$\begin{array}{l}\text { Merino } \\
\text { Español }\end{array}$} & \multirow{2}{*}{ ANOVA } & \multirow{2}{*}{ Corral et al. (2010) } \\
\hline & $A A^{1}$ & $\begin{array}{l}\text { mayor G\% } \\
\text { y P\% }\end{array}$ & & & \\
\hline & $A A^{2}$ & mayor GT & Altamurana & ANOVA & Dario et al. (2005) \\
\hline & $A A^{1}$ & menor PL & $\begin{array}{c}\text { Serra da } \\
\text { Estrella y } \\
\text { White and } \\
\text { Black } \\
\text { Merino }\end{array}$ & \multirow[t]{2}{*}{ ANOVA } & \multirow[t]{2}{*}{$\begin{array}{l}\text { Ramos et al. } \\
(2009)\end{array}$} \\
\hline & $A A^{1}$ & mayor PT & Merino & & \\
\hline & $\mathrm{BB}^{2}$ & $\begin{array}{l}\text { menor PL, } \\
\text { GT, PT }\end{array}$ & Leccese & ANOVA & Dario et al. (2008) \\
\hline & $\begin{array}{l}A B^{2} \\
A A^{2}\end{array}$ & $\begin{array}{l}\text { mayor PL } \\
\text { mayor GT y } \\
\mathrm{P} \%\end{array}$ & $\begin{array}{c}\text { Chios- } \\
\text { Karagouniko }\end{array}$ & regresión & $\begin{array}{l}\text { Triantaphylopoulos } \\
\text { et al. (2016) }\end{array}$ \\
\hline CSN1S1 & $\mathrm{CC}^{3}$ & mayor PL & $\begin{array}{c}\text { Serra da } \\
\text { Estrella }\end{array}$ & ANOVA & $\begin{array}{l}\text { Ramos et al. } \\
\text { (2009) }\end{array}$ \\
\hline CSN2 & $\begin{array}{l}{G G^{4}} \\
A A^{4}\end{array}$ & $\begin{array}{l}\text { mayor PL } \\
\text { mayor GT y } \\
\text { PT }\end{array}$ & $\begin{array}{l}\text { Merino } \\
\text { Español }\end{array}$ & ANOVA & Corral et al. (2010) \\
\hline
\end{tabular}

1exon 2 posición 1684 (C>G) GenBank X12817.1; ${ }^{2}$ exón 2 (T>C) GenBank X12817.1; ${ }^{3}$ exón 17 posición 15926 (T>C) GenBank JN 560175.1; ${ }^{4}$ exón 7 posición 12099 (A>G) GenBank X79703.

PL: producción de leche; G\%: porcentaje de grasa; P\%: porcentaje de proteína; PT: contenido total de proteína; GT: contenido total de grasa

\subsection{Materiales Y Métodos}

\subsubsection{Animales:}

Debido a restricciones presupuestarias, se tomó una muestra de 70 ovejas para realizar los análisis de asociación en general. En tanto que para CSN3, luego del primer muestro, se aumentó en 80 el número de animales muestreados, haciendo un total de 150. Esto último se realizó tomando en consideración la importancia de la proteína para la elaboración de quesos, y la necesidad de tener representados todos los genotipos para futuros estudios. 


\subsubsection{Muestreos:}

ADN y Análisis moleculares:

Se utilizó la información obtenida en el capítulo 3.

\subsubsection{Análisis Estadísticos:}

El estudio de asociación se realizó de acuerdo a lo propuesto, desde el punto de vista metodológico, por Aulchenko et al. (2007). Se realizó una estimación de valores de cría y de los efectos en el modelos para las siguientes características: producción de leche $(\boldsymbol{P L})$, grasa total (GT), proteína total $(\boldsymbol{P T})$, porcentaje de grasa (G\%), porcentaje de proteínas (P\%) y la incidencia de mastitis subclínicas (MSC). Estas estimaciones se realizaron empleando los modelos identificados y las estimaciones de componentes de varianza realizadas en el capítulo 3, empleando el programa WOMBAT (Meyer, 2007). Una vez realizadas las estimaciones, se predijo el residuo de cada observación como el valor fenotípico observado menos la predicción realizada por el modelo. Como hubo observaciones repetidas, para cada individuo con genotipo se tomó para el análisis el promedio de los residuos predichos. Para cada uno de los genes evaluados (LGB, CSN1S1, CSN2 y CSN3), se estimó el efecto de sustitución empleando regresiones lineales simples de los genotipos en los residuos promedios. Con lo cual, el modelo de regresión empleado fue: $\hat{e}_{i}=\mu+\beta g_{i}+\epsilon_{i}$, donde $\hat{e}_{i}$ es el promedio de los residuos para la oveja $\mathrm{i} ; \beta$ es el efecto del cambio de un alelo por el otro; $g_{i}$ es el genotipo de individuo i, y $\epsilon_{i}$ es el residuo. Los genotipos se codificaron como 0,1 y 2, tomando arbitrariamente 0 como el primer genotipo ordenado alfabéticamente. Por ejemplo, si los genotipos se codifican AA, AB y BB, los mismos serán 0, 1 y 2, respectivamente. Las estimaciones se realizaron empleando el programa $R$ ( $R$ Core Team, 2014). 


\subsection{Resultados}

Los efectos estimados de los genotipos de LGB, CSN1S1, CSN2 y CSN3 sobre los residuos promedios predichos para PL, GT, PT, G\%, P\% y MSC, y sus niveles de significancia ( $p-$ valor) se pueden observar en el cuadro 1. El efecto de CSN1S1 fue significativo para GT y mostró tendencia para PL y PT, y el de CSN2 fue significativo para PT y mostró tendencia para PL y GT. En tanto que los efectos de CSN3 y LGB no resultaron significativo en ninguno de los caracteres productivos bajo estudio. Desde el punto de vista productivo, en CSN1S1, el efecto sobre GT significa 2,18 kg por lactancia de 210 días del genotipo TT en relación al CC. Así como también se observó una tendencia positiva para PL y PT del genotipo TT sobre el CC. En relación a CSN2, para PT el genotipo AA significó $1,98 \mathrm{~kg}$, en lactancias de 210 días, sobre el genotipo GG, y observándose tendencias similares para PL y GT aunque de menor cuantía.

Cuadro 4.2. Efecto de la asociación de los polimorfismos (caseínas y LGB) con caracteres de producción, composición de leche y RCS.

\begin{tabular}{lllll}
\hline & LGB & CSN1S1 & CSN2 & CSN3 \\
\hline \multirow{2}{*}{ PL $(\mathrm{I} / \mathrm{d})$} & $-0,029$ & $0,054^{\#}$ & $-0,059^{\#}$ & $-0,004$ \\
& $(0,28)$ & $(0,07)$ & $(0,05)$ & $(0,81)$ \\
\hline \multirow{2}{*}{ MSC (incidencia/lactancia) } & $-0,043$ & $-0,014$ & 0,027 & $-0,047$ \\
& $(0,42)$ & $(0,80)$ & $(0,64)$ & $(0,28)$ \\
\hline \multirow{2}{*}{ GT $(\mathrm{g} / \mathrm{d})$} & $-2,731$ & $5,211^{*}$ & $-4,986^{\#}$ & 0,4472 \\
& $(0,25)$ & $(0,04)$ & $(0,05)$ & $(0,78)$ \\
\multirow{2}{*}{ G\% } & $-0,072$ & 0,078 & 0,041 & $-0,019$ \\
\hline \multirow{2}{*}{ PT $(\mathrm{g} / \mathrm{d})$} & $(0,36)$ & $(0,38)$ & $(0,65)$ & $(0,73)$ \\
\hline \multirow{2}{*}{ P\% } & $-2,448$ & $4,187^{\#}$ & $-4,725^{*}$ & 0,208 \\
& $(0,24)$ & $(0,07)$ & $(0,04)$ & $(0,88)$ \\
\hline
\end{tabular}

"*” $p<0,05$; “\#” $p<0,10$ 


\subsection{Discusión}

Para LGB, al igual que Mele et al. (2007) en ovejas Massese, Recio et al. (1997) en ovinos Merino y Staiger et al. (2010) en East Friesian, en el presente trabajo no se encontraron asociaciones significativas. En tanto que Ramos et al. (2009) demostraron que ovejas de la raza Serra de Estrela con el genotipo AA tuvieron mayor rendimiento de leche, pero que ovejas Merino con el genotipo $\mathrm{AA}$, por el contrario, tuvieron menor rendimiento de leche, aunque estas últimas tuvieron mayor contenido de proteínas. A su vez, Giaccone et al. (2000) observaron que en ovejas Valle de Belice, un mayor rendimiento de leche en el día control para el genotipo AA, pero un mayor contenido de grasa y proteína para BB. Dario et al. (2008) describieron un efecto de dominancia para el alelo A de LGB, y de incrementar el contenido de grasa en ovejas Leccese. En cambio, Cubric-Curik et al. (2012) encontraron en ovejas Pag que el genotipo AB asociado con mayor la producción de leche. En el estudio realizado por Triantaphylopoulos et al. (2016) encontraron que el genotipo AA tiene mayor porcentaje de grasa y proteína en la raza Chios y Karagouniko. Por otro lado, Nudda et al. (2003), en ovejas Sarda, demostraron que el genotipo BB genera una menor producción de leche, pero no encontrando efectos significativos de LGB sobre la composición láctea. En un trabajo de revisión, Barrilet et al. (2005) concluyen que los efectos de los polimorfismos de LGB sobre la producción láctea y las propiedades tecnológicas son demasiado inconsistentes entre razas, como para poder implementar un único criterio de selección.

Los resultados del presente estudio, indican que aquellos animales con genotipos TT para el locus CSN1S1 presentan una mayor producción de grasa total y una tendencia a mayor producción de leche y de proteína total en ovejas Pampinta. Estudios similares fueron llevados a cabo por diferentes autores, con resultados no consistentes en relación a los del presente trabajo. Por un lado, Mroczkowski et al. (2004) demostraron en ovejas Merino que el genotipo CC era superior para producción de leche y porcentajes de grasa y proteínas. Por otra parte, Giambra et al. (2014) encontraron en ovejas East Friesian que el genotipo CC se asociaba a mayor producción de proteínas, y a una tendencia a una mayor producción de leche y grasa. Por su parte, Ramos et 
al. (2009), en ovejas de la raza Serra de Estrela, encontraron asociación entre el genotipo CC con mayor producción de leche. En tanto Pirisi et al. (1999) encontraron asociación entre el genotipo CC y mayor contenido de proteína total en ovejas Sarda.

Para CSN2, los resultados del presente trabajo indicaron que el genotipo AA as asoció con mayor producción de proteínas totales, y mostró tendencia para mayor producción leche y grasa total. Estos resultados no concuerdan con lo hallado por Corral et al. (2010), quienes entraron asociación entre el genotipo GG y mayor producción de leche, y entre el genotipo AA y mayor porcentaje de grasa y proteína en ovejas Merino.

En relación a CSN3, en el presente trabajo no se encontraron efectos significativos de la mutación estudiada con relación a la producción de leche y sus componentes. Esta caseína fue poco investigada en relación a sus posibles efectos sobre la composición de la leche ovina (Staiger et al., 2010), a pesar de la importancia que tiene para la producción de quesos, principal destino de la leche ovina (Pirisi et al., 1999).

\subsection{Conclusión}

Las asociaciones encontradas entre CSN1S1 con GT y el de CSN2 con PT indican una clara oportunidad de mejora genética en la producción lechera nacional. 


\subsection{Bibliografía}

Amigo, L., Recio, I., \& Ramos, M. (2000). Genetic polymorphism of ovine milk proteins: its influence on technological properties of milk: a review. Int. Dairy J., 10:135-149.

Aulchenko, Y. S., De Koning, D. J., \& Haley, C. (2007). Genomewide rapid association using mixed model and regression: a fast and simple method for genomewide pedigree-based quantitative trait loci association analysis. Genet. 177: 577-585.

Barrillet, F., Arranz, J.J., \& Carta, A. (2005). Mapping quantitative trait loci for milk production and genetic polymorphisms of milk proteins in dairy sheep. Genet. Sel. Evol. 37: 109-123.

Bettinoti, M. (2005). Lechería ovina. Tesis sobre Cuadro de Mando Integral como herramienta para crear una actividad sustentable. Tesis Msc. UBA. Facultad de Agronomía- Escuela de Graduados Alberto Soriano.

Bevilacqua, C., Helbling, J. C., Miranda, G., \& Martin, P. (2006). Translational efficiency of casein transcripts in the mammary tissue of lactating ruminants. Repro. Nutr. Develop., 46: 567578.

Busetti, M.R. \& Suárez, V.H. (2010). Encuesta Sanitaria-Productiva. [En línea]: Disponible en: http://www.produccion-animal.com.ar/ (05/01/2017).

Caravaca, F., J. Carrizosa, B. Urrutia, F. Baena, J. Jordana, M. Amills, B. Badaoui, A. Sanchez, A. Angiolillo, \& J. M. Serradilla. (2009). Short communication: Effect of alphaS1-casein (CSN1S1) and kappa-casein (CSN3) genotypes on milk composition in Murciano Granadina goats. J. Dairy Sci. 92:2960-2964.

Caravaca, F., Ares, J. L., Carrizosa, J., Urrutia, B., Baena, F., Jordana, J., Badaoui, B., Sánchez, A., Angiolillo, A. Amills, M., \& Serradilla, J. M. (2011). Effects of a s1-casein (CSN1S1) and K-casein (CSN3) genotypes on milk coagulation properties in Murciano-Granadina goats. J. Dairy Res., 78: 32-37.

Corral, J.M., Padilla, J.A., \& Izquierdo, M. (2010). Associations between milk protein genetic polymorphisms and milk production traits in Merino sheep breed. Livest. Sci. 129: 73-79. 
Cubric-Curik, V., Feligini, M., Lukac-Havranek, J., Curik, I., \& Enne, G. (2002). Genetic polymorphism of B-lactoglobulin in native sheep from the Island of Pag. Food Technol. Biot., 40: 75-78.

Dagnachew, B. S., \& Ådnøy, T. (2014). Additive and dominance effects of casein haplotypes on milk composition and quality in Norwegian dairy goats. Small Rumin. Res. 122: 59-69.

Dario, C., Carnicella, D., \& Bufano, G. (2005). Effect of $\beta$-lactaglobulin genotypes on ovine milk composition in altamurana breed. Arch. Zootec, 54: 105-108.

Dario, C., Carnicella, D., Dario, M., \& Bufano, G. (2008). Genetic polymorphism of $\beta$-lactoglobulin gene and effect on milk composition in Leccese sheep. Small Rumin. Res. 74: 270-273.

Giaccone, P., Di Stasio, L., Macciotta, N. P., Portolano, B., Todaro, M., \& Cappio-Borlino, A. L. D. O. (2000). Effect of $\beta$-lactoglobulin polymorphism on milk-related traits of dairy ewes analysed by a repeated measures design. J. Dairy Res., 67: 443-448.

Giambra, I.J., Brandt, H., \& Erhardt, G. (2014). Milk protein variants are highly associated with milkperformance traits in East Friesian Dairy and Lacaune sheep. Small Rumin. Res. 121: 382-394.

Gigli, I., Riggio, V., Monteleone, G., Cacioppo, D., Rosa, A.J.M., \& Maizon, D.O. (2007). Relationship between beta lactoglobulin and subclinical mastitis in Valle del Belice sheep breed. Italian J. Anim. Sci. 6:140-142.

Gigli I., Stazionati, M.F., Busetti, M.R., \& Maizon, D.O. (2012). Caracterización genética de las principales proteínas de la leche en ovejas Pampinta. XV Congreso Latinoamericano de Genética en argentina, Rosario.

Garzón, A.I., \& Martínez, J. (1992). $\beta$-lactoglobulin in Manchega sheep breed. Relationship with milk technological indexes in handcraft manufacture of Manchego cheese. XXIII Int. Conf. Anim. Gen. Interlaken, g. 19.

Kusza, S., Veress, G., Kukovics, S., Jávor, A., Sanchez, A., Angiolillo, A., \& Bősze, Z. (2007). Genetic polymorphism of as1-and as2-caseins in Hungarian Milking Goats. Small Rumin. Res. 68: 329-332. 
Martini, M., Salari, F., Scolozzi, C., Cecchi, F., Ceriotti, G., \& Caroli, A. (2006). Relationship between milk genetic polymorphism and physico-chemical and nutritional quality of sheep milk. In 14th International Congress of Fe. Me. SP Rum, Lugo, Santiago de Compostela, Spain.

Mele, M., Conte, G., Serra, A., Buccioni, A., \& Secchiari, P. (2007). Relationship between betalactoglobulin polymorphism and milk fatty acid composition in milk of Massese dairy ewes. Small Rumin. Res. 73: 37-44.

Meyer, K. (2007). WOMBAT_A tool for mixed model analyses in quantitative genetics by restricted maximum likelihood (REML). J. Zhejiang Univ. Sci. B 8: 815-821.

Mroczkowski, S., Korman, K., Erhardt, G., Piwczynski, D., \& Borys, B. (2004). Sheep milk protein polymorphism and its effect on milk performance of Polish Merino. Archiv fur Tierzucht, 47: 114-121.

Nudda, A., Feligini, M., Battacone, G., Macciotta, N. P. P., \& Pulina, G. (2003). Effects of lactation stage, parity, $\beta$-lactoglobulin genotype and milk SCC on whey protein composition in Sarda dairy ewes.Italian J. Anim. Sci., 2: 29-39.

Pirisi, A., Piredda, G., Papoff, C.M., Di Salvo, R., Pintus, S., Garro, G., Ferranti, P., \& Chianese, L. (1999). Effects of sheep as1-casein CC, CD and DD genotypes on milk composition and cheesemaking properties. J. Dairy Res. 66: 409-419.

Ramos, A. M., Matos, C. A. P., Russo-Almeida, P. A., Bettencourt, C. M. V., Matos, J., Martins, A., Pinheiro, C., \& Rangel-Figueiredo, T. (2009). Candidate genes for milk production traits in Portuguese dairy sheep. Small Rumin. Res. 82: 117-121.

Recio, I., Fernandez-Fournier, A., Martin-Alvarez, P.J., \& Ramos, M. (1997). $\beta$-Lactoglobulin polymorphism in ovine breeds: influence on cheesemaking properties and milk composition. Lait. 77: 259-265.

Rozbicka-Wieczorek, A., Radzik-Rant, A., Rant, W., \& Puppel, K. (2015). The effect of breed, $\beta$ lactoglobulin variants and somatic cell count on yield, chemical components and whey protein composition in milk of non-dairy sheep. JAPS: J. Anim. \& Plant Sci., 25. 
Sacchi, P., Chessa, S., Budelli, E., Bolla, P., Ceriotti, G., Soglia, D., Rasero, R., Cauvin, E., \& Caroli, A. (2005). Casein haplotype structure in five Italian goat breeds. J. Dairy Sci., 88: $1561-1568$.

Schalm, O.W., \& Noorlander, D.O. (1957). Experiment and observations leading to development of the California mastitis test. Journal of the American Veterinary Medical Asossiation, 5:199207.

Staiger, E.A, Thonney, M.L, Buchanan, J.W, Rogers, E.R, Oltenacu, P.A., \& Mateescu, R.G. (2010). Effect of prolactin, $\beta$-lactoglobulin, and k-casein genotype on milk yield in East Friesian sheep. J Dairy Sci 93: 1736-1742.

Triantaphyllopoulos, K. A., Koutsouli, P., Kandris, A., Papachristou, D., Markopoulou, K. E., Mataragka, A., Massouras, T., \& Bizelis, I. (2016). Effect of $\beta$-lactoglobulin gene polymorphism, lactation stage and breed on milk traits in Chios and Karagouniko sheep breeds. Annals of Anim. Sci. 


\section{Kappa caseína, tiempo de coagulación y rendimiento quesero}

\subsection{Revisión bibliográfica}

La kappa caseína (CSN3), una fosfoproteína, es fundamental para la formación y estabilización de las micelas lipídicas de la leche. La digestión de esta proteína es necesaria para la formación del coagulo en la fabricación del queso, ya que la misma provoca la precipitación de las micelas. Al no ser sensible al calcio $\left(\mathrm{Ca}^{+2}\right)$, cuando se agrega quimosina actúa sobre ésta, fraccionándola en dos partes, la hidrófila y la hidrófoba. Esta última unida a la micela, al perderse su fracción hidrófila, ya no cumple la función de estabilización de las micelas, precipitando las demás caseínas (Thompson et al., 2009). CSN3 tiene una estructura y propiedades características que determinan sus interacciones y su funcionalidad: 1.- Interacciona con las caseínas sensibles al calcio $\mathrm{Ca}^{+2}$ para formar las micelas; 2.- Presenta estructura anfipática como se mencionó antes; 3.Presenta una secuencia específica donde actúa la quimosina para la proteólisis limitada, lo que permite la eliminación selectiva del dominio polar, comenzando la coagulación de las micelas (Ferrandini et al., 2006). Lo que mejor se adapta a estos requisitos es una capa superficial de CSN3, lo que también satisface la observación de que el contenido de CSN3 es inversamente proporcional al tamaño de la micela (Horne, 2006; Dalgleish et al., 1989). Al ser una micela de tamaño pequeño, permite una disposición más compacta de las micelas sensibilizadas y por lo tanto más enlaces intermicelares cuando se forman en una red (Walsh et al., 1998; Horne, 2006; Walstra et al., 1986). El tamaño de las micelas en ovejas tiene un diámetro mediano, de $193 \mathrm{~nm}$ a 202 nm, comparado con las de otros rumiantes (Park et al., 2007; Brulé et al., 2000). El diámetro de las micelas es una de las propiedades fisicoquímicas que afectan la elaboración de quesos, junto con el pH. Bencini (2002), demostró en ovejas que el tiempo de coagulación decrece de 17 a 7 minutos cuando el pH desciende de 6,65 a 6,16. Este parámetro marca una diferencia en la 
velocidad del tiempo de coagulación, jugando un papel importante (Bittante et al., 2012; Kübarsepp et al., 2005). Pugliese et al., (2000) durante un año tuvo moderadas variaciones en el pH de leche de ovejas Massese, pero tuvo altas variaciones en todos los parámetros de la cuajada (CV 50\%), él se lo atribuye al alimento, al clima, como así también. a factores grupales o individuales (orden y etapa de lactancia), lactancias de primavera u otoño. Además, la proporción de calcio por caseína, dado que la presencia de iones de $\mathrm{Ca}^{+2}$ es indispensable para la floculación de las micelas de caseínas modificadas por la acción de la quimosina. La temperatura de tratamiento a la que se someta la leche es otro factor. Se observó que cuando la temperatura se acerca a $38^{\circ} \mathrm{C}$ (comparado con $30^{\circ}$ y $34^{\circ} \mathrm{C}$ ) se acorta el tiempo de coagulación y no es afectada la consistencia del cuajo. Esto es lógico esperar debido a que el cuajo tiene una actividad máxima cuando la temperatura se aproxima a la temperatura corporal de los corderos. Las distintas concentraciones de minerales en la leche causan diferencias en el tiempo de coagulación y rendimiento de la cuajada. La concentración del contenido de éstos, depende de la raza, la dieta, el individuo, el estado de lactación y su estado de salud (Park et al., 2007). Por ejemplo, Sevi et al. (2004) demostró que el contenido de $\mathrm{Ca}^{+2}$ en leche permanece constante durante la lactancia en ovejas Comisana que tuvieron partos de otoño, pero aquellas que lo tuvieron en invierno, tuvieron una reducción significativa sobre todo en la lactancia tardía. Lo mismo ocurrió con el contenido de fósforo de la leche.

Todas estas variables físico químicas están correlacionadas con las variables de coagulación, como así también, con su composición. Pellegrini et al. (1994) demostró un aumento en la firmeza de la cuajada durante la lactancia asociada con el aumento de proteínas y grasas, adjudicando esto a que durante la lactancia aumenta el contenido de grasa y proteína (Pugliese et al., 2000), mientras que la tasa de endurecimiento del cuajo disminuye. Este incremento, se puede explicar, en parte, por la disminución en el rendimiento de leche que normalmente ocurre durante la curva de lactancia (Carta et al., 1995). La evolución de la lactosa difiere del comportamiento de las grasas, las proteínas y las caseínas (Pellegrini et al., 1994; Pugliese et al., 2000), observándose una disminución de la lactosa en la leche con el avance de la lactancia. En tanto, Jaramillo et al. (2008) atribuyeron una mayor resistencia de la cuajada con un mayor contenido de 
proteína total en leche. Por otro lado, Kübarsepp et al. (2005) señalan una correlación positiva entre el aumento de la materia grasa y la disminución del tiempo de coagulación. Esto puede deberse a que el contenido de grasa afecta el pH (Duranti et al., 2016), como se mencionó anteriormente, y a menor $\mathrm{pH}$ decrece el tiempo de coagulación. Con el avance de la lactancia, la aptitud de la leche para la elaboración del queso disminuye debido a cambios en su composición (Jaramillo et al., 2008), a la actividad de las células somáticas y a una enzima proteasa llamada plasmina (Sevi et al., 2004).

Según Dalgleish et al. (1989) las micelas de diferentes tamaño tienen diferentes contenidos de CSN3, por lo que se observan diferentes comportamientos de coagulación. El inicio de la coagulación es lento para micelas de tamaño grande y pequeño, pero es rápido para micelas de tamaño mediano. En tanto que Tornadijo et al. (1998) sostienen que la cuajada obtenida de leche con micelas grandes de caseínas otorgan un gel más firme y de rápido desuerado. El tiempo de coagulación es el tiempo que transcurre desde la aplicación de la quimosina hasta la aparición de los primeros "copos" que se unen formando un gel que de a poco va adquiriendo dureza (Tornadijo et al., 1998). La evaluación de las propiedades de la coagulación de la leche es importante para la fabricación del queso. Se dice que una leche tiene buena aptitud para la coagulación cuando coagula rápidamente en presencia de la enzima, tiene un desuerado corto y forma una cuajada firme, dando lugar a un buen queso. La reactividad de la leche con el cuajo, tasa de formación de la cuajada y la resistencia de la cuajada, tienen un efecto positivo en todo el proceso de elaboración del queso y posterior maduración (Tornadijo et al., 1998). La repetibilidad del tiempo de coagulación es alta, por lo tanto también lo podría ser su heredabilidad, con lo cual la mejora del tiempo de coagulación podría realizarse por selección (Bittante et al., 2012). Puledda et al. (2016) encuentran una alta heredabilidad para el tiempo de coagulación en ovejas Sarda $(0,23)$, donde concluye que se puede lograr un progreso genético breve en el tiempo.

Las variantes genéticas (especialmente de CSN3), influyen fuertemente en el tiempo de coagulación y en el comportamiento tecnológico de la leche (Amigo et al., 2000). Se han encontrado dos variantes del análisis de las proteínas para CSN3 (Alais \& Jolles, 1967; Soulier et al., 1974) y 3 variantes genéticas con digestión (RFLP) (Gregorio et al., 1991). Más recientemente 
Ceriotti et al. (2004) encontró un polimorfismo de un sólo nucleótido (SNP) en la posición 237, y Feligini et al. (2005) localizó un SNP en la posición 443 del ARNm. Se ha demostrado que ciertas variantes de CSN3 tienen un efecto favorable sobre las propiedades de la cuajada. Caravaca et al. (2011) encuentran en cabras Murciano-Granadina que el genotipo de CSN3 se asocia exclusivamente con el tiempo de coagulación, teniendo un menor tiempo de coagulación aquellos animales que portaban el genotipo AB 11,22 min comparado con BB 13,43 min. Pazzola et al. (2014) demostró el mismo efecto del genotipo en cabras de raza Sarda, donde la CSN3 influyó en las variables de la coagulación. Animales con genotipo BB tuvieron un retardo en el tiempo de coagulación, siendo la leche de estos las más bajas en $\mathrm{pH}$. Por otro lado, los homocigotas AA fueron los de mayor firmeza de cuajo. Por otro lado, Kübarsepp et al. (2005) encuentran en vacas que el genotipo BB fue significativamente mejor que AA para los parámetros de coagulación. De todas maneras debe observarse que el conjunto de mutaciones que caracterizan las variantes $\mathrm{A}$ y B en cabras y en vacas son completamente diferentes entre ellas, y diferentes de las variantes de CSN3 de ovejas. El gen CSN3 caprino comprende 5 exones con la región codificante para la proteína madura contenido en los exones 3 y 4 . Según Yahyaoui et al. (2003), que realizó la tipificación del gen por amplificación del exón 3 (469bp) y 4 (645bp), obtuvo los alelos A, B y C, y en el análisis de secuencia del exón 3 encontró un SNP $(A>G)$ en la posición 27. Por otra parte, para la genotipificación del gen de CSN3 en bovinos, se puede utilizar PCR-RFLP. Según Alexander et al. (1988), amplificando un fragmento de 530 bp se puede identificar las dos variantes mayoritarias ( $\mathrm{A}$ y $B$ ) de este gen, en donde la variante A tiene Thr en la posición 136 y Asp en la posición 148 de la proteína madura, mientras que la variante B tiene residuos de lle y Ala en las respectivas posiciones.

Bittante et al. (2012) clasificaron los factores genéticos que afectan el tiempo de coagulación. La raza se encuentra en primer lugar, y las condiciones ambientales generan gran variación, en particular el calor juega un rol importante (Peana et al., 2007), ya que el estrés calórico hace que los animales reaccionen con una sucesión de respuestas fisiológicas y endocrinas que tienen efecto directo en el rendimiento y composición de la leche. A su vez, no hay ingesta de alimento, por lo que se reducen los nutrientes disponibles para la glándula mamaria. 
Esto conlleva a desmejorar las características de la cuajada y del queso. Peana et al. (2007) encontró caídas significativas en el rendimiento de la leche hasta un 15\% (aproximadamente 0,30 $\mathrm{kg} / \mathrm{día} /$ cabeza) cuando las temperaturas máxima y media fueron superiores a $21-24^{\circ} \mathrm{C}$ y $15-21^{\circ} \mathrm{C}$, respectivamente. Asimismo, la humedad relativa del aire, influye positivamente en el rendimiento, mostrando un aumento de hasta $10 \%(0,18 \mathrm{~kg} /$ día /cabeza) cuando esta era superior al $45-55 \%$. Entre los factores, se encuentra la estructura de los genes que codifican las proteínas de la leche, y los efectos de sus variantes genéticas en el proceso de elaboración de queso. Los genes mayores de las proteínas de la leche, son otro factor muy importante. En este sentido, se han realizado muchos estudios para identificar rasgos genéticos asociados a producción de leche, para realizar selección asistida por marcadores (MAS) (Georges et al., 1995). Se debe a su vez considerar el efecto poligénico aditivo.

El efecto del genotipo de CSN3 ha resultado significativo para el tiempo de coagulación (Pazzola et al., 2014; Duranti et al., 2016; Maioli et al., 2007; Kübarsepp et al., 2005). Muy pocos estudios se han llevado a cabo sobre las propiedades de coagulación en pequeños rumiantes, especialmente en ovinos (Puledda et al., 2016). En general, los reportes sobre este tema están basados en el polimorfismo de CSN3, debido a que ésta juega un papel clave, es la responsable de la estructura primaria de la cuajada del queso, la coagulación afectaría la composición del queso, la textura y la reología (Selvaggi et al., 2014).

El comportamiento coagulante de la leche está fuertemente influenciado por los factores climáticos y nutricionales, como ya se mencionara, además está relacionado con el tipo de lactación y la época de parición a las que está sujeto el animal. Pugliese et al. (2000) demostraron en ovejas Massese que lactancias cortas iniciadas en primavera tienen menor tiempo de coagulación (2,55 min) comparadas con lactancias cortas y largas iniciadas en otoño (3,83 min y 8,86 min, respectivamente). Según Sevi et al. (2004), los parámetros de la cuajada son afectados por la época de parto y la etapa de la lactancia, obteniendo mejores resultados con las pariciones de otoño comparadas con las de invierno. A su vez, también influyen el número y el estado de lactancia (Pazzola et al., 2014). La aptitud para la elaboración de queso mejora después de la cuarta lactancia (Pugliese et al., 2000; Kuchtík et al., 2008) a diferencia de la demostrado por 
Novotna et al. (2009); Jaramillo et al. (2008); y Pellegrini et al. (1997) quienes reportaron que la mejor cuajada se encuentra en la segunda parición, y luego comienza a declinar pero sin causar efecto en las propiedades de coagulación. Teniendo en cuenta los días en lactancia, los tiempos más largo de coagulación fueron entre el día 33 y 67 en lactancia y los más cortos hacia la mitad de la lactación en Frisona del Este (East Friesian), en lactancias de 191 días (Kuchtík et al., 2008). El motivo por el cual sería más extenso, es porque al comienzo de la lactancia el contenido de sólidos totales, proteína y grasa es bajo en comparación con la mitad y el fin de la misma (Pavić et al., 2002; Pugliese et al., 2000).

Con respecto al tiempo de coagulación y rendimiento quesero, en ovejas raza Massese, Martini et al. (2008) obtuvo un tiempo de coagulación de 12,83 $(5,03)$ minutos, mientras que el rendimiento fue de 20,11\% (2,81). En razas Manchega y Lacaune (Abdelgawad et al., 2016), donde se evaluó las propiedades de la coagulación para elaboración de quesos de leche proveniente de ovejas con MSC (Lacaune) y sin MSC (Manchega y Lacaune), los valores del tiempo de coagulación para las ovejas sin MSC fueron de 10,8 minutos y 9,90 minutos, respectivamente. Mientras que aquellas leches con MSC tuvieron un mayor tiempo de coagulación (25,2 minutos), debido a que la integridad de las micelas de caseínas se encuentra comprometida llevando a un gel deficiente. Abdelgawad et al. (2016) indicaron que la lactosa es un factor clave balanceando los cambios osmóticos entre la sangre y la leche de la ubre, ya que en animales infectados con MSC hay una disminución de la lactosa que equilibra el efecto osmótico del aumento del contenido mineral. Las leches provenientes de animales con MSC tienen una lenta coagulación, como consecuencia de una la disminución de la concentración del $\mathrm{Ca}^{+2}$, fósforo y potasio. Si incrementamos la concentración de $\mathrm{Ca}^{+2}$ inducimos a un tiempo de coagulación corto. Tanto el tiempo de coagulación de la leche, como el que tarda la cuajada en adquirir firmeza, aumentan de forma significativa con los RCS (Raynal-Ljutovac et al., 2007). En general, es deseable minimizar el tiempo de coagulación, porque de esta manera se reduce el tiempo de procesamiento requerido para la elaboración de queso. En ovejas Sarda (Puledda et al., 2016), el tiempo de coagulación hallado fue de 15,18 (4,29) minutos, y el rendimiento fue de $36,24 \%(9,33)$. Novotna et al. (2009) investigaron, según el estado de lactación y el parto, el rendimiento lechero, 
composición y propiedades de la leche de oveja en 10 cruzas de ovejas criadas en granjas orgánicas, La media según el estado de lactación y parición fue de $3,36(0,88)$ minutos de tiempo de coagulación.

En la raza Pampinta, se trató de estimar la asociación entre el genotipo del gen de CSN3 y el tiempo de coagulación y rendimiento quesero. La probabilidad de encontrar ovejas de los tres genotipos fue muy baja. La prueba se realizó dos años consecutivos, pero no se obtuvo un número suficiente de animales de dos de los genotipos como para realizar las comparaciones. El genotipo más frecuente para CSN3 en Pampinta fue el CC (el SNP C>T posición 443, acceso GenBank: X51822; (Feligini et al., 2005), mediante pirosecuenciación; y el SNP T>C posición 237, GenBank X51822 (Ceriotti et al., 2004)); encontrando en muy baja frecuencia el TC. No hubo diferencias entre los genotipos con respecto al tiempo de coagulación, pero si se encontraron diferencias en el rendimiento quesero a nivel teórico, obteniendo mejores rendimientos el genotipo TC. Trabajando con un bajo número de animales, los valores obtenidos, sin embargo, estuvieron dentro de los reportados para otras razas de ovejas lecheras. Los valores estuvieron cercanos a los mínimos de los rangos reportados en otras razas, posiblemente por las diferencias de manejo que existen. Es difícil comparar resultados en cuanto a las propiedades de coagulación de la leche, ya que las condiciones de operación (temperatura, cantidad y calidad del cuajo, equipamiento) no son necesariamente idénticas.

Algunas investigaciones han contribuido a la comprensión de las propiedades de cuajo de razas de ovejas lechera, especialmente en países mediterráneos. Sin embargo las propiedades tecnológicas de muchas razas no se han estudiado. Teniendo en cuenta que la mayoría de los programas de mejoramiento se basan únicamente en los caracteres cuantitativos (litros de leche) y cualitativos (contenido de grasa y proteínas) de la leche (Ugarte et al., 2001) y no en su desempeño en la elaboración de quesos. Como la leche de oveja se destina casi en su totalidad a la elaboración de quesos, la estimación de los rasgos de coagulación pueden permitir un marco futuro de selección para tales rasgos (Puledda et al., 2016). 


\subsection{Bibliografía}

Abdelgawad, A.R., Rovai, M., Caja, G., Leitner, G., \& Castillo, M. (2016). Evaluating coagulation properties of milk from dairy sheep with subclinical intramammary infection using near infrared light scatter. A preliminary study. J. Food Eng. 168: 180-190.

Alais, C., \& Jollès, P. (1967). Isolation, Purification, and Analysis of Two K-Casein-like Fractions from Sheep Casein 1, 2. J. Dairy Sci. 50: 1555-1561.

Alexander, L. J., Stewart, A. F., Mackinlay, A. G., Kapelinskaya, T. V., Tkach, T. M., \& Gorodetsky, S. I. (1988). Isolation and characterization of the bovine k-casein gene. Eur. J. Biochem. 178: 395-401.

Amigo, L., Recio, I., \& Ramos, M. (2000). Genetic polymorphism of ovine milk proteins: its influence on technological properties of milk—a review. Int. Dairy J, 10: 135-149.

Bencini, R. (2002). Factors affecting the clotting properties of sheep milk. J. Sci. Food Agric. 82: 705-719.

Bittante, G., Penasa, M., \& Cecchinato, A. (2012). Invited review: Genetics and modeling of milk coagulation properties. J. Dairy Sci., 95: 6843-6870.

Brule, G., Lenoir, J., \& Remeuf, F. (2000). The casein micelle and milk coagulation. In Cheesemaking: From Science to Quality Assurance, Eck A \& Gillis J, eds., 2nd Edition, Lavoisier Publishing, Paris, 7-40.

Ceriotti G, Chessa S, Bolla P, Budelli E, Bianchi L, Duranti E, Caroli A. (2004) Single nucleotide polymorphisms in the ovine casein genes detected by polymerase chain reaction-single strand conformation polymorphism. J Dairy Sci. 87:2606-2613.

Caravaca, F., Ares, J.L., Carrizosa, J., Urrutia, B., Baena, F., Jordana, J., Badaoui, B., Angiolillos, A., Amill, M., \& Serradilla J.M. (2011). Effects of as1-casein (CSN1S1) and K-casein (CSN3) genotypes on milk coagulation properties in Murciano-Granadina goats. J.Dairy Res. 78:3237. 
Carta, A., Sanna, S.R., \& Casu, S. (1995). Estimating lactation curves and seasonal effects for milk, fat and protein in Sarda dairy sheep with a test day model. Livest. Prod. Sci. 44, 37-44.

Clark, J.T. (2004). Processing of frozen sheep milk - current procedures and difficulties encountered.

Dalgleish, D. G., Horne, D. S., \& Law, A. J. R. (1989). Size-related differences in bovine casein micelles. Biochimica et Biophysica Acta (BBA)-General Subjects, 991: 383-387.

Duranti, E., Bolla, P., Caroli, A., Chiofalo, L., Di Stasio, L., Fortina, R., Martini, M., Piccolo, V., \& Zullo, A. (2016). Problem concerning ovine milk clotting aptitude. Ital. J. Anim. Sci. 2:1, 8995.

Feligini, M., Vlaco, S., Cubriccurik, V., Parma, P., Greppi, G. F., \& Enne, G. (2005). A single nucleotide polymorphism in the sheep k-casein coding region. J. Dairy Res. 72: 317-321.

Ferrandini, E., Castillo, M., López, M.B., \& Laencina, J. (2006). Modelos estructurales de la micela de caseína. An. Vet. (Murcia) 22: 5-18.

Georges, M., Nielsen, D., Mackinnon, M., Mishra, A., Okimoto, R., Pasquino, A. T., Sargeant, L.S., Sorensen, A., Steele, M.R., Zhao, X., Womack, J.E., \& Hoeschele, I. (1995). Mapping quantitative trait loci controlling milk production in dairy cattle by exploiting progeny testing. Genet. 139: 907-920.

Gregorio, P., Rando, A., Pieragostini, E., \& Masina, P. (1991). DNA polymorphism at the casein loci in sheep. Anim. Genet. 22: 21-30.

Horne, D. S. (2006). Casein micelle structure: models and muddles. Curr. Opin. Colloid \& Interface Sci., 11: 148-153.

Jaramillo, D.P., Zamora, A., Guamis, B., Rodriguez, M., \& Trujillo, A.J. (2008). Cheesemaking aptitude of two Spanish dairy ewe breeds: Changes during lactation and relationship between physico-chemical and technological properties. Small Rumin. Res. 78: 48-55.

Kübarsepp, I., Henno, M., Viinalass, H., \& Sabre, D. (2005). Effect of K-casein and $\beta$-lactoglobulin genotypes on the milk rennet coagulation properties. Agr. Res, 1: 55-64. 
Kuchtik, J., Sustova, K., Urban, T. \& Zapletal, D. (2008). Effect of the stage of lactation on milk composition, its properties and the quality of rennet curdling in East Friesian ewes. Czech J. Anim. Sci., 53: 55-63.

Moioli, B., D'andrea, M., \& Pilla, F. (2007). Candidate genes affecting sheep and goat milk quality. Small Rumin. Res. 68: 179-192.

Martini, M., Scolozzi, C., Cecchi, F., Mele, M., \& Salari, F. (2008). Relationship between morphometric characteristics of milk fat globules and the cheese making aptitude of sheep's milk. Small Rumin. Res. 74: 194-201.

Mercanti, D.J., Busetti, M.R., Meinardi, C.A., \& Zalazar, C.A. (2008). Studies on a fast method for determining the yield in the production of Argentinean sheep cheeses. Food Chem. 107, $1717-1723$.

Novotná, L., Kuchtik, J., Sustová, K., Zapletal, D., \& Filipcik, R. (2009). Effects of Lactation Stage and Parity on Milk Yield, Composition and Properties of Organic Sheep Milk. J. Appl. Anim. Res. 36: 71-76.

Park, Y.W., Juarez, M., Ramos, M., \& Haenlein, G.F.W. (2007). Physico-chemical characteristics of goat and sheep milk. Small Rumin. Res. 68: 88-113.

Pavić, V., Antunac, N., Mioč, B., Ivanković, A., \& Havranek, J. L. (2002). Influence of stage of lactation on the chemical composition and physical properties of sheep milk. Czech J. Anim. Sci., 47: 80-84.

Pazzola, M., Dettori, M.L., Cipolat-Gotet, C., Cecchinato, A., Bittante, G., \& Vacca, G.M. (2014). Phenotypic factors affecting coagulation properties of milk from Sarda ewes. J. Dairy Sci. 97: $7247-7257$.

Peana, I., Fois, G., \& Cannas, A. (2007). Effects of heat stress and diet on milk production and feed and energy intake of Sarda ewes. Ital. J. Anim. Sci, 6(sup1), 577-579.

Pellegrini, O., Remeuf, F., \& Rivemale, M. (1994). Evolution des caracteristiques physicochimiques et des parametres de coagulation du lait de brebis collecte dans la region de Roquefort. Lait 74: 425-442. 
Pugliese, C., Acciaioli, A., Rapaccini, S., Parisi, G., \& Franci, O. (2000). Evolution of chemical composition, somatic cell count and renneting properties of the milk of Massese ewes. Small Rumin. Res. 35: 71-80.

Puledda, A., Gaspa, G., Manca, M.G., Serdino, J., Urgeghe, P.P., Dimauro, C., Negrini, R., \& Macciotta, N.P.P. (2016). Estimates of heritability and genetic correlations for milk coagulation properties and individual laboratory cheese yield in Sarda ewes. Anim. 1 - 9.

Raynal-Ljutovac, K., Pirisi, A., De Cremoux, R., \& Gonzalo, C. (2007). Somatic cells of goat and sheep milk: analytical, sanitary, productive and technological aspects. Small Rumin. Res. 68: 126-144.

Selvaggi, M., Laudadio, V., Dario, C., \& Tufarelli, V. (2014). Investigating the genetic polymorphism of sheep milk proteins: a useful tool for dairy production. (wileyonlinelibrary.com) DOI 10.1002/jsfa.6750.

Sevi, A., Albenzio, M., Marino, R., Santillo, A., \& Muscio, A. (2004). Effects of lambing season and stage of lactation on ewe milk quality. Small Rumin. Res. 51: 251-259.

Soulier, S., Ribardeau-Dumas, B., \& Denamur, R. (1974). Purification of k-casein from sheep. Europ. J. Bioch. $50: 445-452$.

Thompson, A., Boland M., \& Singh H. (2009). Milk Protein: From Expression to Food. Academic Press. 153-140.

Tornadijo, M. E., Marra, A. I., Fontán, M. G., Prieto, B., \& Carballo, J. (1998). La calidad de la leche destinada a la fabricación de queso: calidad química milk quality for cheese production: chemical quality a calidade da leite destinada á fabricación de queixo: calidade química. J. Food, 2: 79-91.

Ugarte, E., Ruiz, R., Gabiña, D., \& Beltrán de Heredia, I. (2001). Impact of high-yielding foreign breeds on the Spanish dairy sheep industry. Livest. Prod. Sci. 71: 3-10.

Walsh, C. D., Guinee, T. P., Reville, W. D., Harrington, D., Murphy, J. J., T O’Kennedy, B., \& FitzGerald, R. J. (1998). Influence of K-casein genetic variant on rennet gel microstructure, cheddar cheesemaking properties and casein micelle size. Int. Dairy J., 8: 707-714. 
Walstra, P., \& van Vliet, T. (1986) The physical chemistry of curd making. Neth. Milk Dairy J.I 40: 241-259.

Wendorff, W.L., Dufek, M.A., Jaeggi, J. J., Peng, Y., Berger, Y. M. \& Lucey, J.A. (2008). Impact of handling and thawing on cheesemaking properties of frozen sheep milk. In Proc. of $14^{\text {th }}$ Great Lakes Dairy Sheep Symposium. 35-44.

Yahyaoui, M.H., Angiolillo, A., Pilla, F., Sanchez, A. \& Folch, J.M. (2003). Characterization and genotyping of the caprine kappa casein variants. J. Dairy Sci. 86: 2715-2720 


\section{Discusión General}

En esta tesis se han abordado diferentes aspectos relacionados con la genética de la raza Pampinta. Los análisis permiten elaborar algunas consideraciones generales:

- Los parámetros genéticos estimados, con la base de datos de los últimos 7 años de la raza Pampinta, estuvieron en concordancia con la bibliografía.

- Se analizaron varios modelos para la estimación de las varianzas genéticas y fenotípicas de 6 caracteres: producción de leche (l/d); grasa total (g/d); proteínas totales (g/d); porcentaje de grasa; porcentaje de proteínas y mastitis subclínica (presencia/ausencia) en 210 d de lactancia. Los efectos clasificatorios que se utilizaron fueron: edad al primer parto, la combinación año de parto y época de parto, orden de parto, tipo de parto y crianza, días desde el parto al primer control lechero, extensión de lactancia. Destacándose el efecto año-estación de parto, y resultando irrelevante la edad al primer parto. Como efectos aleatorios: el componente permanente de las observaciones repetidas entre lactancias de ovejas, el componente genético aditivo, y el término del error.

- Las heredabilidades resultaron de medianas a bajas, para los caracteres de producción. A su vez, mastitis subclínica mostró mayor variación genética aditiva, con un CV aditivo del $55 \%$, en tanto que grasa total mostró menor variación genética aditiva, CV\% aditivo del $25 \%$. Las correlaciones entre producción de leche, grasa total y proteínas totales resultaron altas. Las correlaciones entre porcentaje de grasa con producción de leche y proteínas totales resultaron negativas, siendo las genéticas de mayor valor. Si bien las correlaciones fenotípicas entre mastitis subclínica y los caracteres productivos resultaron negativas, lo cual es favorable desde el punto de vista productivo, las correlaciones genéticas resultaron todas positivas, indicando que una mejora en producción de leche o grasa total, aumentaría la incidencia de mastitis subclínica. Las repetibilidades también resultaron altas. 
- $\quad$ Se obtuvieron las frecuencias génicas y genotípicas para mutaciones previamente descriptas para otras razas de $C S N 1 S 1, C S N 2, C S N 3, L G B, S D B 2$ de la cabaña de la EEA Anguil (INTA) y de cabañas privadas. No se observaron diferencias entre ellas, y aunque algunas frecuencias alélicas coincidieron con las reportadas en bibliografía para otras razas ovinas, se observan importantes diferencias en el material empleado para las determinaciones.

- $\quad$ Se estimó la frecuencia de los haplotipos para los genes de las caseínas. Siendo el más frecuente TAC, y sólo cuatro haplotipos (TAC, CAC, TGC, TAT) representaron más del 75\% del total de los haplotipos.

- Las asociaciones entre los caracteres de producción y mastitis subclínicas con los polimorfismos de CSN1S1, CSN2, CSN3 y LGB resultaron significativas $(p<0,05)$ para CSN1S1 con grasa total y para CSN2 con proteínas totales. Por otra parte, para CSN1S1 con producción de leche y con proteínas totales y para CSN2 con producción de leche y con grasas totales mostraron sólo una tendencia $(p<0,1)$. No se observó ningún efecto significativo entre los caracteres productivos y mastitis subclínica con CSN3 y $L G B$.

- $\quad$ En función de la variabilidad del polimorfismo de CSN3 observada, la probabilidad de encontrar ovejas de los tres genotipos posibles resultó baja. Por lo cual, se trabajó con muestras repetidas de muy pocos animales. Sin embargo, los valores obtenidos de tiempo de coagulación, estuvieron dentro de los reportados para otras razas de ovejas lecheras. Éstos estuvieron cercanos a los mínimos de los rangos reportados en otras razas, posiblemente por las diferencias de manejo que existen. 


\subsection{Conclusiones}

Primera - de los modelos empleados, para estimar las varianzas y covarianzas genéticas y fenotípicas, usando modelos mixtos de observaciones repetidas, la inclusión de los efectos clasificatorios, extensión de la lactancia y año-estación de parto, resultó significativa.

Segunda - los caracteres producción de leche, grasas totales, proteínas totales, grasa en porcentaje, proteína en porcentaje y mastitis subclínicas presentaron heredabilidades de medianas a bajas. En base a las correlaciones genéticas estimadas, seleccionar por producción de leche producirá una respuesta no deseada en mastitis subclínicas y grasa y proteínas en porcentaje.

Tercera - la raza Pampinta presenta polimorfismos para las proteínas de leche, caseínas, lacto-globulinas, y defensina 2 en las mutaciones estudiadas.

Cuarta - la cabaña de la EEA Anguil y las cabañas privadas en el estudio son una misma población tomando como referencia el polimorfismo de los genes estudiados.

Quinto - considerando las asociaciones de los caracteres productivos y los polimorfismos, se puede sostener que Pampinta posee frecuencia alelos favorablemente asociados a caracteres productivos como producción de leche, grasas totales y proteínas totales. Lo que puede emplearse para definir criterio de selección molecular. 